Cochrane Database of Systematic Reviews

\title{
Gastro-oesophageal reflux treatment for prolonged non-specific cough in children and adults (Review)
}

Chang AB, Lasserson TJ, Gaffney J, Connor FL, Garske LA

Chang AB, Lasserson TJ, Gaffney J, Connor FL, Garske LA.

Gastro-oesophageal reflux treatment for prolonged non-specific cough in children and adults.

Cochrane Database of Systematic Reviews 2011, Issue 1. Art. No.: CD004823.

DOI: 10.1002/14651858.CD004823.pub4.

www.cochranelibrary.com 
TABLE OF CONTENTS

HEADER 1

ABSTRACT

PLAIN LANGUAGE SUMMARY

BACKGROUND

OBJECTIVES

METHODS

RESULTS

Figure 1.

Figure 2.

Figure 3.

Figure 4.

Figure 5.

DISCUSSION

Figure 6.

AUTHORS' CONCLUSIONS

ACKNOWLEDGEMENTS

REFERENCES

CHARACTERISTICS OF STUDIES

DATA AND ANALYSES

Analysis 1.1. Comparison 1 Thickened versus unthickened feeds (infants), Outcome 1 Subjects cured (of cough) at end of study.

Analysis 1.2. Comparison 1 Thickened versus unthickened feeds (infants), Outcome 2 Cough frequency. ...............................

Analysis 2.1. Comparison 2 PPI versus placebo (children), Outcome 1 Coughing (\% days/week).

Analysis 2.2. Comparison 2 PPI versus placebo (children), Outcome 2 Clinical failures (still coughing at end of trial or reporting period).

Analysis 2.3. Comparison 2 PPI versus placebo (children), Outcome 3 Treatment-emergent serious adverse events. ...............

Analysis 3.1. Comparison 3 PPI versus placebo (> 18 years), Outcome 1 Clinical failures (still coughing at end of trial or reporting period).

Analysis 3.2. Comparison 3 PPI versus placebo (> 18 years), Outcome 2 Mean cough score at end of trial (1st arm cross-over/ parallel-group trials).

Analysis 3.3. Comparison 3 PPI versus placebo (> 18 years), Outcome 3 Change in cough scores (end-beginning of intervention - 1st arm cross-over/parallel-group trials).

Analysis 3.4. Comparison 3 PPI versus placebo ( $>18$ years), Outcome 4 Change in cough scores (cross-over studies; standardised scale).

Analysis 3.5. Comparison 3 PPI versus placebo (> 18 years), Outcome 5 Absolute cough scores (cross-over studies, standardised scale).

Analysis 3.6. Comparison 3 PPI versus placebo (> 18 years), Outcome 6 Change in cough score after 4 weeks treatment (1st arm cross-over/parallel-group trials).

Analysis 3.7. Comparison 3 PPI versus placebo (> 18 years), Outcome 7 Difference in cough scores at week 8 - week 4 (1st arm cross-over/parallel-group trials).

APPENDICES

WHAT'S NEW

HISTORY

CONTRIBUTIONS OF AUTHORS

DECLARATIONS OF INTEREST

SOURCES OF SUPPORT

DIFFERENCES BETWEEN PROTOCOL AND REVIEW

INDEX TERMS 
[Intervention Review]

\section{Gastro-oesophageal reflux treatment for prolonged non-specific cough in children and adults}

Anne B Chang ${ }^{1}$, Toby J Lasserson², Justin Gaffney ${ }^{3}$, Frances L Connor ${ }^{4}$, Luke A Garske 5

1Royal Children's Hospital, Brisbane and Menzies School of Health Research, CDU, Darwin, Queensland Children's Respiratory Centre and Queensland Children's Medical Research Institute, Brisbane, Australia. ${ }^{2}$ Cochrane Editorial Unit, The Cochrane Collaboration, London, UK. ${ }^{3}$ Respiratory Medicine, Royal Children's Hospital, Brisbane, Australia. ${ }^{4}$ Gastroenterology, Royal Children's Hospital, Brisbane, Australia. ${ }^{5}$ Respiratory Medicine, Princess Alexandra Hospital, Brisbane, Australia

Contact address: Anne B Chang, Royal Children's Hospital, Brisbane and Menzies School of Health Research, CDU, Darwin, Queensland Children's Respiratory Centre and Queensland Children's Medical Research Institute, Herston Road, Herston, Brisbane, Queensland, 4029, Australia. annechang@ausdoctors.net, Anne.chang@menzies.edu.au.

Editorial group: Cochrane Airways Group

Publication status and date: New search for studies and content updated (conclusions changed), published in Issue 1, 2011.

Citation: Chang AB, Lasserson TJ, Gaffney J, Connor FL, Garske LA. Gastro-oesophageal reflux treatment for prolonged non-specific cough in children and adults. Cochrane Database of Systematic Reviews 2011, Issue 1. Art. No.: CD004823. DOI: 10.1002/14651858.CD004823.pub4.

Copyright @ 2011 The Cochrane Collaboration. Published by John Wiley \& Sons, Ltd.

\section{A B S T R A C T}

\section{Background}

Gastroesophageal reflux disease (GORD) is said to be the causative factor in up to $41 \%$ of adults with chronic cough. Treatment for GORD includes conservative measures (diet manipulation), pharmaceutical therapy (motility or prokinetic agents, $\mathrm{H}_{2}$-antagonist and proton pump inhibitors (PPI)) and fundoplication.

\section{Objectives}

To evaluate the efficacy of GORD treatment on chronic cough in children and adults with GORD and prolonged cough that is not related to an underlying respiratory disease, i.e. non-specific chronic cough.

\section{Search methods}

We searched the Cochrane Airways Group Specialised Register, the Cochrane Register of Controlled Trials (CENTRAL), MEDLINE, EMBASE, review articles and reference lists of relevant articles. The date of last search was 8 April 2010.

\section{Selection criteria}

All randomised controlled trials (RCTs) on GORD treatment for cough in children and adults without primary lung disease.

\section{Data collection and analysis}

Two review authors independently assessed trial quality and extracted data. We contacted study authors for further information.

\section{Main results}

We included 19 studies (six paediatric, 13 adults). None of the paediatric studies could be combined for meta-analysis. A single RCT in infants found that PPI (compared to placebo) was not efficacious for cough outcomes (favouring placebo OR $1.61 ; 95 \% \mathrm{Cl} 0.57$ to 4.55 ) but those on PPI had significantly increased adverse events (OR 5.56; 95\% CI 1.18 to 26.25) (number needed to treat for harm in four weeks was $11(95 \% \mathrm{Cl} 3$ to 232$)$ ). In adults, analysis of $\mathrm{H}_{2}$ antagonist, motility agents and conservative treatment for GORD was not possible (lack of data) and there were no controlled studies of fundoplication. We analysed nine adult studies comparing PPI (two to three months) to 
placebo for various outcomes in the meta-analysis. Using intention-to-treat, pooled data from studies resulted in no significant difference between treatment and placebo in total resolution of cough (OR $0.46 ; 95 \% \mathrm{Cl} 0.19$ to 1.15$)$. Pooled data revealed no overall significant improvement in cough outcomes (end of trial or change in cough scores). We only found significant differences in sensitivity analyses. We found a significant improvement in change of cough scores at end of intervention (two to three months) in those receiving PPI (standardised mean difference $-0.41 ; 95 \% \mathrm{Cl}-0.75$ to -0.07 ) using generic inverse variance analysis on cross-over trials. Two studies reported improvement in cough after five days to two weeks of treatment.

\section{Authors' conclusions}

PPI is not efficacious for cough associated with GORD symptoms in very young children (including infants) and should not be used for cough outcomes. There is insufficient data in older children to draw any valid conclusions. In adults, there is insufficient evidence to conclude definitely that GORD treatment with PPI is universally beneficial for cough associated with GORD. Clinicians should be cognisant of the period (natural resolution with time) and placebo effect in studies that utilise cough as an outcome measure. Future paediatric and adult studies should be double-blind, randomised controlled and parallel-design, using treatments for at least two months, with validated subjective and objective cough outcomes and include ascertainment of time to respond as well as assessment of acid and/or non-acid reflux.

\section{PLAIN LANGUAGE SUMMARY}

\section{Gastro-oesophageal reflux treatment for prolonged non-specific cough in children and adults}

Cough in association with gastroesophageal reflux disease (GORD) is common in adults with chronic cough. The objective of this review was to evaluate the effectiveness of GORD treatment in children and adults with GORD and prolonged cough that is not related to an underlying respiratory disease, i.e. non-specific chronic cough.

Nineteen studies fulfilled our predetermined criteria but only six could be combined (in meta-analysis). We obtained additional data from trialists. We were not able to combine results in children due to limited data. Thickened feeds had an inconsistent effect. Proton pump inhibitors (PPI) did not reduce cough and should not be used for cough in young children.

In adults with cough and GORD, no significant difference was found in clinical cure using proton pump inhibitors (PPI) for cough and GORD. Using other outcomes, there was also no significant difference between PPI and placebo. This review also highlights a large placebo and time period effect (natural resolution with time) of treatment for chronic cough. In adults treatment with PPI for cough associated with GORD is inconsistent and its benefit variable. There was insufficient data to draw any conclusion from other therapies for cough associated with GORD. 


\section{B A C K G R O U N D}

Cough is the most common symptom presenting to general practitioners (Britt 2002). Worldwide, the desire to reduce the impact of the symptom of cough is reflected in the billions of dollars spent on over the counter cough and cold medications. Non-specific cough has been defined as non-productive cough in the absence of identifiable respiratory disease or known aetiology (Chang 2001). Prolonged or chronic cough has been variously defined as a cough which persists for longer than three to eight weeks.

Gastroesophageal reflux (GOR) (reflux of gastric contents into the oesophagus) can be acid or non-acid (volume or alkaline reflux) and these occur physiologically, especially in the post-cibal state (AMA 1996). When reflux is 'excessive', GOR disease (GORD) is present. Symptoms attributed to GORD range from a variety of gastrointestinal/abdominal symptoms (abdominal pain, halitosis, water brash etc.) to extra-oesophageal symptoms (cough, hoarseness, laryngeal problems, ear disease, dental erosion etc.) (AMA 1996). In 2006 and 2009, the definition of GORD was refined to "a condition that develops when the reflux of stomach contents causes troublesome symptoms and/or complications" (Vakil 2006; Vandenplas 2009).

Cohort studies in adults suggest that gastroesophageal reflux disease (GORD) related to acid causes $21 \%$ to $41 \%$ of chronic nonspecific cough, even in many with no gastrointestinal symptoms of GORD (Irwin 1990). When successfully treated, GORD-related cough is associated with a decrease in objective measurements of cough sensitivity (O'Connell 1994). In animals, potent acid instillation in to the oesophagus causes airway neurogenic inflammation (Daoui 2002). In adult humans similar experimentation causes cough in a temporal manner (within 70 seconds) (Ing 1994). Although a temporal relationship has been shown in the laboratory, cough is reported in some earlier studies to resolve only after a mean time period of 169 to 179 days following treatment for acid-GORD related cough (Irwin 2002a). It is thus not surprising that conflicting data have been reported and others have shown that acid GORD is associated with, but not the causative factor for, cough. Also, effective treatment of GORD that resolves gastrointestinal GORD symptoms may have no effect on objective pulmonary data (Ferrari 1995). Furthermore, like asthma and GORD, both GORD and cough are common diseases, often co-exist, and their association does not imply cause and effect (AMA 1996; Rudolph 2001; Vakil 2006; Vandenplas 2009). Nevertheless, several reviews/guidelines suggest a therapeutic trial of three to six months of GORD treatment for non-specific chronic dry cough in both adults and children (Corrao 1996; Irwin 2002a; Kiljander 2003).

Current treatment for GORD includes conservative anti-reflux measures (diet, positioning etc.), pharmacological approaches (acid suppressing agents: histamine ${ }_{2}\left(\mathrm{H}_{2}\right)$ receptor antagonists, proton pump inhibitors (PPI) and prokinetic agents: domperidone, erythromycin, metoclopramide and previously cisapride) and surgical approaches (Nissen or Toupet fundoplication by laparoscopic or open procedures) (Rudolph 2001).

There are several definitions of GORD. Excessive distal oesophageal acidification is the most common clinical scenario of GORD and can be defined by the histological presence of reflux oesophagitis (on biopsy) or distal oesophageal pH-metry (24-hour pH study) (AMA 1996). Distal pH-metry is the most sensitive method for defining acid GORD and is a standard test recommended for evaluating chronic cough (Chung 1996; Irwin 1998). In children, acid GORD is present if distal $\mathrm{pH}$-metry shows a reflux index $(\%$ time $\mathrm{pH}<4)$ of $>10 \%$ in infants and $>7 \%$ (3\% to $7 \%$ considered indeterminate) in children aged over 12 months, as suggested by the GORD guidelines of the European and American paediatric gastroenterology groups (Rudolph 2001; Vandenplas 1993; Vandenplas 2009). Dual channel (proximal and distal) oesophageal pH-metry has also been used in assessing GORD with arguable clinical use even in the assessment of patients at risk for upper airway complications of GORD (Rudolph 2001). However, there is variation in what constitutes an abnormal reflux index; in adults the definition of abnormal pH-metry consistent with GORD varies from a reflux index of greater than $3.9 \%$ to 7.2\% (AMA 1996).

A systematic review examining the efficacy of the various treatment modalities for prolonged non-specific cough in adults and children and GORD would help clarify the link (or otherwise) between cough and GORD.

\section{O B J E C T IVES}

To evaluate the effectiveness of GORD treatment in adults and children with GORD and prolonged cough not related to an underlying respiratory disease, i.e. non-specific chronic cough.

\section{METHODS}

\section{Criteria for considering studies for this review}

\section{Types of studies}

All randomised controlled trials of any GORD treatment with cough as an outcome, where cough is not primarily related to an underlying respiratory disorder (such as cystic fibrosis, asthma, chronic obstructive airway disease, suppurative lung disease etc.) or medication use (angiotensin converting enzyme [ACE] inhibitor).

\section{Types of participants}

Adults, children or both with chronic (three or more weeks) nonspecific cough (dry and non-productive cough without any other respiratory symptom, sign or systemic illness).

Exclusion criteria were: cough related to mycoplasma, pertussis and chlamydia, presence of underlying cardio-respiratory condition, current or recurrent wheeze (greater than two episodes), presence of other respiratory symptoms (productive cough, haemoptysis, dyspnoea), presence of other respiratory signs (clubbing, chest wall deformity, respiratory noises such as wheeze on auscultation and other adventitious sounds), presence of any sign of systemic illness (failure to thrive, aspiration, neurological or developmental abnormality) and presence of lung function abnormality.

\section{Types of interventions}

All randomised controlled comparisons of therapies for GORD. We did not include trials only comparing two or more medications without a placebo comparison group. We evaluated the following treatment regimes:

1. anti-reflux conservative measures;

2. $\mathrm{H}_{2}$ receptor antagonists;

3. proton pump inhibitors (PPI); and

4. surgical therapy. 
We included trials that included the use of other medications or interventions if all participants had equal access to such medications or interventions.

\section{Types of outcome measures}

We made attempts to obtain data on at least one of the following outcome measures.

\section{Primary outcomes}

Proportions of participants who were not cured or not substantially improved at follow up (failure to cure). Cure is defined as complete resolution of cough or substantial reduction as predetermined by trialist, such as 70\% reduction in cough indices (Chang 1998b).

\section{Secondary outcomes}

1. Proportions of participants who were not cured at follow up.

2. Proportions of participants who were not substantially improved at follow up.

3. Mean difference in cough indices (cough diary, cough frequency, cough scores).

4. Proportions experiencing adverse effects of the intervention (e.g. rash, surgical morbidity etc.).

5. Proportions experiencing complications (e.g. requirement for medication change, repeat surgery etc.).

We determined the proportions of participants who failed to improve on treatment and the mean clinical improvement using the following hierarchy of assessment measures (i.e. where two or more assessment measures were reported in the same study, we used the outcome measure that was listed first in the hierarchy).

1. Objective measurements of cough indices (cough frequency, cough receptor sensitivity).

2. Symptomatic (quality of life, Likert scale, visual analogue scale, level of interference of cough, cough diary) - assessed by the patient (adult or child).

3. Symptomatic (quality of life, Likert scale, visual analogue scale, level of interference of cough, cough diary) - assessed by the parents/carers.

4. Symptomatic (Likert scale, visual analogue scale, level of interference of cough, cough diary) - assessed by clinicians.

5. Relevant airway markers consistent with inflammation.

\section{Search methods for identification of studies}

We used the following topic search strategy to identify the relevant randomised controlled trials listed on the electronic databases:

("gastro-oesophageal reflux" OR "gastroesophageal reflux" OR "gastro-esophageal reflux" OR "reflux" OR "ger" OR "gerd" OR "acid" OR "esophagus" OR "oesophagus", all as [textword] or [MeSH]) AND ("cough" as [textword] or [MeSH])

For the full strategies please see Appendix 2; Appendix 3 and Appendix 4.

We identified trials from the following sources:

1. the Cochrane Controlled Trials Register (CENTRAL), which includes the Cochrane Airways Group Specialised Register;
2. MEDLINE 1966 to current (topic search strategy combined with the MEDLINE randomised controlled trial search filter as outlined in the Airways Group module);

3. OLDMEDLINE 1951 to 1965 (topic search strategy combined with the MEDLINE randomised controlled trial search filter as outlined in the Airways Group module);

4. EMBASE 1997 to current (topic search strategy combined with the EMBASE randomised controlled trial search filter as outlined in the Airways Group module);

5. the lists of references in relevant publications; and

6. written communication with the authors of trials included in the review when necessary.

Searches are current as of April 2010.

\section{Data collection and analysis}

\section{Selection of studies}

From the title, abstract or descriptions, two review authors (ABC, LAG) independently reviewed the literature searches to identify potentially relevant trials for full review. We conducted searches of bibliographies and texts to identify additional studies. From the full text using specific criteria, the same two review authors independently selected trials for inclusion. We measured agreement using kappa statistics. We resolved disagreement by consensus.

\section{Data extraction and management}

We reviewed trials that satisfied the inclusion criteria wand recorded the following information: study setting, year of study, source of funding, patient recruitment details (including number of eligible participants), inclusion and exclusion criteria, criteria used for GOR diagnosis, GOR symptoms, randomisation and allocation concealment method, numbers of participants randomised, blinding (masking) of participants, care providers and outcome assessors, dose and type of GORD therapy, duration of therapy, co-interventions, numbers of patients not followed up, reasons for withdrawals from study protocol (clinical, side effects, refusal and other), details on side effects of therapy, and whether intention-to-treat analyses were possible. We extracted data on the outcomes described previously. We requested further information from the authors if required.

\section{Assessment of risk of bias in included studies}

In the previous reviews, we used an assessment score and the Jadad score. For this update we have removed the Jadad score and in its place have included a quality assessment based on the Cochrane Handbook for Systematic Reviews of Interventions (Handbook 2008) and entered assessments into 'Risk of bias' (RoB) tables. When authors of papers gave additional data, we based quality assessments and Jadad scores on additional data supplied. A single review author our assessed four components in the RoB.

1. Adequate sequence generation.

2. Allocation concealment.

3. Blinding.

4. Free of other bias.

Two review authors ( $A C$ and $L G$ ) independently performed the second assessment scoring system and included this in Characteristics of included studies. We measured inter-review author reliability for 
the identification of high-quality studies for each component using the Kappa statistic. The four components of quality were assessed:

1. Allocation concealment. Trials were scored as: Grade A: adequate concealment; Grade B: unclear; Grade C: clearly inadequate concealment (Grade $A$ = high quality).

2. Blinding. Trials were scored as: Grade A: participant and care provider and outcome assessor blinded; Grade B: outcome assessor blinded; Grade C: unclear; Grade D: no blinding of outcome assessor (Grade A, B = high quality).

3. Reporting of participants by allocated group. Trials were scored as: Grade A: the progress of all randomised participants in each group described; Grade B: unclear or no mention of withdrawals or drop outs; Grade C: the progress of all randomised participants in each group clearly not described (Grade $\mathrm{A}=$ high quality).

4. Follow up. Trials were scored as: Grade A: outcomes measured in $>90 \%$ (where withdrawals due to complications and side effects are categorised as treatment failures); Grade B: outcomes measured in $80 \%$ to $90 \%$; Grade C: unclear; Grade D: outcomes measured in $<80 \%$ (Grade $A=$ high quality).

\section{Data synthesis}

An initial qualitative comparison of all the individually analysed studies examined whether pooling of results (meta-analysis) was reasonable. This took into account differences in study populations, inclusion/exclusion criteria, interventions, outcome assessment and estimated effect size. We included the results from studies that met the inclusion criteria and reported any of the outcomes of interest in the subsequent meta-analyses. In cross-over trials (Eherer 2003; Kiljander 2000), when data were combined with those from parallel studies, we only used effect estimates from the first arm (Elbourne 2002). There is some debate over the handling of cross-over data (Clarke 2003; Elbourne 2002) and we considered that it was invalid to use second-arm data given the known period effect of cough (i.e. cough tends to resolve with time (Chang 2001)) and the likely bias associated with carry-over effect (studies had short wash out time of two weeks compared to eight weeks of therapy in each arm).

For the dichotomous outcome variables of each individual study, we calculated relative and absolute risk reductions using a modified intention-to-treat analysis. This analysis assumes that participants not available for outcome assessment have not improved (and probably represents a conservative estimate of effect). For primary outcome, we calculated an estimate of the numbers needed to treat (NNT) for benefit (NNT-B) and harm (NNT-H) from pooled data with 'intention-to-treat' used as the denominator and calculated using the formula 1 /risk difference (Clarke 2003). We defined event as successful treatment defined by absence of cough by end of treatment period.

We derived imputed correlation coefficient for calculating standard deviations of change from baseline (Clarke 2003) from other studies in the review. We calculated the summary weighted risk ratio and $95 \%$ confidence interval (fixed-effect model) using the inverse of the variance of each study result for weighting. We pooled data from similar studies, assuming cough indices were normally distributed continuous variables. For cross-over studies, mean treatment differences were calculated from raw data, extracted or imputed and entered as a fixed-effect standardised mean difference using generic inverse variance (GIV). This gave a weighted SD unit difference and 95\% confidence intervals (RevMan 2008). We tested heterogeneity between the study results to see if it reached statistical significance using a $\mathrm{Chi}^{2}$ test. We included the $95 \%$ confidence interval estimated using a random-effects model whenever there were concerns about statistical heterogeneity.

We did not include gastrointestinal symptoms in the forest plots as it was not an objective of this review.

\section{Subgroup analysis and investigation of heterogeneity}

Subgroup analysis:

We planned an a priori subgroup analysis.

1. Age: adults or children (aged $<18$ years and $<12$ months).

2. Definition of GORD used: acid GORD defined by pH-metry or oesophageal biopsy or non-acid/volume (alkaline) reflux or 'extra-oesophageal reflux'.

3. Intervention type: medical or surgical intervention.

Medical intervention further subgrouped to:

a) $\mathrm{H}_{2}$ antagonist;

b) proton pump inhibitor (PPI); and

c) conservative therapy.

\section{Sensitivity analysis}

We planned sensitivity analyses to assess the impact of the potentially important factors on the overall outcomes:

1. variation in the inclusion criteria;

2. differences in the medications used in the intervention and comparison groups;

3. differences in outcome measures;

4. analysis using a random-effects model;

5. analysis by treatment received;

6. analysis by intention-to-treat;

7. analysis by study design - parallel and cross-over studies (added after protocol written).

We planned to test for publication bias using a funnel plot.

\section{RES U L T S}

\section{Description of studies}

\section{Results of the search}

The 2008 search resulted in 432 potential titles. Of these we retrieved 10 papers, excluded six papers and included four new studies. One of the included studies (Wo 2006) was identified from an excluded paper (Coron 2007) that was a generic review of the subject. All four studies (Chao 2007; Moukarzel 2007; Pawar 2007; Wo 2006) were supported by the pharmaceutical industry involved in the product trialled in the study. This updated Cochrane Review now has a total of 19 included studies ( 18 from the previous version and one from the current update). See Appendix 1 for details of the results of previous searches. The 2009 search identified 457 potential titles; 15 papers were retrieved but none fulfilled inclusion criteria. Two studies were added to the excluded studies list. The 2010 
search identified 460 potential studies, six papers were retrieved and one RCT (Orenstein 2009) was added.

\section{Included studies}

\section{Paediatrics}

There were six studies in children; five in infants and one in children, with the most recent study (Orenstein 2009) added in the 2010 update. Orenstein and colleagues' study described increased cough with thickened feeds as an intervention in a diverse group of infants with cough and GORD (Orenstein 1992). Although most in the group were otherwise well infants, some had primary respiratory disease (hence did not have non-specific cough). Four studies (Chao 2007; Moukarzel 2007; Orenstein 1992; Vanderhoof 2003) reported on the use of specific anti-regurgitation formula milk (as opposed to thickened formula) in infants with GORD that included cough as an outcome measure. However, Moukarzel 2007 did not provide data specific to cough in the publication. Orenstein and colleagues' study described increased cough with thickened feeds as an intervention in a diverse group of infants with cough and GORD (Orenstein 1992). Although most in the group were otherwise well infants, some had primary respiratory disease (hence did not have non-specific cough). Three studies were supported (one in part) by the manufacturers of the milk utilised (Chao 2007; Moukarzel 2007; Vanderhoof 2003) and we excluded the other (Xinias 2003) because it was an open non-randomised (but controlled) trial. Outcome measures of the four studies on infants varied: in two multi-centre studies (Moukarzel 2007; Vanderhoof 2003), cough was reported as part of a symptom complex (with gag or choke, etc.) and although the authors provided further information, the data could not be used for analysis in this review. In one study only a small number of infants had cough (nine of 81) (Chao 2007) displayed in Analysis 1.1 (no significant difference between groups).

There was a single RCT on PPI in infants (Orenstein 2009) and the authors provided additional data specific to cough outcomes that were not available in the publication. There were no controlled trials on surgery in infants.

The single study in children (Dordal 1994) included children with asthma; its exclusion criteria were insufficiently defined to allow classification of participants as having non-specific cough and it is unclear if the study was a randomised study. There were no controlled trials on the use of PPIs or surgery in children.

\section{Adults}

In adults, 13 studies were included; eleven were published articles, one in abstract form (Kopec 2001) and one in a conference report plus abstract (Ing 1997). We sought additional data from all but one author(s); six responded but only three (Eherer 2003; Kiljander 2000; Vaezi 2006) were able to provide additional data that could be used for the meta-analysis. Although all studies included cough that was presumed associated with GOR, criteria for entry into the studies varied. In six studies, participants enrolled through the otolaryngology department and had 'laryngitis' symptoms (Eherer 2003; Havas 1999; Noordzij 2001; Steward 2004; Wo 2006). One study based in medical clinics also primarily enrolled participants with chronic 'laryngitis' (Vaezi 2006). In these studies where subjects were recruited from otolaryngology clinics, primary lung disease (such as asthma defined by hyper-responsiveness) as an exclusion criteria were not as stringent as they were in the studies enrolled through medical outpatients (Ing 1997; Jaspersen
1999; Kiljander 2000; Ours 1999). Mean age of participants reported in studies was 46 to 58 years (range 18 to 80 years). Some studies had predominantly males (Eherer 2003; Ours 1999) whereas others had predominantly females (Kiljander 2000; Steward 2004; Wo 2006). Two studies had similar proportions of males to females (Pawar 2007; Vaezi 2006). In all but one study (Jaspersen 1999), presence of GOR (or extra-oesophageal reflux) was confirmed objectively. However in Vaezi 2006 only $29 \%$ of participants had pHmetry characteristics of GORD. In most studies the diagnosis of GOR was made with $\mathrm{pH}$-metry, and some included dual channels. None of the studies used alkaline or volume reflux as an entry criteria although oesophageal manometry was used in two studies.

There were 10 parallel studies and three cross-over studies, all of which had wash-out periods of two weeks. Ten studies compared PPI to placebo but varying doses and frequencies were used. Studies involving participants with 'laryngitis' (El Serag 2001; Eherer 2003; Havas 1999; Noordzij 2001; Pawar 2007; Steward 2004; Vaezi 2006) generally used higher doses of PPI (twice-daily regime). Three studies used omeprazole (Kiljander 2000; Noordzij 2001; Ours 1999), one used esomeprazole (Vaezi 2006) and the other three studies used a different PPI, pantoprazole (Eherer 2003; Wo 2006), rabeprazole (Pawar 2007; Steward 2004) and lansoprazole (El Serag 2001; Havas 1999). One study compared PPI to ranitidine (Jaspersen 1999) and another was a two-factorial design using cisapride and diet intervention (Kopec 2001). In one study (Steward 2004) all subjects (i.e. both controls and intervention groups) also received instructions for lifestyle modification. There was a single study on $\mathrm{H}_{2}$-antagonist versus placebo (Ing 1997), published only as a report on an oral presentation and abstract format. Data from this study were presented graphically (provided by the author) and could not be used as points on the graph were unclear (number in the study did not equate to the number of points on the graph). There were no randomised controlled studies assessing surgical interventions.

Length of intervention in the study on $\mathrm{H}_{2}$-antagonist versus placebo was two weeks each (Ing 1997). In the studies using PPI, length of intervention was two to three months (or eight to 12 weeks) and two studies had prolonged follow up post-trial (Ours 1999). Outcome measures for all studies were subjective cough scales of varying types. Two studies had outcome assessments done midway through trial (Havas 1999; Noordzij 2001), one had several evaluations during the trial (Vaezi 2006) but only one of these studies provided 'during trial' cough data in the paper (Noordzij 2001). Objective cough monitoring was not used in any study. In all but one study, gastrointestinal or 'extra-oesophageal' symptoms of GORD were also outcome measures. Adverse events were specifically mentioned in six studies.

\section{Risk of bias in included studies}

The quality score varied. One study scored as 'high quality' in all four categories (Steward 2004). Five studies (Eherer 2003; El Serag 2001; Ours 1999; Vaezi 2006; Wo 2006) scored as 'high quality' in three categories and four studies did have any high-quality points for all four categories. Agreement between the two main review authors (AC and LG) for quality of studies was excellent; weighted kappa score was 0.88 for Jadad score and 0.77 for quality assessment.

In the studies in infants, randomisation and blinding were clearly described in three studies (Orenstein 1992; Orenstein 2009; Vanderhoof 2003). Randomisation method and blinding were not men- 
tioned in the other two studies in infants (Chao 2007; Moukarzel 2007) or in the study in children (Dordal 1994). In the adult studies, the randomisation process was clearly described in four but allocation concealment was unclear in all but one study (Steward 2004; Figure 1). Method of blinding (i.e. appearance of placebo) was clear- ly described in five studies (Eherer 2003; Noordzij 2001; Ours 1999; Vaezi 2006; Wo 2006). There were only four studies with data (including data that were sought from authors) that could be utilised as intention-to-treat for selected analysis (Eherer 2003; Kiljander 2000; Ours 1999; Vaezi 2006) without making any assumptions.

Figure 1. Risk of bias graph: review authors' judgements about each risk of bias item presented as percentages across all included studies.

Adequate sequence generation?

Allocation concealment?

Blinding? (Clinical cureifailure)

Blinding? (Cough frequency or score)

Free of other bias?

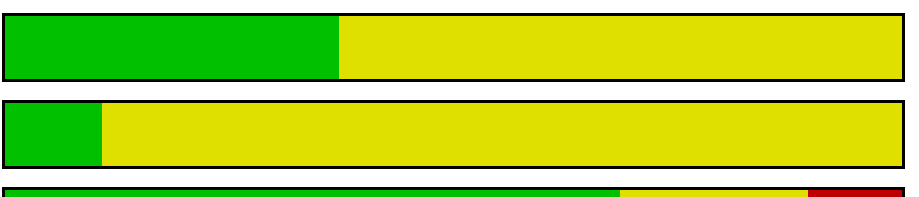

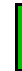
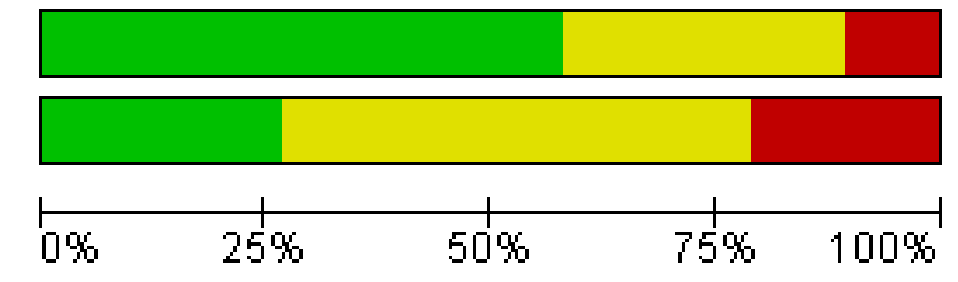

Yes (low risk of bias) $\square$ Unclear

No (high risk of bias)

An overview of the risk of bias judgements according to the four domains we applied the tool to is provided in Figure 1. Specific study and item-level judgements are given in Figure 2. 
Figure 2. Risk of bias summary: review authors' judgements about each risk of bias item for each included study.

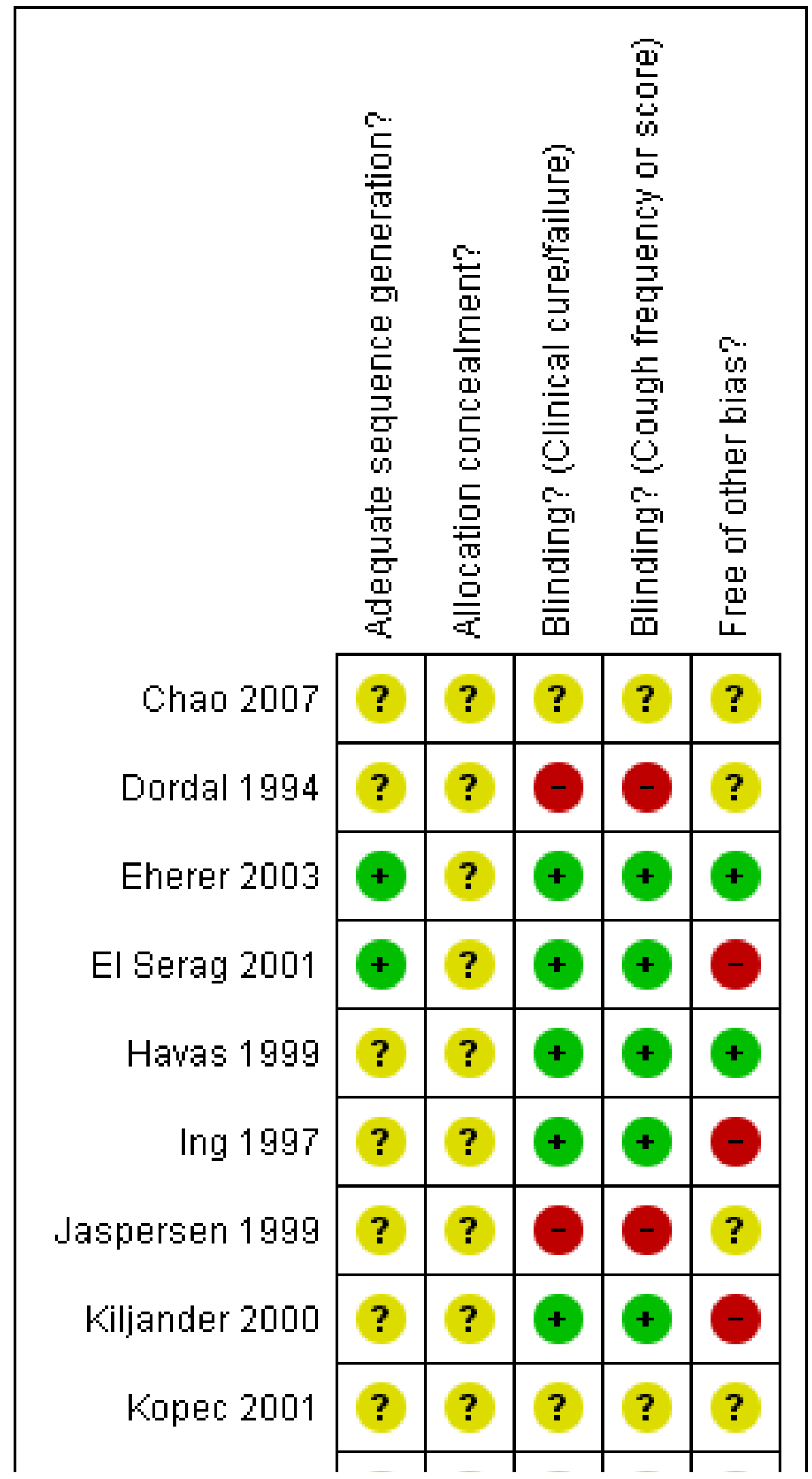


Figure 2. (Continued)

\begin{tabular}{|c|c|c|c|c|c|}
\hline Kopec 2001 & ? & $?$ & $?$ & $?$ & $?$ \\
\hline Moukarzel 2007 & $?$ & $?$ & $?$ & $?$ & $?$ \\
\hline Noordzij 2001 & $?$ & $?$ & & & \\
\hline Orenstein 1992 & & $?$ & $?$ & $?$ & $?$ \\
\hline Orenstein 2009 & & & & $?$ & \\
\hline Ours 1999 & & $?$ & & & \\
\hline Pawar 2007 & $?$ & $?$ & & & $?$ \\
\hline Steward 2004 & & + & & & $?$ \\
\hline vaeri 2006 & $?$ & $?$ & & & 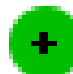 \\
\hline Vanderhoof 2003 & $?$ & $?$ & & $?$ & $?$ \\
\hline Mo 2006 & & $?$ & & & $?$ \\
\hline
\end{tabular}




\section{Effects of interventions}

The 19 studies included 985 randomised participants (534 paediatrics, 476 adults) with 506 (413 paediatrics, 412 adults) completing the trials. Seventeen articles were published in English, one in German (Jaspersen 1999) and another in French (Dordal 1994). In the updated searches of 2005, 2006 and 2007 three studies (El Serag 2001; Steward 2004; Vaezi 2006) were found from recent review articles and the numbers above include these papers. Some of the trialists responded to requests for data. Although entry criteria were fulfilled in some participants, data on cough alone in these participants was not available on one study (El Serag 2001) but was available in the other two studies (Steward 2004; Vaezi 2006).

\section{Paediatrics}

There were insufficient data in infants and children that could be combined for display in the graphs as trials in infants were too dissimilar. The studies on formula-thickening (Chao 2007; Moukarzel 2007; Orenstein 1992; Vanderhoof 2003) in infants found improvement in GORD symptoms referring to the gastrointestinal system but data for effect on cough were inconsistent. The smaller study (Orenstein 1992) described a significant increase in cough frequency post-feeds when thickened feeds were given (Figure 3; Analysis 3.1). The multicentre study described decrease in percentage of feeds associated with cough/gag/choke episodes in infants given pre-thickened milk (Vanderhoof 2003). Cough/gag/choke was grouped as a secondary outcome and scored in a binary manner in the study of Vanderhoof and colleagues (Vanderhoof 2003). We sought additional information which was provided but the authors were unable to provide data on cough alone (cough was included in symptom complex with choke or gag or cough). In the Chao 2007 study, the number of children with cough was small $(n=9$ out of 81 infants who completed the study) and the difference between groups was not significant (Analysis 1.1). In the Moukarzel 2007 study, although cough was an outcome measure, cough-specific data were not presented in the paper. In the excluded study Xinias and colleagues found no effect of the anti-regurgitation formula milk on cough (Xinias 2003). No adverse events were reported in of these studies.

Figure 3. Forest plot of comparison: 2 PPI versus placebo (> 18 years), outcome: 2.1 Clinical failures (still coughing at end of trial or reporting period).

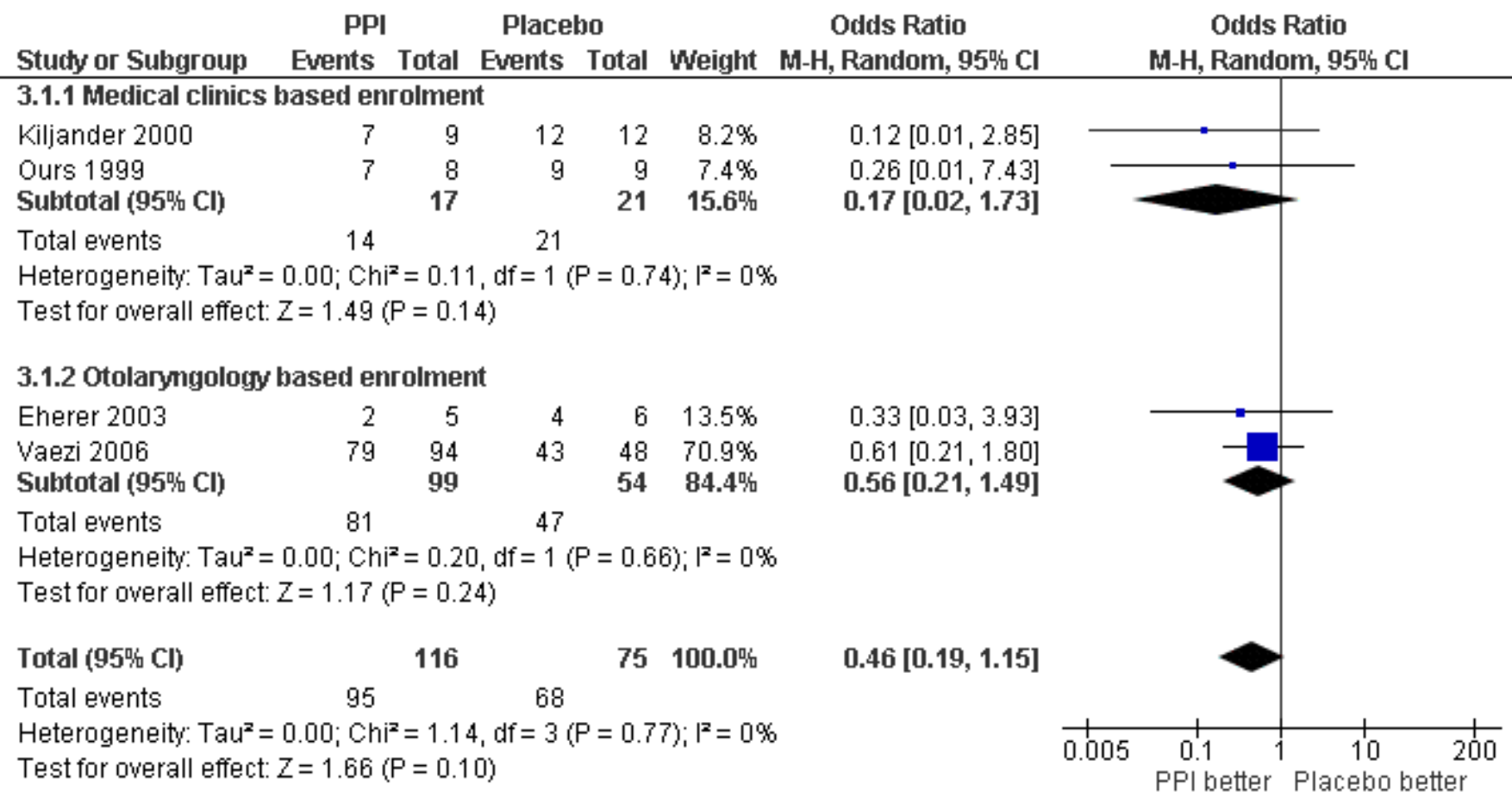

The sole study on PPI in paediatrics found no significant difference in cough outcomes between infants in the lansoprazole and placebo groups. When all children were considered the mean difference of $\%$ days with cough (Analysis 2.1; Figure 4) between groups was not significant (MD 8.60; $95 \% \mathrm{Cl}-2.85$ to 20.05). There was also no difference between groups (OR $1.61 ; 95 \% \mathrm{Cl} 0.57$ to 4.55$)(95 \% \mathrm{Cl}=$ NNT-B of 11 to NNT-H of 8) when only infants who had a cough at baseline were considered (Analysis 2.2). For both cough outcomes, the data favoured the placebo group. Orenstein and colleagues also described "no difference in efficacy between lansoprazole and placebo for symptoms attributed to GERD in infants" (Orenstein 2009). Treatment-emergent serious adverse events (as defined by authors) were significantly more common in the PPI group (OR 5.56; $95 \% \mathrm{Cl} 1.18$ to 26.25 (Analysis 2.3), with NNT-H in four weeks of 11 (95\% $\mathrm{Cl} 3$ to 232), depicted in a Cates plot (Figure 5). 
Figure 4. Forest plot of comparison: 3 PPI versus placebo (children), outcome: 3.1 Coughing (\% days/week).

\begin{tabular}{|c|c|c|c|c|c|c|c|c|c|}
\hline \multirow[b]{2}{*}{ Stucty or Subgroup } & \multicolumn{3}{|c|}{ PPI } & \multicolumn{3}{|c|}{ Placebo } & \multicolumn{2}{|r|}{ Mean Difference } & \multirow{2}{*}{$\begin{array}{l}\text { Mean Difference } \\
\mathrm{N}, \text { Fixed, 95\% } \mathrm{Cl}\end{array}$} \\
\hline & Mean & SD & Total & Mean & SD & Total & Weight & N, Fixed, 95\% Cl & \\
\hline Orenstein 2009 & 0 & 42.9 & 81 & -8.6 & 30.43 & 81 & $100.0 \%$ & $8.60[-2.85,20.05]$ & \\
\hline Total (95\% Cl) & & & 81 & & & 81 & $100.0 \%$ & $8.60[-2.85,20.05]$ & \\
\hline $\begin{array}{l}\text { Heterogeneity: Not a } \\
\text { Test for overall effec }\end{array}$ & $\begin{array}{l}\text { plicable } \\
Z=1.47\end{array}$ & & & & & & & & 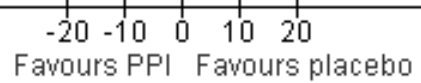 \\
\hline
\end{tabular}

Figure 5. Cates plot: In the control group, 25 out of 1000 had a serious adverse event over 4 weeks, compared to 123 (95\% Cl 29 to 399) out of 1000 for the PPI group

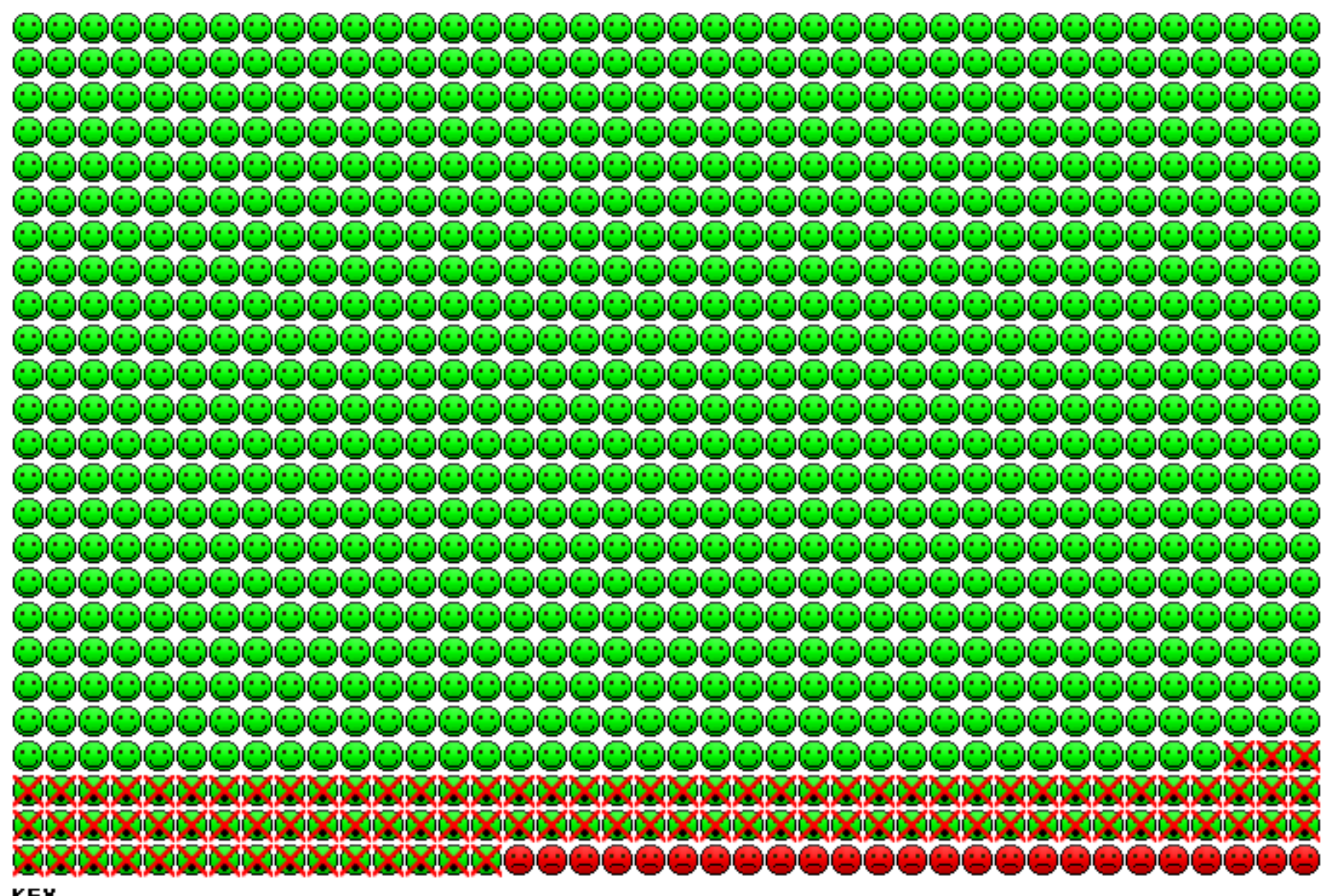

KEY

Good outcome

Bad outcome

Better with treatment

Better with control

Dordal and colleagues described no significant effect of cisapride or domperidone on cough presumably secondary to GORD (Dordal 1994).

\section{Adults}

\section{Cough outcomes}

In the single study comparing PPI to $\mathrm{H}_{2}$-antagonist, $70 \%$ of those on PPI improved versus $30 \%$ of participants on $\mathrm{H}_{2}$-antagonist 
(Jaspersen 1999). Data from the only study comparing $\mathrm{H}_{2}$-antagonist to placebo was presented graphically and showed improvement in cough scores by intervention in all participants and the effect was significant by two weeks (Ing 1997).

In the 10 studies comparing PPI or cisapride to placebo, all but two studies showed no difference between improvement of cough scores in the active versus placebo arms (Eherer 2003; Havas 1999; Kopec 2001; Noordzij 2001; Ours 1999; Steward 2004; Vaezi 2006; Wo 2006). Only two studies described a significant difference in favour of PPI (Kiljander 2000; Pawar 2007). In the meta-analysis the outcomes are described below:

\section{Primary outcome: Failure to cure (outcome 03.01)}

This was the only outcome where intention-to-treat data could be utilised in all included studies (Eherer 2003; Kiljander 2000; Ours 1999; Vaezi 2006) displayed in the forest plot. The pooled OR effect estimate was 0.46 and non-significant $(95 \% \mathrm{Cl} 0.19$ to 1.15$)$ (Analysis 3.1; Figure 3), resulting in a NNT of $12(95 \%$ CI NNT-B of 4 to NNT$\mathrm{H}$ of 90$)$. In Wo and colleagues' study, the "\% of subjects with adequate relief" was reported to be similar in both the PPI group and the placebo group ( $40 \%$ and $42 \%$ respectively, $P=0.89$ ) (Wo 2006). As data specific for cough could not be obtained, this study was not included in the meta-analysis.

\section{Mean cough score at end of trial (outcome 03.02)}

Ina pooled analysis of four studies (Eherer 2003; Kiljander 2000; Noordzij 2001; Pawar 2007), the effect of active drug was of borderline statistical significance (SMD $-0.38 ; 95 \% \mathrm{Cl}-0.77$ to $0, \mathrm{P}=0.05$ ) (Analysis 3.2). A pooled analysis of data from cross-over studies (Eherer 2003; Kiljander 2000) was also not significant (SMD -0.29; $95 \% \mathrm{Cl}$ -0.62 to 0.04$)$.

\section{Change in cough scores at end of intervention (parallel-group/1st arm} cross-over data) (outcome 03.03 to 05 )

Pooled analysis for all six studies (Eherer 2003; Havas 1999; Kiljander 2000; Noordzij 2001; Steward 2004; Pawar 2007) was statistically significant (SMD $-0.39,95 \% \mathrm{Cl}-0.77$ to -0.08 ) (Analysis 3.3; Figure $6)$, and there was a moderate level of heterogeneity $\left(1^{2}=12 \%\right)$. The two studies (Kiljander 2000; Noordzij 2001) which utilised omeprazole showed a significant benefit (SMD $-0.71 ; 95 \% \mathrm{Cl}-1.29$ to -0.41 ) and no significant heterogeneity. The studies that utilised other PPIs (lansoprazole, rabeprazole or pantoprazole) (Eherer 2003; Havas 1999; Steward 2004; Pawar 2007) showed no significant benefit of PPI over placebo. Within each subgroup, there was no significant heterogeneity and the between-group test for difference between omeprazole and the other PPIs was non-significant (SMD $-0.45 ; 95 \% \mathrm{Cl}-1.13$ to 0.23 ). This subgroup analysis was post hoc. Kiljander 2000 and Noordzij 2001, the two studies that used omeprazole, were also the studies that reported data at week four and whilst the study drugs may have an effect over a longer period than one month, the evidence from our analyses should be cautiously applied for several reasons. Firstly the sample sizes of the trials were small and the sensitivity of the symptom scales is as yet unqualified. However, data from the two cross-over trials (Eherer 2003; Kiljander 2000) assessing mean change in symptoms may confer some validity to the notion that there is an effect on symptom change. When these data were pooled using change from baseline scores, there was a significant difference of -0.41 standard deviation units $(95 \% \mathrm{Cl}-0.75$ to -0.07$)$ (Analysis 3.4). The result with absolute scores was not statistically significant (Analysis 3.5).

\section{Change in cough scores at week four of intervention (outcome 03.06)}

Two studies (Kiljander 2000; Noordzij 2001) could be utilised for assessment of time effect i.e. after four weeks of intervention. The change in cough score was in favour of PPI use but was not significant $(P=0.09)$ with a standardised mean difference of $-0.51(95 \% \mathrm{Cl}$ -1.08 to 0.06 ) (Analysis 3.6).

Change in cough score between week eight (end of intervention) and week four (mid-intervention) (outcome 03.07)

Two studies (Kiljander 2000; Noordzij 2001) could be utilised for assessment of time effect from eight weeks (two months) to four weeks (one month) of intervention. There was no significant difference between change in cough score between week eight and week four (SMD of $-0.44 ; 95 \% \mathrm{Cl}-1.04$ to 0.16 ) (Analysis 3.7

Determination of time to respond and duration of treatment effect was limited. The two studies that reported on scores midway through trial (at one month (Noordzij 2001) and at six weeks (Havas 1999)) found no difference in scores between midway scores versus end of trial scores. In the meta-analysis, whereby raw data was obtained from Kiljander 2000 (data from Havas 1999 could not be included), no significant effect was found between week eight and week four. In one cross-over study, cough resolved while on omeprazole in two adults but recurred in the washout phase (Kiljander 2000). One study that reported time to response (Ours 1999) was also the only paper that had follow up post-trial (open nonRCT followed the double-blind, randomised, placebo-controlled parallel trial). The authors reported that cough totally resolved or showed a downward decline in cough scores in five to 14 days in coughers who responded to open-label PPI (Ours 1999).

In contrast to the paediatric data, none of these adult studies reported any significant adverse events to interventions and hence 'number needed to harm' was not relevant in this review. Heterogeneity between studies included for meta-analysis was non-significant for all outcomes analysed. The funnel plots for the cough outcomes were asymmetrical but study numbers were small. Association between level of risk and benefit was not possible.

\section{Gastrointestinal symptoms of GORD}

All studies with sufficient data provided reported significant improvement in gastrointestinal symptoms over time but the treatment arm was no different from the placebo arm in five studies (Eherer 2003; Havas 1999; Noordzij 2001; Pawar 2007; Wo 2006 ). In two studies, improvement in GORD symptoms could not be determined from lack of data or GORD symptoms were presumed absent (Ing 1997; Kopec 2001).

\section{Laryngeal symptoms and scores}

All eight studies that included this outcome measure reported significant improvement in other laryngitis symptoms over time (Eherer 2003; El Serag 2001; Havas 1999; Noordzij 2001; Steward 2004; Vaezi 2006; Wo 2006). In six studies, the difference in total symptom improvement was similar in both the treatment arm and placebo arms (Eherer 2003; Havas 1999; Pawar 2007; Steward 2004; Vaezi 2006; Wo 2006). One study found significant differences between PPI and placebo in hoarseness and throat clearing but not in throat pain (Noordzij 2001). Another study (El Serag 2001) described that a higher proportion of participants in the PPI group $(86 \%)$ had a complete response when compared to the placebo group (40\%) but no significant difference in laryngoscopy assess- 
ment. One study described no difference between PPI and placebo in total score but an improvement in cough score in favour of $\mathrm{PPI}$, yet the objective score in reflux (by video laryngoscopy) significantly favoured the placebo group (Pawar 2007). Wo and colleagues described that at the four-week follow-up period post-cessation of treatment, those on PPI had a significantly higher recurrence of laryngeal symptoms then those on placebo (Wo 2006).

When assessed by laryngoscopy, four studies described significant improvement in laryngoscopy-based scores but again the improvement in those receiving PPI was similar to those on placebo (Eherer 2003; Havas 1999; Steward 2004; Vaezi 2006). However, Noordzij 2001 found no significant difference in laryngoscopy scores before and after treatment in both arms. Pawar 2007 and Wo 2006 described a significant difference between groups, both favouring the placebo group.

\section{Sensitivity analyses}

Limiting the analysis to studies with higher quality scores (Jadad score of five, as in previous versions) did not change the primary outcome (proportions not cured) with an OR of $0.52(95 \% \mathrm{Cl} 0.20$ to 1.35 ) (all-inclusive effect estimate was OR $0.46 ; 95 \% \mathrm{Cl} 0.19$ to 1.15). It was not possible to perform this on other outcomes. Varying the inclusion criteria by removing studies of participants enrolled from otolaryngology clinics also did not change the primary outcome (OR $0.17 ; 95 \% \mathrm{Cl} 0.02$ to 1.73 ). Varying inclusion criteria by limiting studies to participants with 'laryngitis' also did not change the primary outcome (OR $0.24 ; 95 \% \mathrm{Cl} 0.21$ to 1.49 ). It was again not possible to test this effect on other outcomes. Varying the inclusion criteria by removing studies of participants enrolled from medical clinics did not alter non-significance of results (altered 'change in cough score' outcome from all-inclusive SMD -0.39; $95 \% \mathrm{Cl}-0.71$ to -0.08 to SMD $-0.18 ; 95 \% \mathrm{Cl}-0.71$ to 0.35 ). 'Mean cough score at end of trial' did not significantly change when medical clinic studies were omitted(SMD $-0.34 ; 95 \% \mathrm{Cl}-0.97$ to 0.28 ) and analysis was not possible for the primary outcome. It was not possible to test for analysis for medication class type or study size because of all studies were small and only studies on PPI could be used in metaanalysis. Analysis by treatment received did not change the primary outcome, i.e. proportions not cured (OR $0.3 ; 95 \% \mathrm{Cl} 0.06$ to 1.44). As analyses for other outcomes were performed on 'treatment received' (intention-to-treat analysis was not possible), this was not repeated for the other three outcomes. There was no difference in results when we used a random-effects model in all outcome measures. When, however, data from both arms of the cross-over studies were treated as parallel studies, we found a significant difference between week eight and week four (SMD $-0.76 ; 95 \% \mathrm{Cl}-1.27$ to -0.25 ) suggesting that the non-significant effect is possibly related to a small sample size.

\section{DISCUSSION}

This systematic review of 19 studies (six in infants/children and 13 in adults) has shown a lack of high-level evidence that the treatment of gastroesophageal reflux disease (GORD) associated cough improves cough measured by subjective methods (i.e. subjective cough). Studies on milk formula-thickening yielded inconsistent results and the single randomised controlled trial (RCT) on proton pump inhibitors (PPI) in paediatrics (162 children) found no significant difference between groups for cough as primary outcome ( $95 \% \mathrm{Cl}$ of number needed to treat for benefit (NNT-B) of 11 to number needed to treat for harm (NNT-H) of eight) or other cough out- comes. Importantly, serious adverse events, particularly lower respiratory tract infections, occurred significantly more frequently in the lansoprazole group compared with the placebo group, the NNT$\mathrm{H}$ after four weeks was 11 (95\% $\mathrm{Cl} 3$ to 232). In adults, there was no significant effect in the pooled analysis and the beneficial effect was seen only in the subgroup analysis. The OR for cough resolution pooled from four adult studies was not statistically significant (NNT-B of 4 to NNT-H of 90). This review also highlights the large placebo and time period effect of treatment for chronic cough.

The beneficial effects of PPI for cough and GORD were inconsistent. The only significant differences were change in cough scores at the end of studies which used omeprazole (Kiljander 2000; Noordzij 2001; both these studies also reported four weeks change at which time point there was no significant difference in change in cough scores) and in the generic inverse variance (GIV) analysis of cross-over studies (Eherer 2003; Kiljander 2000). Non-significant changes were found in the primary outcome measure of failure to cure, as well as in mean cough score at end of trial (borderline non-significant) and when all studies were combined for change in cough score at end of trial analysis. While a possible contributor to this is the lack of power, another possible contributor to the inconsistent and small treatment effect is that, as cough and GORD are both common symptoms, the presumed GORD-related cough was not caused by GORD. This explanation suggests that in a high proportion of cases of presumed GORD-related cough, there is in fact an alternative cause for the persistent cough. Indeed cough is the most common symptom presenting to doctors (Britt 2002). Both GOR and cough are common diseases, which often co-exist and this association does not imply cause and effect (Field 1999). Indeed the probability of both symptoms co-existing merely by chance is high, and cough can induce reflux episodes as described in asthma and GORD literature (Field 1999; Zerbib 2002). However, our finding of an effect of therapy with PPI to improve cough when measured using change scores at the end of the trials does suggest that in a proportion of cases of chronic cough with associated GORD, GORD could be a contributing cause of cough. However, the non-significant NNT is relatively large at 12 (95\% CI NNT-B of 4 to NNT-H of 90$)$.

Other possible influences on the results of this review include degree of acid inhibition achieved, duration of therapy, outcomes of cough measured, and type of GORD (acid versus non-acid/volume reflux). The degree of acid inhibition achieved in the treatment is probably a small factor, if it is a factor at all, given that in the majority of studies resolution of GORD symptoms (of the gastrointestinal system) was achieved. However, it is also possible that different degrees of acid suppression are required to control the different manifestations of GORD. Subjective cough outcomes were variable between studies and in all studies the diary systems used were unvalidated. Subjective cough monitoring is subject to various influences (Chang 1998) and less reliable than objective cough monitoring in both adults (Hsu 1994) and children (Chang 2003; Chang 1998). In large RCTs, the influence of the type of outcome measures should be equal in both arms, but if one medication is more likely to improve symptoms other than cough, cough-specific symptom reporting may be differentially influenced. This is relevant as in the majority of included studies resolution of other GORD symptoms was achieved, which may have influenced cough-specific reporting.

Some clinical heterogeneity was present in the participants of the studies included as the majority but not all participants enrolled from otolaryngology clinics had cough. However, using separate 
analysis the direction of change in favour of PPI use was the same in patients enrolled from medical or from otolaryngology clinics. Indeed, excluding patients from otolaryngology clinics (or with laryngitis) did not alter the level of statistical significance of the primary outcome. There was no significant statistical heterogeneity in studies between omeprazole and other PPIs, but these data are limited by small sample sizes and different doses used by the different groups of trialists. The studies using omeprazole used either $40 \mathrm{mg}$ daily (Kiljander 2000) or twice-daily (Noordzij 2001), while the dosage for lansoprazole was $30 \mathrm{mg}$ twice-daily (Havas 1999), rabeprazole was $20 \mathrm{mg}$ twice-daily (Steward 2004) and pantoprazole was $40 \mathrm{mg}$ twice-daily (Eherer 2003). Other outcome analysis would not be possible without the studies based in otolaryngology clinics, which would have resulted in non-significant changes in all the outcomes shown in the forest plots, with the exception of change in cough scores at the end of intervention which was significant in the single medical clinic study with data available. Another recent systematic review on laryngo-pharyngeal reflux (LPR) (where cough is often a dominant symptom), concluded that "high-dose proton pump inhibitor is no more effective than placebo in producing symptomatic improvement or resolution of laryngo-pharyngeal symptoms" (Gatta 2007).

Resolution of cough in response to effective treatment is the ideal outcome in these trials. However a clinically significant improvement, rather than total resolution of cough, may be relevant and acceptable to patients with poor quality of life. The magnitude of change in cough score that constitutes a clinically relevant improvement is unknown. The NNT for clinical significant improvement (as opposed to cough resolution) is unknown.

Data on length of therapy required to achieve a change in cough score are inconsistent. One study reported significant improvement after two weeks of $\mathrm{H}_{2}$-antagonist in all participants (Ing 1997), which is a less potent acid-suppressing agent than PPI (Rudolph 2001). Ours 1999 made specific reference to the response time of five to 14 days in those whose cough was relieved by PPI in the open-label phase. However, in the meta-analysis limited to two studies where outcomes at four weeks were available (Kiljander 2000; Noordzij 2001), a trend to improvement was seen at week four and again at eight weeks but this was not statistically significant. If data from cross-over trials were analysed as parallel trials (i.e. as first-arm data), there was a significant difference between week eight and week four cough scores. While data on length of therapy is inconclusive, results from this review suggest that a trial of at least eight to nine weeks would be long enough to expect a significant improvement. This is also supported by a RCT comparing two doses of lansoprazole (30 mg twice-daily to $30 \mathrm{mg}$ daily). In participants whose cough responded to lansoprazole, the response was seen by four weeks and extended therapy (12 weeks) conferred no significant additional benefit (Baldi 2006). There is no RCT data to support recommendations of a six-month therapy trial, in contrast to uncontrolled observations, that GORD-associated cough takes a mean of a five to six months to take effect (Corrao 1996; Irwin 2002a).

PPIs are currently the most potent non-surgical intervention for acid-GORD and no adverse events were reported in these studies. The use of these medications as a trial of therapy thus probably has little risk. However, an epidemiological study reported that adults on PPI or $\mathrm{H}_{2}$ antagonist have an increased risk of having community-acquired pneumonia (adjusted relative risk of $1.89(95 \% \mathrm{Cl} 1.36$ to 2.62 ) and 1.63 (95\% Cl 1.07 to 2.48 ) respectively (Laheij 2004)). This risk translates to "approximately one case of pneumonia for every 100 years of patient exposure" (Gregor 2004). Another study described an increased risk of hip fractures associated with PPI use; the adjusted odds ratio for hip fracture associated with more than one year of PPI therapy was 1.44 (95\% Cl 1.30 to 1.59) (Yang 2006). Moreover, use of PPI has been reported to cause cough (Howaizi 2003) and the package insert for omeprazole includes cough as an adverse event in $1.1 \%$ of adults. In contrast to pharmaceutical interventions, there were no randomised studies on surgical intervention, which carries a small but significant rate of serious adverse events.

Some authors suggest that cough in association with GORD related to acid reflux can occur with normal $\mathrm{pH}$-metry and indices (i.e. require reflux index of $0 \%$ ), and that cough can take a prolonged time (a year) to settle post-GORD intervention (Irwin 2002b). Such assertions are difficult to prove or disprove in the context of the difficulties with using cough as the primary outcome measure in studies and the feasibility of the required studies. The difficulties relating GORD to cough as causative (as opposed to an association) has been recently summarised (Chang 2010; Eastburn 2007). There is discordance between cough guidelines produced by adult respiratory groups (which assert that GORD is a common cause of cough) to those originating from gastroenterology societies (which assert that the cause and effect is unclear) (Vakil 2006; Vandenplas 2009) when attributing cough and GORD. However, considerations of non-acid reflux require further studies and perhaps multichannel intraluminal electrical impedance monitoring, said to be a more sensitive alternative technology for evaluating all types of GORD (acid and non-acid) (Shay 2004) may prove useful.

\section{Quality of the evidence}

The validity of this systematic review is hindered by the disparate nature of the interventions considered and the resulting small number studies, with only selected availability of unpublished data. Given the distribution of effects for the primary outcome, this may be a reason to suspect publication bias (Figure 6). Furthermore although 19 studies were identified, data could only be used for a subset of them. Our efforts to obtain numerical outcome data from a number of investigators have only been partially successful. This review is also limited by a lack of validated scales and objective data on cough as well as a lack of allocation concealment data and possibly by clinical heterogeneity of participants and medications. The review is primarily concerned with people who do not have primary lung disease but this as an exclusion factor could not be stringently applied in all studies. In all but four studies (Pawar 2007; Steward 2004; Vaezi 2006; Wo 2006), participants were selected for gastro-intestinal symptoms or objective evidence of GORD and most but not all participants had cough. GORD criteria also varied between studies which may influence results. Most studies did not utilise GORD criteria specified by guidelines published by American and European Gastrointestinal Associations (AMA 1996; Rudolph 2001; Vandenplas 1993). There are also no data on nonacid reflux. 
Figure 6. Funnel plot of comparison: 2 PPI versus placebo (> 18 years), outcome: 2.1 Clinical failures (still coughing at end of trial or reporting period).

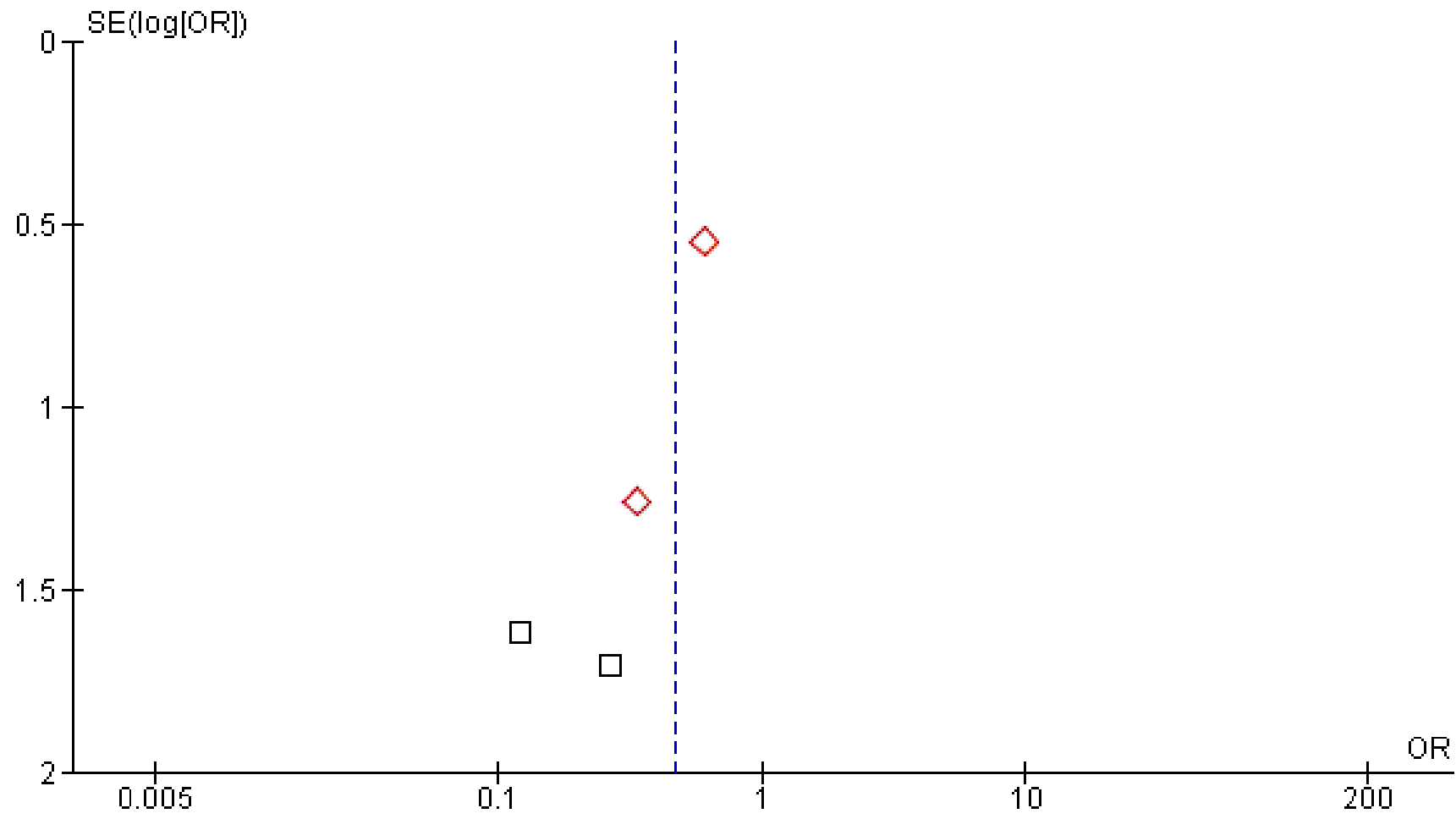

\section{Subgroups}

Medical clinics based enrolment

Otolaryngology based enrolment

\section{Potential biases in the review process}

The review process was protected from bias by following a prepublished protocol. We minimised bias by assessing studies independently and resolving differences of opinion by discussion. Data extraction was also performed in duplicate to reduce bias. We also contacted almost all authors for additional data. Many provided unpublished data (see Acknowledgements section) which reduced potential bias. However authors from one large negative study (Vaezi 2006) did not provide additional data and it is likely that inclusion of data from this study into the meta-analysis (for 'change in cough score' outcome) would add to the doubt of benefit of PPIs for cough in adults.

\section{Agreements and disagreements with other studies or reviews}

In contrast to the small effect of GORD treatment on cough found in RCTs, in non-controlled trials (see Characteristics of excluded studies) the improvement rate of surgical intervention for GORD-associated cough has been reported to be as high as 92\% (Wright 2003) with cure rates as high as $81 \%$ (Brouwer 2003). For non-surgical intervention, e.g. with PPI alone (Habermann 2002) or PPI with motility agents (Poe 2003), cough improvement rates of $86 \%$ to $100 \%$ have been reported (Habermann 2002; Poe 2003). The large difference between the effect of treatment of GORD on cough seen in randomised controlled and uncontrolled trials is likely related to the period effect and/or placebo effect also reported in other treatments for cough (Chang 1999). The placebo effect of cough treatments has been reported to be as high as $85 \%$ (Eccles 2002). The high rate of placebo effect was specifically highlighted in two of the included studies (Eherer 2003; Noordzij 2001).

Another systematic review on laryngo-pharyngeal reflux (LPR) (where cough is often a dominant symptom), had similar findings to this review. Gatta et al concluded that "high-dose proton pump inhibitor is no more effective than placebo in producing symptomatic improvement or resolution of laryngo-pharyngeal symptoms" (Gatta 2007).

Also, a small prospective concurrent controlled study (non-randomised) described non-significant difference in the adults with laryngo-pharyngeal reflux (LPR) (and unresponsive to PPI) who had laparoscopic Nissen fundoplication versus controls (Swoger 2006).

\section{AUTHORS' CONCLUSIONS}

\section{Implications for practice}

Cough and gastrointestinal symptoms of GORD are common ailments and the presence of both symptoms by chance is high (in a cohort of patients with chronic cough, the chance occurrence maybe as high as 25\%) (Eastburn 2007). There is insufficient evidence to conclude that in adults GORD treatment with PPI for cough 
associated with GORD is beneficial. The beneficial effect was only seen in secondary subgroup analysis and is small. Given the significant morbidity of chronic cough in many patients, a trial of therapy with PPI in adults with chronic cough and GORD maybe considered but has to be balanced with the reported increased (but small) risk of pneumonia in adults (Laheij 2004) on acid suppressant therapy. If a therapeutic or empiric trial of PPI is undertaken for treatment of cough, symptom improvement seems most likely to occur by two to eight weeks, although the optimal duration is uncertain. We would thus recommend that empiric trials not be abandoned before eight weeks until better evidence is available. However, the period effect (natural resolution with time) of cough is significant. Clinicians should also be cognisant of the large influence of placebo intervention seen in studies that utilise cough as an outcome measure. It is probable that a proportion of adult patients with chronic cough are subjected to longer-term PPI because of an initial apparent response due to this placebo effect, when their cough is in fact not caused by their incidental GORD. There is insufficient data to support (or refute) common recommendations of diet manipulation or use of motility agents either as a single agent or in conjunction with PPIs in the management of GORD and cough.

In children, based on current data, PPIs should not be used empirically. The single relatively large high quality study on the utility of PPI for cough associated with GORD found no beneficial effect in infants and those on lansoprazole had significantly increased serious adverse events, in particular lower respiratory infections. Data on milk modification for infants and cough with GORD is insufficient to make specific recommendations. Until more evidence is available in the form of well-designed RCTs, other causes of cough should be considered in children with cough and GORD, prior to any consideration of empiric treatment with a prolonged course of GORD medications/interventions.

\section{Implications for research}

Despite the widely advocated proposal that GORD-associated cough is common and that prolonged treatment is required, there is a paucity of RCT data on how effective GORD management is in treating cough associated with GORD. Sufficiently powered RCTs examining time for improvement and resolution of cough as well as optimal duration of therapy using valid cough outcomes are required. These cough outcomes should include objective tools (e.g. ambulatory cough monitors) and validated subjective cough instruments, such as cough specific quality if life instruments (Birring 2003; French 2002; Newcombe 2008) and cough diaries (Chang 1998; Hsu 1994). Studies on prediction of response to treatment would also be useful for clinical practice. The significant time period effect and placebo influences on cough as a symptom would render open label studies difficult to interpret. Design of future RCTs should be parallel and placebo-controlled, and have sufficient follow-up time post-trial to evaluate the possible carry-over effect or recurrence of cough post-cessation of therapy. All three crossover studies reported a significant carry-over effect (Eherer 2003; Ing 1997; Kiljander 2003); cross-over designed studies should therefore not be repeated. Objective measurement of reflux (acid and non-acid) whilst on therapy would also be beneficial. Given the possible significant harm of surgical intervention and the recommendation of surgical intervention if cough does not resolve with nonsurgical intervention for cough presumed associated with GORD symptoms (Irwin 1998), the need for a randomised controlled study of surgical intervention is substantial. Respiratory illness and pharmacokinetics of medications (Sinaiko 2001) in children are sufficiently different to that in adults to warrant separate studies on children using child-appropriate valid outcomes (Chang 2003).

\section{ACKNOWLEDGEMENTS}

We thank Dr Chris Cates and Dr Michael McKean and for their advice, supportive role and comments on the protocol and review. We are also grateful to Elizabeth Arnold for performing the relevant searches and obtaining the articles, and Toby Lasserson for translation of German and French papers, Charlotta Pisinger for Czechoslovakian translation and Gianni Ferrara for Italian translation. We also thank Drs. Eherer, Ing, Kiljander, Kopec, Orenstein, El Serag, Omari, Steward and Vanderhoof and Ms Raanan for responding and provision of additional data when available. For the 2007 update, we thank Susan Hansen for performing the search as well as obtaining the relevant articles. For the 2010 update, we thank Emma Welsh for her support, comments and amendments. 
R E F E R E N C E S

\section{References to studies included in this review}

Chao 2007 \{published and unpublished data\}

Chao HC, Vandenplas Y. Comparison of the effect of a cornstarch thickened formula and strengthened regular formula on regurgitation, gastric emptying and weight gain in infantile regurgitation. Diseases of the Esophagus 2007;20:155-60.

Dordal 1994 \{published data only\} Dordal MT, Baltazar MA, Roca I, Marques L, Server MT, Botoy J. Nocturnal spasmodic cough in the infant. Evolution after antireflux treatment [Toux spasmodique nocturne chez l'enfant. Evolution après traitement antireflux]. Allergergie et Immunology 1994;26(2):53-8.

\section{Eherer 2003 \{published and unpublished data\}}

Eherer AJ, Habermann W, Hammer HF, Kiesler K, Friedrich G, Krejs GJ. Effect of pantoprazole on the course of refluxassociated laryngitis: a placebo-controlled double-blind crossover study. Scandinavian Journal of Gastroenterology 2003;38(5):462-7.

\section{El Serag 2001 \{published data only (unpublished sought but not} used)\}

El Serag HB, Lee P, Buchner A, Inadomi JM, Gavin M, McCarthy DM. Lansoprazole treatment of patients with chronic idiopathic laryngitis: a placebo-controlled trial. American Journal of Gastroenterology 2001;96(4):979-83.

\section{Havas 1999 \{published data only (unpublished sought but not} used)\}

Havas T, Huang S, Levy M, Abi-Hanna D, Truskett P, Priestly J, et al. Posterior pharyngolaryngitis: double-blind randomised placebo-controlled trial of proton pump inhibitor therapy. Australian Journal of Oto-Laryngology 1999;3(3):243-6.

Ing 1997 \{published and unpublished data\} Ing A. Chronic cough. Respirology 1997;2(4):309-16.

\section{Jaspersen 1999 \{published data only\}}

Jaspersen D, Diehl KL, Geyer P, Martens E. Omeprazole in refluxassociated chronic persistent cough [Omeprazol - (Antra MUPS) bei refluxassoziiertem chronisch-persistierenden Husten]. Endoskopie Heute 1999;12(2):12-4.

\section{Kiljander 2000 \{published and unpublished data\}} Kiljander TO, Salomaa ER, Hietanen EK, Terho EO. Chronic cough and gastro-oesophageal reflux: a double-blind placebocontrolled study with omeprazole. European Respiratory Journal 2000;16(4):633-8.

\section{Kopec 2001 \{published and unpublished data\}}

Kopec SE, Irwin RS, French CL, Wilson MM, Bol S. A doubleblind randomized placebo-controlled trial comparing diet and/ or cisapride. American Journal of Respiratory \& Critical Care Medicine 2001;163(5 Suppl):A64.
Moukarzel 2007 \{published data only\}

Moukarzel AA, Abdelnour $\mathrm{H}$, Akatcherian C. Effects of a prethickened formula on esophageal $\mathrm{pH}$ and gastric emptying of infants with GER. Journal of Clinical Gastroenterology 2007;41:823-9.

\section{Noordzij 2001 \{published data only (unpublished sought but not used)\}}

Noordzij JP, Khidr A, Evans BA, Desper E, Mittal RK, Reibel JF, et al. Evaluation of omeprazole in the treatment of reflux laryngitis: a prospective, placebo-controlled, randomized, double-blind study. Laryngoscope 2001;111(12):2147-51.

\section{Orenstein 1992 \{published data only\}}

Orenstein SR, Shalaby TM, Putnam PE. Thickened feedings as a cause of increased coughing when used as therapy for gastroesophageal reflux in infants. Journal of Pediatrics 1992;121(6):913-5.

\section{Orenstein 2009 \{published and unpublished data\}}

Orenstein SR, Hassall E, Furmaga-Jablonska W, Atkinson S, Raanan M. Multicenter, double-blind, randomized, placebocontrolled trial assessing the efficacy and safety of proton pump inhibitor lansoprazole in infants with symptoms of gastroesophageal reflux disease. Journal of Pediatrics 2009;154(4):e4.

\section{Ours 1999 \{published data only (unpublished sought but not} used)\}

Ours TM, Kavuru MS, Schilz RJ, Richter JE. A prospective evaluation of esophageal testing and a double-blind, randomized study of omeprazole in a diagnostic and therapeutic algorithm for chronic cough. American Journal of Gastroenterology 1999;94(11):3131-8.

Pawar 2007 \{published data only (unpublished sought but not used)\}

* Pawar S, Lim HJ, Gill M, Smith TL, Merati A, Toohill RJ, Loehrl TA. Treatment of postnasal drip with proton pump inhibitors: a prospective, randomized, placebo-controlled study. American Journal of Rhinology 2007;21:695-701.

Steward 2004 \{published data only (unpublished sought but not used)\}

Steward DL, Wilson KM, Kelly DH, Patil MS, Schwartzbauer HR, Long JD, et al. Proton pump inhibitor therapy for chronic laryngo-pharyngitis: a randomized placebo-control trial. Otolaryngology - Head and Neck Surgery 2004;131(4):342-50.

\section{Vaezi 2006 \{published data only (unpublished sought but not used)\} \\ * Vaezi MF, Richter JE, Stasney CR, Spiegel JR, Iannuzzi RA, Crawley JA, et al. Treatment of chronic posterior laryngitis with esomeprazole. Laryngoscope 2006;116(2):254-60.}

\section{Vanderhoof 2003 \{published data only (unpublished sought but not used)\}}

Vanderhoof JA, Moran JR, Harris CL, Merkel KL, Orenstein SR. Efficacy of a pre-thickened infant formula: a multicenter, 
double-blind, randomized, placebo-controlled parallel group trial in 104 infants with symptomatic gastroesophageal reflux. Clinical Pediatrics 2003;42(6):483-95.

\section{Wo 2006 \{published data only\}}

Wo JM, Koopman J, Harrell SP, Parker K, Winstead W, Lentsch E. Double-blind, placebo-controlled trial with single-dose pantoprazole for laryngopharyngeal reflux. American Journal of Gastroenterology 2006;101:1972-8.

\section{References to studies excluded from this review}

Ahmad 2004 \{published data only\}

Ahmad I, Batch AJ. Acid reflux management: ENT perspective. Journal of Laryngology \& Otology 2004;118(1):25-30.

\section{Allen 1998 \{published data only\}}

Allen CJ, Anvari M. Gastro-oesophageal reflux related cough and its response to laparoscopic fundoplication. Thorax 1998;53(11):963-8.

\section{Allen 2002 \{published data only\}}

Allen CJ, Anvari M. Preoperative symptom evaluation and esophageal acid infusion predict response to laparoscopic Nissen fundoplication in gastroesophageal reflux patients who present with cough. Surgical Endoscopy 2002;16(7):1037-41.

\section{Allen 2004 \{published data only\}}

Allen CJ, Anvari M. Does laparoscopic fundoplication provide long-term control of gastroesophageal reflux related cough?. Surgical Endoscopy 2004;18(4):633-7.

\section{Baldi 2006 \{published data only\}}

Baldi F, Cappiello R, Cavoli C, Ghersi S, Torresan F, Roda E. Proton pump inhibitor treatment of patients with gastroesophageal reflux-related chronic cough: a comparison between two different daily doses of lansoprazole. World Journal of Gastroenterology 2006;12(1):82-8.

\section{Baldi 2006a \{published data only\}}

Baldi F, Cavoli C, Ghersi S, Mantovani L, Torresan F, Roda E. Cost-effectiveness of different diagnostic strategies to assess gastro-oesophageal reflux disease in patients with unexplained chronic persistent cough in Italy. Digestive \& Liver Disease 2006;38(7):452-8.

\section{Belafsky 2008 \{published data only\}}

Belafsky PC, Rees CJ, Rodriguez K, Pryor JS, Katz PO. Esophagopharyngeal reflux. Otolaryngology - Head and Neck Surgery 2008;138:57-61.

\section{Birk 2009 \{published data only\}}

Birk J, Pruitt R, Haber G, Raijman I, Baluyut A, Meiselman M, et al. The Plicator procedure for the treatment of gastroesophageal reflux disease: a registry study. Surgical Endoscopy and Other Interventional Techniques 2009;23:423-31.

\section{Brouwer 2003 \{published data only\}}

Brouwer R, Kiroff GK. Improvement of respiratory symptoms following laparoscopic Nissen fundoplication. ANZ Journal of Surgery 2003;73(4):189-93.

\section{Chandra 2007 \{published data only\}}

Chandra KM, Harding SM. Therapy insight: treatment of gastroesophageal reflux in adults with chronic cough. Nature Clinical Practice Gastroenterology \& Hepatology 2007;4:604-13.

Chen 2000 \{published data only\}

Chen RY, Thomas RJ. Results of laparoscopic fundoplication where atypical symptoms coexist with oesophageal reflux. ANZ Journal of Surgery 2000;70(12):840-2.

\section{Coron 2007 \{published data only\}}

Coron E, Hatlebakk JG, Galmiche JP. Medical therapy of gastroesophageal reflux disease. Current Opinion in Gastroenterology 2007;23:434-9.

Dalby-Payne 2003 \{published data only\}

Dalby-Payne JR, Morris AM, Craig JC. Meta-analysis of randomized controlled trials on the benefits and risks of using cisapride for the treatment of gastroesophageal reflux in children. Journal of Gastroenterology \& Hepatology 2003;18(2):196-202.

\section{DeMeester 1990 \{published data only\}}

DeMeester TR, Bonavina L, lascone C, Courtney JV, Skinner DB. Chronic respiratory symptoms and occult gastroesophageal reflux. A prospective clinical study and results of surgical therapy. Annals of Surgery 1990;211(3):337-45.

Dore 2007 \{published data only\}

Dore MP, Pedroni A, Pes GM, Maragkoudakis E, Tadeu V, Pirina P, et al. Effect of antisecretory therapy on atypical symptoms in gastroesophageal reflux disease. Digestive Diseases \& Sciences 2007;52(2):463-8

\section{Duffy 2003 \{published data only\}}

Duffy JP, Maggard M, Hiyama DT, Atkinson JB, McFadden DW, $\mathrm{Ko} \mathrm{CY}$, et al. Laparoscopic Nissen fundoplication improves quality of life in patients with atypical symptoms of gastroesophageal reflux. American Surgeon 2003;69(10):833-8.

\section{Ekstrom 2000 \{published data only\}}

Ekstrom T, Johansson KE. Effects of anti-reflux surgery on chronic cough and asthma in patients with gastro-oesophageal reflux disease. Respiratory Medicine 2000;94(12):1166-70.

\section{El Hennawi 2004 \{published data only\}}

El Hennawi DD, Iskander NM, Ibrahim IH, Serwah AH. Persistent cough: prevalence of gastroesophageal reflux and study of relevant laryngeal signs. Otolaryngology - Head and Neck Surgery 2004;131(5):767-72.

\section{Eubanks 2001 \{published data only\}}

Eubanks TR, Omelanczuk P, Hillel A, Maronian N, Pope CE, Pellegrini CA. Pharyngeal $\mathrm{pH}$ measurements in patients with respiratory symptoms before and during proton pump inhibitor therapy. American Journal of Surgery 2001;181(5):466-70. 
Farrell 2001 \{published data only\}

Farrell TM, Richardson WS, Trus TL, Smith CD, Hunter JG. Response of atypical symptoms of gastro-oesophageal reflux to antireflux surgery. British Journal of Surgery 2001;88(12):1649-52.

\section{Fock 2008 \{published data only\}}

Fock KM, Talley NJ, Fass R, Goh KL, Katelaris P, Hunt R, et al. Asia-Pacific consensus on the management of gastroesophageal reflux disease: update. Journal of Gastroenterology and Hepatology 2008;23:8-22.

\section{Fraser 2000 \{published data only\}}

Fraser AG, Morton RP, Gillibrand J. Presumed laryngopharyngeal reflux: investigate or treat?. Journal of Laryngology \& Otology 2000;114(6):441-7.

\section{Gatta 2007 \{published data only\}}

Gatta L, Vaira D, Sorrenti G, Zucchini S, Sama C, Vakil N. Metaanalysis: the efficacy of proton pump inhibitors for laryngeal symptoms attributed to gastro-oesophageal reflux disease. Alimentary Pharmacology \& Therapeutics 2007;25(4):385-92.

\section{Gilger 2008 \{published data only\}}

Gilger MA, Tolia V, Vandenplas Y, Youssef NN, Traxler B, Illueca M. Safety and tolerability of esomeprazole in children with gastroesophageal reflux disease. Journal of Pediatric Gastroenterology and Nutrition 2008;46:524-33.

\section{Greason 2002 \{published data only\}}

Greason KL, Miller DL, Deschamps C, Allen MS, Nichols FC III, Trastek VF, et al. Effects of antireflux procedures on respiratory symptoms. Annals of Thoracic Surgery 2002;73(2):381-5.

\section{Grill 1985 \{published data only\}}

Grill BB, Hillemeier AC, Semeraro LA, McCallum RW, Gryboski JD. Effects of domperidone therapy on symptoms and upper gastrointestinal motility in infants with gastroesophageal reflux. Journal of Pediatrics 1985;106(2):311-16.

\section{Habermann 1999 \{published data only\}}

Habermann W, Eherer A, Lindbichler F, Raith J, Friedrich G. Ex juvantibus approach for chronic posterior laryngitis: results of short-term pantoprazole therapy. Journal of Laryngology \& Otology 1999;113(8):734-9.

\section{Habermann 2002 \{published data only\}}

Habermann W, Kiesler K, Eherer A, Friedrich G. Short-term therapeutic trial of proton pump inhibitors in suspected extraesophageal reflux. Journal of Voice 2002;16(3):425-32.

\section{Hui 2000 \{published data only\}}

Hui TT, Fass SM, Giurgiu DI, Lida A, Takagi S, Phillips EH. Gastroesophageal disease and nausea: does fundoplication help or hurt?. Archives of Surgery 2000;135(5):545-9.

\section{Hunter 1996 \{published data only\}}

Hunter JG, Trus TL, Branum GD, Waring JP, Wood WC. A physiologic approach to laparoscopic fundoplication for gastroesophageal reflux disease. Annals of Surgery 1996;223(6):673-85.

\section{Irwin 1993 \{published data only\}}

Irwin RS, French CL, Curley FJ, Zawacki JK, Bennett FM. Chronic cough due to gastroesophageal reflux. Clinical, diagnostic, and pathogenetic aspects. Chest 1993;104(5):1511-17.

\section{Irwin 2002 \{published data only\}}

Irwin RS, Zawacki JK, Wilson MM, French CT, Callery MP. Chronic cough due to gastroesophageal reflux disease: failure to resolve despite total/near-total elimination of esophageal acid. Chest 2002;121(4):1132-40.

\section{Issing 2004 \{published data only\}}

Issing WJ, Karkos PD, Perreas K, Folwaczny C, Reichel O. Dualprobe 24-hour ambulatory $\mathrm{pH}$ monitoring for diagnosis of laryngopharyngeal reflux. Journal of Laryngology \& Otology 2004;118(11):845-8.

\section{Katzka 1996 \{published data only\}}

Katzka DA, Paoletti V, Leite L, Castell DO. Prolonged ambulatory $\mathrm{pH}$ monitoring in patients with persistent gastroesophageal reflux disease symptoms: testing while on therapy identifies the need for more aggressive anti-reflux therapy. American Journal of Gastroenterology 1996;91(10):2110-13.

Leeder 2002 \{published data only\}

Leeder PC, Watson DI, Jamieson GG. Laparoscopic fundoplication for patients with symptoms but no objective evidence of gastroesophageal reflux. Diseases of the Esophagus 2002;15(4):309-14.

\section{Monini 2006 \{published data only\}}

Monini S, Di Stadio A, Vestri A, Barbara M. Silent reflux: ex juvantibus criteria for diagnosis and treatment of laryngeal disorders. Acta Oto-Laryngologica 2006;126(8):866-71.

\section{Murray 2006 \{published data only\}}

Murry T, Tabaee A, Owczarzak V, Aviv JE. Respiratory retraining therapy and management of laryngopharyngeal reflux in the treatment of patients with cough and paradoxical vocal fold movement disorder. Annals of Otology, Rhinology \& Laryngology 2006;115(10):754-8.

Novitsky 2002 \{published data only\}

Novitsky YW, Zawacki JK, Irwin RS, French CT, Hussey VM, Callery MP. Chronic cough due to gastroesophageal reflux disease: efficacy of antireflux surgery. Surgical Endoscopy 2002;16(4):567-71.

\section{Omari 2006 \{published data only\}}

Omari TI, Benninga MA, Sansom L, Butler RN, Dent J, Davidson GP. Effect of baclofen on esophagogastric motility and gastroesophageal reflux in children with gastroesophageal reflux disease: a randomized controlled trial. Journal of Pediatrics 2006;149(4):468-74.

\section{Oridate 2008 \{published data only\}}

Oridate N, Takeda H, Asaka M, Nishizawa N, Mesuda Y, Mori M, et al. Acid-suppression therapy offers varied laryngopharyngeal and esophageal symptom relief in laryngopharyngeal reflux patients. Digestive Diseases \& Sciences 2008;53:2033-8. 
Poe 2003 \{published data only\}

Poe RH, Kallay MC. Chronic cough and gastroesophageal reflux disease: experience with specific therapy for diagnosis and treatment. Chest 2003;123(3):679-84.

\section{Songur 2008 \{published data only\}}

Songur N, Songur Y, Cerci SS, Ozturk O, Sahin U, Senol A, et al. Gastroesophageal scintigraphy in the evaluation of adult patients with chronic cough due to gastroesophageal reflux disease. Nuclear Medicine Communications 2008;29:1066-72.

\section{Swoger 2006 \{published data only\}}

Swoger J, Ponsky J, Hicks DM, Richter JE, Abelson TI, Milstein C, et al. Surgical fundoplication in laryngopharyngeal reflux unresponsive to aggressive acid suppression: a controlled study. Clinical Gastroenterology \& Hepatology 2006;4(4):433-41.

Thoman 2002 \{published data only\}

Thoman DS, Hui TT, Spyrou M, Phillips EH. Laparoscopic antireflux surgery and its effect on cough in patients with gastroesophageal reflux disease. Journal of Gastrointestinal Surgery 2002;6(1):17-21.

\section{Tibbling 1993 \{published data only\}}

Tibbling L. Wrong-way swallowing as a possible cause of bronchitis in patients with gastroesophageal reflux disease. Acta Oto-Laryngologica 1993;113(3):405-8.

\section{Tibbling 1995 \{published data only\}}

Tibbling L, Gibellino FM, Johansson KE. Is mis-swallowing or smoking a cause of respiratory symptoms in patients with gastroesophageal reflux disease?. Dysphagia 1995;10(2):113-16.

van Zanten 2006 \{published data only\}

Van Zanten SV, Armstrong D, Chiba N, Flook N, White RJ, Chakraborty B, et al. Esomeprazole $40 \mathrm{mg}$ once a day in patients with functional dyspepsia: the randomized, placebocontrolled 'ENTER' trial. American Journal of Gastroenterology 2006;101(9):2096-106.

\section{Waring 1995 \{published data only\}}

Waring JP, Lacayo L, Hunter J, Katz E, Suwak B. Chronic cough and hoarseness in patients with severe gastroesophageal reflux disease. Diagnosis and response to therapy. Digestive Diseases and Sciences 1995;40(5):1093-7.

\section{Wo 1997 \{published data only\}}

Wo JM, Grist WJ, Gussack G, Delgaudio JM, Waring JP. Empiric trial of high-dose omeprazole in patients with posterior laryngitis: a prospective study. American Journal of Gastroenterology 1997;92(12):2160-5.

\section{Wright 2003 \{published data only\}}

Wright RC, Rhodes KP. Improvement of laryngopharyngeal reflux symptoms after laparoscopic Hill repair. American Journal of Surgery 2003;185(5):455-61.

\section{Xinias 2003 \{published data only\}}

Xinias I, Spiroglou K, Demertzidou V, Karatza E, Panteliadis C. An anti-regurgitation milk formula in the management of infants with mild to moderate gastroesophageal reflux. Current Therapeutic Research, Clinical \& Experimental 2003;64(4):270-8.

Yang 2006 \{published data only\}

Yang JY, Lee HY, Kim NH, Kim YS. The effect of a proton-pump inhibitor in unexplained chronic cough patients. [Korean]. Tuberculosis \& Respiratory Diseases 2006;61:137-42.

\section{References to studies awaiting assessment}

Morice 2008 \{published data only\}

Morice AH, Donaldson JE, Fathi HH. The efficacy of dietary intervention in the treatment of reflux cough [Abstract]. American Thoracic Society International Conference. 2008; A897 [\#E121]

\section{Additional references}

\section{Altman 1998}

Altman DG. Confidence intervals for the number needed to treat. BMJ 1998;317(7168):1309-12.

\section{AMA 1996}

American Gastroenterological Association. American Gastroenterological Association medical position statement: guidelines on the use of esophageal $\mathrm{pH}$ recording. Gastroenterology 1996;110(6):1981.

\section{Birring 2003}

Birring SS, Prudon B, Carr AJ, Singh SJ, Morgan MD, Pavord ID. Development of a symptom specific health status measure for patients with chronic cough: Leicester Cough Questionnaire (LCQ). Thorax 2003;58(4):339-43.

\section{Britt 2002}

Britt H, Miller GC, Knox S, Charles J, Valenti L, Henderson J, et al. Bettering the Evaluation and Care of Health - A Study of General Practice Activity; 2002. Australian Institute of Health and Welfare. Report no.: AlHW Cat. No. GEP-10.

\section{Chang 1998}

Chang AB, Newman RG, Carlin J, Phelan PD, Robertson CF. Subjective scoring of cough in children: parent-completed vs child-completed diary cards vs an objective method. European Respiratory Journal 1998;11:462-6.

\section{Chang 1998b}

Chang AB, Phelan PD, Carlin J, Sawyer SM, Robertson CF. Randomised controlled trial of inhaled salbutamol and beclomethasone for recurrent cough. Archives of Disease in Childhood 1998;79:6-11.

\section{Chang 1999}

Chang AB. State of the art: cough, cough receptors, and asthma in children. Pediatric Pulmonology 1999;28:59-70.

\section{Chang 2001}

Chang AB, Asher MI. A review of cough in children. Journal of Asthma 2001;38(4):299-309. 


\section{Chang 2003}

Chang AB, Phelan PD, Robertson CF, Roberts RDG, Sawyer SM. Relationship between measurements of cough severity. Archives of Disease in Childhood 2003;88:57-60.

\section{Chang 2010}

Chang AB, Connor FL, Petsky HL, Eastburn MM, Lewindon PJ, Hall C, et al. An objective study of acid reflux and cough in children using an ambulatory $\mathrm{pH}$ metry-cough logger. Archives of Disease in Childhood 2010;epub ahead of print:June 1.

\section{Chung 1996}

Chung KF, Lalloo UG. Diagnosis and management of chronic persistent dry cough. Postgraduate Medicine 1996;72(852):594-8.

\section{Clarke 2003}

Clarke M, Oxman AD, editors. Formulating the problem. The Cochrane Reviewers' Handbook 4.2 [updated November 2002]. The Cochrane Collaboration, 2003.

\section{Corrao 1996}

Corrao WM. Chronic persistent cough: diagnosis and treatment update. Pediatric Annals 1996;25(3):162-8.

\section{Daoui 2002}

Daoui S, Agostino B, Gallelli L, Emonds X, Rossi F, Advenier C. Tachykinins and airway microvascular leakage induced by $\mathrm{HCl}$ intra-oesophageal instillation. European Respiratory Journal 2002;20:268-73.

\section{Eastburn 2007}

Eastburn MM, Katelaris PH, Chang AB. Defining the relationship between gastroesophageal reflux and cough: probabilities, possibilities and limitations. Cough 2007;3:4. [DOI: 10.1186/1745-9974-3-4]

\section{Eccles 2002}

Eccles R. The powerful placebo in cough studies?. Pulmonary Pharmacology \& Therapeutics 2002;15(3):303-8.

\section{Elbourne 2002}

Elbourne DR, Altman DG, Higgins JP, Curtin F, Worthington HV, Vail A. Meta-analyses involving cross-over trials: methodological issues. International Journal of Epidemiology 2002;31(1):140-9.

\section{Ferrari 1995}

Ferrari M, Olivieri M, Sembenini C, Benini L, Zuccali V, Bardelli $E$, et al. Tussive effect of capsaicin in patients with gastroesophageal reflux without cough. American Journal of Respiratory \& Critical Care Medicine 1995;151:557-61.

\section{Field 1999}

Field SK, Sutherland LR. Gastroesophageal reflux and asthma: are they related?. Journal of Asthma 1999;36(8):631-44.

\section{French 2002}

French CT, Irwin RS, Fletcher KE, Adams TM. Evaluation of a cough-specific quality-of-life questionnaire. Chest 2002;121(4):1123-31.

\section{Gregor 2004}

Gregor JC. Acid suppression and pneumonia: a clinical indication for rational prescribing. JAMA 2004;292(16):2012-3.

\section{Handbook 2008}

Higgins JPT, Green S (editors). Cochrane Handbook for Systematic Reviews of Interventions Version 5.0.2 [updated September 2009]. The Cochrane Collaboration, 2008. Available from www.cochrane-handbook.org.

\section{Howaizi 2003}

Howaizi M, Delafosse C. Omeprazole-induced intractable cough. Annals of Pharmacotherapy 2003;37(11):1607-9.

\section{Hsu 1994}

Hsu JY, Stone RA, Logan-Sinclair RB, Worsdell M, Busst CM, Chung KF. Coughing frequency in patients with persistent cough: assessment using a 24 hour ambulatory recorder. European Respiratory Journal 1994;7:1246-53.

\section{Ing 1994}

Ing AJ, Ngu MC, Breslin AB. Pathogenesis of chronic persistent cough associated with gastroesophageal reflux. American Journal of Respiratory \& Critical Care Medicine 1994;149(1):160-7.

\section{Irwin 1990}

Irwin RS, Curley FJ, French CL. Chronic cough. The spectrum and frequency of causes, key components of the diagnostic evaluation, and outcome of specific therapy. American Review of Respiratory Disease 1990;141:640-7.

\section{Irwin 1998}

Irwin RS, Boulet LP, Cloutier MM, Fuller R, Gold PM, Hoffstein V, et al. Managing cough as a defence mechanism and as a symptom. A consensus panel report of the American College of Chest Physicians. Chest 1998;114(2 Suppl):133S-81S.

\section{Irwin 2002a}

Irwin RS, Madison JM. Diagnosis and treatment of chronic cough due to gastro-esophageal reflux disease and postnasal drip syndrome. Pulmonary Pharmacology \& Therapeutics 2002;15(3):261-6

\section{Irwin 2002b}

Irwin RS, Zawacki JK, Wilson MM, French CT, Callery MP. Chronic cough due to gastroesophageal reflux disease: failure to resolve despite total/near-total elimination of esophageal acid. Chest 2002;121(4):1132-40.

\section{Kiljander 2003}

Kiljander TO. The role of proton pump inhibitors in the management of gastroesophageal reflux disease-related asthma and chronic cough. American Journal of Medicine 2003;115(Suppl 3A):65S-71S.

\section{Laheij 2004}

Laheij RJ, Sturkenboom MC, Hassing RJ, Dieleman J, Stricker BH, Jansen JB. Risk of community-acquired pneumonia and use of gastric acid-suppressive drugs. JAMA 2004;292(16):1955-60. 


\section{Newcombe 2008}

Newcombe PA, Sheffield JK, Juniper EF, Halstead RA, Masters IB, Chang AB. Development of a parent-proxy quality-of-life chronic cough-specific questionnaire: clinical impact vs psychometric evaluations. Chest 2008;133:386-95.

\section{O'Connell 1994}

O'Connell F, Thomas VE, Pride NB, Fuller RW. Capsaicin cough sensitivity decreases with successful treatment of chronic cough. American Journal of Respiratory \& Critical Care Medicine 1994;150:374-80.

\section{RevMan 2008 [Computer program]}

The Nordic Cochrane Centre, The Cochrane Collaboration. Review Manager (RevMan). Version 5.0. Copenhagen: The Nordic Cochrane Centre, The Cochrane Collaboration, 2008.

\section{Rudolph 2001}

Rudolph CD, Mazur LJ, Liptak GS, Baker RD, Boyle JT, Colletti RB, et al. Guidelines for evaluation and treatment of gastroesophageal reflux in infants and children: recommendations of the North American Society for Pediatric Gastroenterology and Nutrition. Journal of Pediatric Gastroenterology \& Nutrition 2001;32(Suppl 2):1S-31S.

\section{Shay 2004}

Shay S, Tutuian R, Sifrim D, Vela M, Wise J, Balaji N, et al. Twenty-four hour ambulatory simultaneous impedance and $\mathrm{pH}$ monitoring: a multicenter report of normal values from 60 healthy volunteers. American Journal of Gastroenterology 2004;99(6):1037-43.

\section{Sinaiko 2001}

Sinaiko AR, Daniels SR. The use of short-acting nefedipine in children with hypertension: another example of the need for comprehensive drug testing in children. Journal of Paediatrics 2001;139:7-9.

\section{Swoger 2006}

Swoger J, Ponsky J, Hicks DM, Richter JE, Abelson TI, Milstein C, et al. Surgical fundoplication in laryngopharyngeal reflux

\section{CHARACTERISTICS OF STUDIES}

Characteristics of included studies [ordered by study ID] unresponsive to aggressive acid suppression: a controlled study. Clinical Gastroenterology and Hepatology 2006;4:433-41.

\section{Vakil 2006}

Vakil N, van Zanten SV, Kahrilas P, Dent J, Jones R. The Montreal definition and classification of gastroesophageal reflux disease: a global evidence-based consensus. American Journal of Gastroenterology 2006;101(8):1900-20.

\section{Vandenplas 1993}

Vandenplas Y, Ashkenazi A, Belli D, Boige N, Bouquet J, Cadranel S, et al. A proposition for the diagnosis and treatment of gastro-oesophageal reflux disease in children: a report from a working group on gastro-oesophageal reflux disease. European Journal of Pediatrics 1993;152:704-11.

\section{Vandenplas 2009}

Vandenplas Y, Rudolph CD, Di LC, et al. Pediatric gastroesophageal reflux clinical practice guidelines: joint recommendations of the North American Society for Pediatric Gastroenterology, Hepatology, and Nutrition (NASPGHAN) and the European Society for Pediatric Gastroenterology, Hepatology, and Nutrition (ESPGHAN). Journal of Pediatric Gastroenterology and Nutrition 2009;49:498-547.

\section{Yang 2006}

Yang YX, Lewis JD, Epstein S, Metz DC. Long-term proton pump inhibitor therapy and risk of hip fracture. JAMA 2006;296:2947-53.

\section{Zerbib 2002}

Zerbib F, Guisset O, Lamouliatte H, Quinton A, Galmiche JP, Tunon-de-Lara JM. Effects of bronchial obstruction on lower esophageal sphincter motility and gastroesophageal reflux in patients with asthma. American Journal of Respiratory \& Critical Care Medicine 2002;166(9):1206-11.

* Indicates the major publication for the study

\section{Chao 2007}

Methods Single centre, double-blinded, randomised, placebo-controlled trial that compared a commercial cornstarched milk anti-reflux (AR) formula to a regular $1.25 \%$ strength formula

Infants given regular milk at baseline and scintigraphy performed. Diaries collected and repeat scintigraphy performed using the intervention formula

Randomisation method not well described. Allocation by envelope

High quality score: $B, C, A, B$

Study was financially supported by a pharmaceutical industry

Participants

100 included infants, 81 completed the 2-month clinical follow up 
Chao 2007 (Continued)

Intervention group $(n=41)$ : mean age - 90.2 (SD 26.8) days, 21 males, 20 females

Placebo group ( $n=40)$ : mean age - 90.5 (SD 27.4) days, 21 males, 19 females

Only total of 9 children had cough as a symptom

Inclusion criteria: non-breast-fed infants (age 2-4 months) presenting with frequent regurgitation/vomiting ( $>3$ times/day)

Exclusion criteria: infants with atopic symptoms such as eczema, watery rhinorrhoea or diarrhoea suspecting cow's milk allergy, presence of mechanical obstruction such as infantile hypertrophic pyloric stenosis and malrotation (excluded with an upper gastrointestinal barium study)

\begin{tabular}{|c|c|c|}
\hline Interventions & \multicolumn{2}{|c|}{ A cornstarch-thickened anti-reflux formula compared to $1.25 \%$ strength regular formula for 2 months } \\
\hline Outcomes & \multicolumn{2}{|c|}{$\begin{array}{l}\text { Diary: mean frequency of episodes of regurgitation and/or vomiting, mean feeding volume tolerated as } \\
\text { well as associated symptoms (irritability, cough, choking, crying) during the } 3 \text { days prior to a visit, and } \\
\text { weight gain }\end{array}$} \\
\hline & \multicolumn{2}{|c|}{ 90-minute milk scintigraphy with $500 \mu \mathrm{Cl}$ technetium to quantify gastric emptying } \\
\hline Notes & - & \\
\hline \multicolumn{3}{|l|}{ Risk of bias } \\
\hline Bias & Authors' judgement & Support for judgement \\
\hline $\begin{array}{l}\text { Adequate sequence gener- } \\
\text { ation? }\end{array}$ & Unclear risk & Not described \\
\hline Allocation concealment? & Unclear risk & Envelope drawing system, no further information described \\
\hline $\begin{array}{l}\text { Blinding? } \\
\text { Clinical cure/failure }\end{array}$ & Unclear risk & Not stated if parents were blinded to type of formula \\
\hline $\begin{array}{l}\text { Blinding? } \\
\text { Cough frequency or score }\end{array}$ & Unclear risk & Not applicable for this study \\
\hline Free of other bias? & Unclear risk & Insufficient data \\
\hline
\end{tabular}

\section{Dordal 1994}

Methods

Controlled parallel study comparing cisapride with domperidone and no treatment (as control). At baseline, patients were examined clinically. They underwent skin prick tests, spirometry, chest X-ray and gastro-oesophageal imaging (bolus liquid was administered and a computer-generated image traced the path of the liquid through the oesophagus). Gastroesophageal imaging graded from 1 to 4 . $1=$ normal, $2=$ partial retention of bolus ( 5 to 10 secs), $3=$ retention of bolus ( 10 to 20 secs), $4=$ prolonged retention of bolus ( $>20$ seconds). If gastroesophageal imaging of child $>=2$, child eligible

Drop outs: $\mathrm{n}=10,15.4 \%$ of those recruited. 4 drop outs from cisapride group ( 2 from adverse events, 2 lost), 2 from domperidone (lost) and 4 from no treatment group (lost)

Randomisation not mentioned, blinding not described and allocation method not described

High quality score: C, C, B, B

Participants

65 children (number screened not given) from outpatients with predominant nocturnal cough (with or without asthma) and GORD symptoms. 15 of the 55 participants who completed trial had cough without symptoms of asthma 
Dordal 1994 (Continued)

Median age of groups: cisapride - 6.7 years, SD $2.97(n=21,15$ males, 6 females); domperidone - 7.05 years, SD 3.05 ( $n=23,10$ males, 13 females); control - 6.4 years, SD $2.62(n=11,5$ males, 6 females)

Inclusion criteria: children with cough (with or without co-exiting asthma), predominantly nocturnal symptoms, reflux symptoms

Exclusion: none described

\begin{tabular}{|c|c|c|}
\hline Interventions & \multicolumn{2}{|c|}{$\begin{array}{l}\text { Cisapride ( } 0.2 \mathrm{mg} / \mathrm{kg} 20 \text { minutes before each meal) with domperidone }(0.2 \mathrm{mg} / \mathrm{kg} 15 \text { minutes before } \\
\text { each meal) and no treatment (as control) for } 12 \text { weeks } \\
\text { All also received the following: withhold food } 2 \text { hours before bedtime, reduce intake of acidic foods, } \\
\text { lower size of meals, but increase frequency, raise height of the head of the bed by } 10 \mathrm{~cm} \text { and sleeping } \\
\text { on one's side }\end{array}$} \\
\hline Outcomes & \multicolumn{2}{|l|}{$\begin{array}{l}\text { 1. Symptoms of cough } \\
\text { 2. Gastro-imaging }\end{array}$} \\
\hline Notes & \multicolumn{2}{|c|}{$\begin{array}{l}\text { Data on children without asthma were not provided. No significant difference found between the } \\
\text { groups }\end{array}$} \\
\hline \multicolumn{3}{|l|}{ Risk of bias } \\
\hline Bias & Authors' judgement & Support for judgement \\
\hline $\begin{array}{l}\text { Adequate sequence gener- } \\
\text { ation? }\end{array}$ & Unclear risk & Randomisation method not described \\
\hline Allocation concealment? & Unclear risk & Information not available \\
\hline $\begin{array}{l}\text { Blinding? } \\
\text { Clinical cure/failure }\end{array}$ & High risk & Controlled trial, no placebo \\
\hline $\begin{array}{l}\text { Blinding? } \\
\text { Cough frequency or score }\end{array}$ & High risk & Controlled trial, no placebo \\
\hline Free of other bias? & Unclear risk & Unable to assess as too little information \\
\hline
\end{tabular}

Eherer 2003

Methods Randomised, double-blind, cross-over study comparing pantoprazole versus placebo in adults with 'laryngitis' symptoms (includes cough) and GORD (defined on pH-metry). Patients with inclusion criteria enrolled from outpatients clinic, telescopic video laryngo-stroboscopy performed and screened for exclusion criteria. Dual channel $\mathrm{pH}$-metry performed and those with excessive reflux $(>4.5 \%$ time $\mathrm{pH}<$ 4) were eligible and randomised

Randomisation by blocks of 4 performed by pharmaceutical supplier. Allocation method not described. Compliance monitoring not described

Drop outs (30\% of those randomised) were not described and were not included as treatment failures in paper, but analysis by intention-to-treat was possible with additional data provided by authors

High quality score: $B, A, A, A$

Participants

21 adults (mean age 48 years, range 20 to 70,16 males, 5 females) randomised from eligible 22 patients; (62 patients screened) with GORD (diagnosed on pH-metry) and symptoms of laryngitis (cough, nocturnal cough, sore throat, hoarseness, sore dysphonic attacks, globus sensation) attending otolaryngeal clinic in a tertiary institution (Karl-Franzens University, Austria). 12 of the 21 had chronic cough, 7 were 
Eherer 2003 (Continued)

initially commenced on placebo, and 5 on pantoprazole. 4 of those with cough (25\%) did not complete trial; 2 in each arm

Inclusion: hoarseness for $>2$ months, laryngitis or other laryngeal symptoms which includes cough

Exclusion: smokers, other causes of laryngitis, prior operations on laryngeal area, laryngeal malignancy, COPD

\begin{tabular}{|c|c|c|}
\hline Interventions & \multicolumn{2}{|c|}{$\begin{array}{l}\text { Placebo or pantoprazole } 40 \mathrm{mg} \text { bd for } 3 \text { months, } 2 \text { weeks wash out followed by pantoprazole or place- } \\
\text { bo for } 3 \text { months }\end{array}$} \\
\hline Outcomes & \multicolumn{2}{|c|}{$\begin{array}{l}\text { 1. Laryngeal symptoms ( } 0 \text { to } 72)=\text { sum of frequency of each symptom by intensity of symptom } \\
\text { 2. Oesophageal symptoms }(0 \text { to } 48)=\text { sum of frequency of each symptom by intensity of symptom } \\
\text { 3. Laryngeal scoring }\end{array}$} \\
\hline & \multicolumn{2}{|c|}{ All scored at 2 weeks after completion of treatment phase } \\
\hline Notes & \multicolumn{2}{|c|}{ Raw cough scores were scores provided by Dr Eherer } \\
\hline \multicolumn{3}{|l|}{ Risk of bias } \\
\hline Bias & Authors' judgement & Support for judgement \\
\hline $\begin{array}{l}\text { Adequate sequence gener- } \\
\text { ation? }\end{array}$ & Low risk & Randomisation by blocks of 4 performed by pharmaceutical supplier \\
\hline Allocation concealment? & Unclear risk & Information not available \\
\hline $\begin{array}{l}\text { Blinding? } \\
\text { Clinical cure/failure }\end{array}$ & Low risk & Placebo-controlled study, identical appearance \\
\hline $\begin{array}{l}\text { Blinding? } \\
\text { Cough frequency or score }\end{array}$ & Low risk & Placebo-controlled study, identical appearance \\
\hline Free of other bias? & Low risk & $\begin{array}{l}\text { Possible but unlikely given that raw data were supplied, negative study de- } \\
\text { spite support from pharmaceutical company. Good follow-up rate }(>90 \%)\end{array}$ \\
\hline
\end{tabular}

\section{El Serag 2001}

\section{Methods}

Randomised, double-blind, parallel study comparing lansoprazole versus placebo in adults with 'laryngitis' symptoms (includes cough) with or without GORD (defined on $\mathrm{pH}$-metry). Patients with inclusion criteria enrolled from otolaryngology outpatients clinic. Video laryngoscopy, dual channel pH-metry, gastroscopy (some also had oesophageal manometry) performed

Allocation method not described. Compliance monitoring by pill counting

Drop outs ( $n=2,9 \%$ of those randomised), one from each arm

High quality score: $B, A, B, A$

Participants

22 adults randomised from 27 patients screened, with laryngitis with or without GORD (diagnosed on $\mathrm{pH}$-metry) and symptoms of laryngitis attending otolaryngeal clinic in a tertiary institution (Houston, Michigan). 14 (64\%) of participants had chronic cough. Distal reflux defined as DeMeester score $>14.7$. 21 males, 1 female in study, mean age 59 (SD 12) years in lansoprazole group, 65 (SD 12) years in placebo group

Inclusion: has (a) 'laryngitis' symptoms as described in outcome measures, (b) posterior laryngitis as assessed by video laryngoscopy and (c) absence of concurrent infections or allergic causes of laryngitis 
El Serag 2001 (Continued)

Exclusion: aerodigestive malignancies, radiation therapy, or previous $\mathrm{GI}$ surgery

\begin{tabular}{ll}
\hline Interventions & Lansoprazole $30 \mathrm{mg}$ bd or placebo bd for 3 months \\
\hline Outcomes & $\begin{array}{l}\text { 1. Symptoms of hoarseness, frequent clearing of throat, dry cough, globus or persistent sore throat for } \\
>3 \text { weeks } \\
\text { 2. Laryngoscopy findings (no scale used for either) }\end{array}$ \\
\hline Notes & Authors contacted for further information but no data were provided
\end{tabular}

\section{Risk of bias}

\begin{tabular}{lll}
\hline Bias & Authors' judgement & Support for judgement \\
\hline $\begin{array}{l}\text { Adequate sequence gener- } \\
\text { ation? }\end{array}$ & Low risk & Computer generated in blocks of 4 \\
\hline Allocation concealment? & Unclear risk & Allocation method not described \\
\hline $\begin{array}{l}\text { Blinding? } \\
\text { Clinical cure/failure }\end{array}$ & Low risk & Placebo-controlled study, identical appearance \\
\hline $\begin{array}{l}\text { Blinding? } \\
\text { Cough frequency or score }\end{array}$ & Low risk & Placebo-controlled study, identical appearance \\
\hline $\begin{array}{l}\text { Free of other bias? } \\
\text { High risk }\end{array}$ & $\begin{array}{l}\text { Unequal baseline characteristics for cough. } 9 \text { of } 12 \text { in PPI group, } 5 \text { of 10 in } \\
\text { placebo group. Supported by pharmaceutical company }\end{array}$ \\
\hline
\end{tabular}

Havas 1999

Methods Randomised, double-blind, parallel study comparing lansoprazole versus placebo in adults with 'posterior pharyngolaryngitis' symptoms (includes cough) with or without GORD (defined on pH-metry). Patients with inclusion criteria enrolled from otolaryngology outpatients clinic. Video laryngoscopy, dual channel $\mathrm{pH}$-metry, gastroscopy and oesophageal manometry performed

Randomisation and allocation method not described. Compliance monitoring not described

Drop outs ( $n=5,25 \%$ of those randomised) data on which group was not given and not included in paper's analysis or described as treatment failures

Quality score: B, A, C, D

Participants

20 adults randomised from 100 patients screened, with laryngopharyngeal reflux with or without GORD (diagnosed on $\mathrm{pH}$-metry) and symptoms of laryngitis attending otolaryngeal clinic in a tertiary institution (Prince of Wales Hospital, Sydney). Distal reflux defined as $\mathrm{pH}<4$ for $>4 \%$ of time, proximal $=\mathrm{pH}$ fall of $>=3$ within nadir of $=<5$ with oesophageal acidification. Of the 15 ( 7 males, 8 females, mean age 52.9 years) who completed the trial, 8 received lansoprazole and 7 placebo

Inclusion: has 'posterior pharyngolaryngitis' assessed by video laryngoscopy and symptoms (described in outcome measures)

Exclusion: severe neurological disorders, chronic airflow limitation, pre-existing anti-secretory medications, severe oesophagitis seen at endoscopy, professional voice users (singers)

\begin{tabular}{ll}
\hline Interventions & Lansoprazole $30 \mathrm{mg}$ bd or placebo bd for 12 weeks \\
\hline Outcomes & $\begin{array}{l}\text { 1. Symptom scores (addition of scores for severity (0 to 3) to scores for frequency (0 to 4)) for each of } 4 \\
\text { symptoms of laryngitis (chronic cough, hoarseness, throat clearing, sore throat pain) }\end{array}$ \\
\hline
\end{tabular}

Gastro-oesophageal reflux treatment for prolonged non-specific cough in children and adults (Review) 
Havas 1999 (Continued)

2. Reflux symptoms scored as above for dysphagia, retrosternal burning pain, acid regurgitation and odynophagia

3. Laryngoscopy findings (0 to 4)

4. Adverse events

Scores obtained at 6 and 12 weeks and data on cough alone were provided in paper

Notes Authors contacted for further information but no data were provided

\section{Risk of bias}

\begin{tabular}{lll}
\hline Bias & Authors' judgement & Support for judgement \\
\hline $\begin{array}{l}\text { Adequate sequence gener- } \\
\text { ation? }\end{array}$ & Unclear risk & Randomisation method not described \\
\hline Allocation concealment? & Unclear risk & Information not available \\
\hline $\begin{array}{l}\text { Blinding? } \\
\text { Clinical cure/failure }\end{array}$ & Low risk & Placebo-controlled study, identical appearance \\
\hline $\begin{array}{l}\text { Blinding? } \\
\text { Cough frequency or score }\end{array}$ & Low risk & Placebo-controlled study, identical appearance \\
\hline \begin{tabular}{l} 
Free of other bias? \\
\hline
\end{tabular} & Low risk & Outcomes in 80\% to 90\% \\
\hline
\end{tabular}

Ing 1997

Methods Double-blind, cross-over study comparing ranitidine with placebo. Patients with chronic persistent cough (> 2 months) with unknown aetiology after a standard diagnostic evaluation were evaluated. They underwent $\mathrm{pH}$-metry and histamine airway hyper responsiveness. $\mathrm{pH}$-metry was repeated in 7 participants, 4 to 6 weeks after the ranitidine treatment period

Drop outs ( $n=1,4 \%$ of those recruited)

Quality score: B, A, C, C

Participants 25 patients randomised (number screened not given) from medical outpatients of a tertiary hospital. All patients had PD20 to histamine $>8$ umols. 13 participants had placebo medication in the first treatment period, and the 11 patients who had ranitidine in the first treatment period ( 1 drop out described)

Mean age was 46.8 (SEM 3.3) years, 11 male, 14 female

Inclusion: chronic cough and significant gastro-oesophageal reflux (presence of $>12$ reflux episodes per 24 hours and time $\mathrm{pH}<4$ was $>0.7 \%$ )

Exclusion: patients with bronchial asthma, chronic bronchitis, allergic rhinitis, sinusitis, post-nasal drip, other respiratory and cardiac diseases, acute respiratory infections occurring within 2 months of the study, smokers or using theophylline or angiotensin converting enzyme inhibitors

\begin{tabular}{ll}
\hline Interventions & $\begin{array}{l}\text { Placebo or ranitidine } 150 \mathrm{mg} \text { bd for } 2 \text { weeks, } 2 \text { weeks wash out followed by ranitidine or placebo for } 2 \\
\text { weeks }\end{array}$ \\
\hline Outcomes & $\begin{array}{l}\text { 1. Cough scores (1 to 4) on a twice-daily on diary cards } \\
\text { 2. Presence of symptoms of GORD }\end{array}$ \\
\hline Notes & Study not published other than in abstract and conference report. Additional data obtained from Dr Ing
\end{tabular}


Ing 1997 (Continued)

Risk of bias

\begin{tabular}{lll}
\hline Bias & Authors' judgement & Support for judgement \\
\hline $\begin{array}{l}\text { Adequate sequence gener- } \\
\text { ation? }\end{array}$ & Unclear risk & Randomisation method not described \\
\hline Allocation concealment? & Unclear risk & Information not available \\
\hline $\begin{array}{l}\text { Blinding? } \\
\text { Clinical cure/failure }\end{array}$ & Low risk & Placebo-controlled study, identical appearance \\
\hline $\begin{array}{l}\text { Blinding? } \\
\text { Cough frequency or score }\end{array}$ & Low risk & Placebo-controlled study, identical appearance \\
\hline Free of other bias? & High risk & Study only published in abstract and review paper format \\
\hline
\end{tabular}

Jaspersen 1999

Methods Randomised, parallel study comparison of omeprazole versus ranitidine. Method of allocation not described. Study was not double-blinded

Compliance monitoring not mentioned

No withdrawals reported

Quality score: B, C, B, C

\section{Participants}

20 adults from outpatients department, with chronic cough, with otherwise normal lung function and negative clinical and radiological findings. 10 participants in omeprazole group ( 5 males, 5 females, mean age 49.4 years SD 16.3) and 10 in ranitidine group ( 6 males, 5 females, mean age 46.5 SD 19.7)

Inclusion: persistent cough for 8 weeks, negative findings from physical examination, negative radiological findings, with either symptoms of GORD or positive investigation of GORD (diagnosed by gastroscopy), and normal lung function

Exclusion: diagnosis of chronic asthma, COPD, chronic bronchitis, other oesophageal disease, ACE inhibitor therapy, ENT abnormalities, or smokers

\begin{tabular}{|c|c|}
\hline Interventions & Omeprazole $10 \mathrm{mg} /$ day or ranitidine $300 \mathrm{mg} /$ day for 8 weeks \\
\hline \multirow[t]{2}{*}{ Outcomes } & $\begin{array}{l}\text { 1. Cough score (range } 0 \text { to } 4 \text { ) } \\
\text { 2. Oesophagitis score (range } 0 \text { to } 4 \text { ) } \\
\text { 3. Adverse events }\end{array}$ \\
\hline & Outcomes recorded for 8 weeks \\
\hline Notes & - \\
\hline \multicolumn{2}{|l|}{ Risk of bias } \\
\hline Bias & Authors' judgement Support for judgement \\
\hline $\begin{array}{l}\text { Adequate sequence gener- } \\
\text { ation? }\end{array}$ & Information not available \\
\hline Allocation concealment? & Information not available \\
\hline
\end{tabular}


Jaspersen 1999 (Continued)

Blinding? $\quad$ High risk No placebo
Clinical cure/failure

\begin{tabular}{lll}
\hline Blinding? & High risk & No placebo \\
Cough frequency or score &
\end{tabular}

\begin{tabular}{ll}
\hline Free of other bias? $\quad$ Unclear risk $\quad$ Insufficient data available \\
\hline
\end{tabular}

\title{
Kiljander 2000
}

$\begin{array}{ll}\text { Methods } & \text { Randomised, double-blind, cross-over study comparing omeprazole versus placebo in adults with } \\ \text { chronic cough and GORD (defined on } \mathrm{pH} \text {-metry). Patients with chronic cough enrolled from pulmonary } \\ \text { outpatients clinic were screened for exclusion criteria. Patients completed 1-week observation by diary } \\ \text { cards, pH-metry then performed and those with excessive reflux were randomised }\end{array}$

Randomisation and allocation method not described

Compliance monitored by pill counts after treatment period

8 did not complete trial ( $27 \%$ of those randomised) were not further described and were not included as treatment failures. Analysis by intention-to-treat for primary outcome only

High quality score: $B, A, A, D$

\begin{abstract}
Participants
29 adults (median age 49, IQR 20-74, 10 males, 19 females) randomised from 48 patients screened, with GORD (diagnosed on $\mathrm{pH}$-metry) and chronic ( $>=2$ months) cough attending pulmonary clinic in a tertiary institution (Turku University, Finland). 12 initially randomised to placebo and 9 to omeprazole

Inclusion: chronic persistent cough (>= 2 months)

Exclusion: abnormal chest or sinus radiology, positive methacholine test, rhinitis, nasal mucosa appearance of cobblestone or muco-purulent secretions, smokers, asthma, chronic bronchitis, use of angiotensin converting enzyme inhibitor
\end{abstract}

Interventions Omeprazole $40 \mathrm{mg}$ per day or placebo for 8 weeks, 2 weeks washout followed by omeprazole or placebo

$\begin{array}{ll}\text { Outcomes } & \begin{array}{l}\text { 1. Weekly daytime cough and night-time cough (cough disturbing sleep) scores = sum of daily 4-point (0 } \\ \text { to 3) scale of symptoms (both have range of } 0 \text { to } 21)\end{array} \\ \text { 2. Weekly gastric symptoms (heartburn, regurgitation, chest pain) = sum of daily } 4 \text { point ( } 0 \text { to } 3) \text { scale of } \\ \text { symptoms (range } 0 \text { to 63). Average of last } 3 \text { weeks at end of each treatment period ( } 8 \text { weeks) }\end{array}$

\section{Risk of bias}

\begin{tabular}{lll}
\hline Bias & Authors' judgement & Support for judgement \\
\hline $\begin{array}{l}\text { Adequate sequence gener- } \\
\text { ation? }\end{array}$ & Unclear risk & $\begin{array}{l}\text { Randomisation by pharmaceutical company that sponsored trial but no de- } \\
\text { tails }\end{array}$ \\
\hline Allocation concealment? & Unclear risk & Information not available \\
\hline $\begin{array}{l}\text { Blinding? } \\
\text { Clinical cure/failure }\end{array}$ & Low risk & Placebo-controlled study, identical appearance \\
\hline Blinding? & Low risk & Placebo-controlled study, identical appearance \\
\hline
\end{tabular}


Kiljander 2000 (Continued)

Cough frequency or score

\begin{tabular}{lll}
\hline Free of other bias? & High risk & $\begin{array}{l}\text { All outcomes not mentioned, drop out rate high (27\%). Sponsored by pharma- } \\
\text { ceutical company }\end{array}$
\end{tabular}

\section{Kopec 2001}

\begin{tabular}{|c|c|}
\hline \multirow[t]{5}{*}{ Methods } & $\begin{array}{l}\text { Partial double-blind, parallel, randomised, placebo-controlled trial comparing diet and/or cisapride } \\
\text { ( } 2 \text {-factorial design). Randomisation of the diet was not blinded, randomisation of cisapride was dou- } \\
\text { ble-blinded }\end{array}$ \\
\hline & $\begin{array}{l}\text { After standard diagnostic work-up for chronic cough, participants who met criteria (authors assume } \\
\text { that this predicts patients have an approximate } 92 \% \text { chance of having chronic cough due to GORD) } \\
\text { were randomised and } \mathrm{pH} \text {-metry performed }\end{array}$ \\
\hline & $\begin{array}{l}\text { Randomisation and allocation method not described } \\
\text { Drop outs ( } n=2,9.5 \% \text { of those randomised) were not described and were not included as treatment } \\
\text { failures. Analysis by intention-to-treat not possible }\end{array}$ \\
\hline & Compliance monitoring not described \\
\hline & Quality score: B, C, C, C \\
\hline \multirow[t]{3}{*}{ Participants } & $\begin{array}{l}21 \text { adults (mean age } 53.5 \text { years, SD 12.9) with chronic cough and GORD randomised from outpatients } \\
\text { clinic (number of eligible patients not given). GORD diagnosed on } \mathrm{pH} \text {-metry or on barium meal }\end{array}$ \\
\hline & Inclusion: adults with chronic cough ( $>8$ weeks) and presumably GORD-related cough \\
\hline & $\begin{array}{l}\text { Exclusion: age }<18 \text { years, pregnancy, known contraindications to receiving cisapride, such as known al- } \\
\text { lergy to the medication, or prolonged QT interval on EKG or concurrent use of medications that might } \\
\text { interact with cisapride to place the patients at risk of a potentially life-threatening cardiovascular com- } \\
\text { plication }\end{array}$ \\
\hline
\end{tabular}

$\begin{array}{ll}\text { Interventions } & \begin{array}{l}2 \text { factorial design using usual care diet or anti-reflux diet and cisapride } 10 \text { mg qid or placebo for } 4 \\ \text { months trial, i.e. 4-arm study }\end{array}\end{array}$

\begin{tabular}{ll}
\hline Outcomes & Cough scores measured by visual analogue score (VAS) from 0 to 100 \\
\hline Notes & No difference found in VAS between groups \\
& Further data provided by author was insufficient for inclusion into meta-analysis \\
\hline
\end{tabular}

\section{Risk of bias}

\begin{tabular}{|c|c|c|}
\hline Bias & Authors' judgement & Support for judgement \\
\hline $\begin{array}{l}\text { Adequate sequence gener- } \\
\text { ation? }\end{array}$ & Unclear risk & Information not available \\
\hline Allocation concealment? & Unclear risk & Information not available \\
\hline $\begin{array}{l}\text { Blinding? } \\
\text { Clinical cure/failure }\end{array}$ & Unclear risk & $\begin{array}{l}\text { Abstract title indicated double-blind study but insufficient information on } \\
\text { placebo }\end{array}$ \\
\hline $\begin{array}{l}\text { Blinding? } \\
\text { Cough frequency or score }\end{array}$ & Unclear risk & $\begin{array}{l}\text { Abstract title indicated double-blind study but insufficient information on } \\
\text { placebo }\end{array}$ \\
\hline Free of other bias? & Unclear risk & Insufficient data available \\
\hline
\end{tabular}


Medical history was obtained and complete physical examination was performed at entry. All infants underwent a 24-hour oesophageal $\mathrm{pH}$ monitoring while receiving alternating normal and anti-reflux milk. Weekly monitoring of episodes of regurgitation, vomiting, coughing, crying and stool frequency and consistency. The volume of each feeding during a 24-hour period once-weekly was also recorded

Randomisation and allocation method not well described

Quality score: B, C, A, B

Study was financially supported by a pharmaceutical industry

\section{Participants}

74 included infants, 60 completed the 1-month clinical follow up. Mean age of group was 3.24 (SD 1.28) months, 40 males, 34 females. Intervention group $n=28$, Placebo group $n=32$. Mean age of infants within each group was not described

Inclusion criteria: non-breast-fed infants (aged $<6$ months) with GOR (determined using Orenstein criteria)

Exclusion criteria: breast-fed and premature infants, infants with history of wheezing, aspiration pneumonia, apnoea, failure to thrive, anaemia, bleeding, laryngitis and apparent life-threatening events. Infants already receiving AR or medications that could affect the motility of the gastrointestinal tract. Parents who subjected infants to overfeeding, dilution errors and inadequate feeding technique

\begin{tabular}{|c|c|c|}
\hline Interventions & \multicolumn{2}{|c|}{ A pre-thickened anti-reflux formula compared to regular formula for 1 month } \\
\hline Outcomes & \multicolumn{2}{|c|}{ Diary: episodes of regurgitation, vomiting, coughing, crying and stool frequency and consistency } \\
\hline & \multicolumn{2}{|c|}{$\begin{array}{l}\text { Data relating to } \mathrm{pH} \text { monitoring (reflux index, oesophageal clearance, etc), electrogastrography (a cuta- } \\
\text { neous recording of gastric myoelectrical activity }\end{array}$} \\
\hline Notes & \multicolumn{2}{|c|}{ Wrote to authors 31 May 2008} \\
\hline \multicolumn{3}{|l|}{ Risk of bias } \\
\hline Bias & Authors' judgement & Support for judgement \\
\hline $\begin{array}{l}\text { Adequate sequence gener- } \\
\text { ation? }\end{array}$ & Unclear risk & Method not described \\
\hline Allocation concealment? & Unclear risk & Information not available \\
\hline $\begin{array}{l}\text { Blinding? } \\
\text { Clinical cure/failure }\end{array}$ & Unclear risk & Uncertain if parents or investigators knew which formula infants were on \\
\hline $\begin{array}{l}\text { Blinding? } \\
\text { Cough frequency or score }\end{array}$ & Unclear risk & Uncertain if parents or investigators knew which formula infants were on \\
\hline Free of other bias? & Unclear risk & Supported by pharmaceutical company \\
\hline
\end{tabular}

\section{Noordzij 2001}

\begin{tabular}{ll}
\hline Methods & $\begin{array}{l}\text { Randomised, double-blind, parallel study comparing omeprazole versus placebo in adults with 'laryn- } \\
\text { gitis' symptoms (includes cough) and GORD (defined on pH-metry) }\end{array}$ \\
\hline
\end{tabular}


Patients with inclusion criteria enrolled from outpatients clinic. Video-laryngo-stroboscopy performed and screened for exclusion criteria. Dual channel pH-metry then performed and those with reflux were eligible and randomised

Randomisation and allocation method not described

Compliance monitoring not described

Drop outs (6.7\% of those randomised) were included in analysis but not described as treatment failures. Analysis by intention-to-treat not possible

Quality score: B, A, A, B

\section{Participants}

30 adults randomised from 53 patients screened) with GORD/laryngopharyngeal reflux (diagnosed on $\mathrm{pH}$-metry) and symptoms of laryngitis attending otolaryngeal clinic in a tertiary institution (University of Virginia). 15 participants in omeprazole group ( 8 males, 7 females, mean age 51.7 years) and 15 in placebo group (8 males, 7 females, mean age 45.3). 2 (6.7\%) did not complete trial, one from placebo group and the other unknown

Inclusion: one or more symptoms of laryngitis for $>3$ months, i.e. symptoms of chronic cough, hoarseness, excessive phlegm, throat clearing, throat pain, lump in throat and acid reflux ( $>4$ episodes proximal $\mathrm{pH}<4$ or 3-point drop in $\mathrm{pH}$ with simultaneous drop in distal $\mathrm{pH}$ of $<4$ )

Exclusion: viral or bacterial laryngitis (undefined), benign vocal fold lesions, occupational exposures causing laryngitis, history of seasonal allergies or laryngeal malignancy

Interventions Omeprazole $40 \mathrm{mg}$ bd or placebo bd for 2 months

Outcomes 1. Symptom scores (multiplication of severity (0 to 100) of symptom by frequency (number of days over last 2 weeks) for each of 6 symptoms of laryngitis (chronic cough, hoarseness, excessive phlegm, throat clearing, throat pain, lump in throat) and 3 symptoms of GOR (dysphagia, odynophagia and heartburn)

\section{Adverse events}

Scores obtained at 1 and 2 months and data on cough alone were provided in paper

Notes Authors contacted for further information but no data were provided

\section{Risk of bias}

\begin{tabular}{lll}
\hline Bias & Authors' judgement & Support for judgement \\
\hline $\begin{array}{l}\text { Adequate sequence gener- } \\
\text { ation? }\end{array}$ & Unclear risk & Method not described \\
\hline Allocation concealment? & Unclear risk & Information not available \\
\hline $\begin{array}{l}\text { Blinding? } \\
\text { Clinical cure/failure }\end{array}$ & Low risk & Placebo-controlled study, identical appearance \\
\hline $\begin{array}{l}\text { Blinding? } \\
\text { Cough frequency or score }\end{array}$ & Low risk & Placebo-controlled study, identical appearance \\
\hline \begin{tabular}{l} 
Free of other bias? \\
\hline
\end{tabular} & High risk & Supported by pharmaceutical company \\
\hline
\end{tabular}


Orenstein 1992

Methods

Randomised, single-blind, cross-over study comparing thickened and unthickened feeds on cough associated with feeds, related to GORD diagnosed by $\mathrm{pH}$-metry, barium swallow or oesophageal biopsy. Assessor was blinded but not care-giver/nurse who fed infants

Randomisation well described (lottery) but allocation method not described

No drop outs mentioned. Uncertain if analysis was by intention-to-treat

Quality score: B, B, B, C

Participants 25 infants randomised (number screened not given) from outpatients of a tertiary gastroenterology centre (Children's Hospital of Pittsburg) referred for GORD

Median post-natal age 7.5 weeks (range 2 to 26), corrected age 7 weeks (6 to 26), gender not given. Symptoms other than cough were irritability in $72 \%$, regurgitation in $60 \%$, apnoea in $28 \%$, history of pneumonia in $4 \%$

Inclusion criteria: not defined

Exclusion: concurrent acute infectious respiratory illness, use of prokinetic or acid reducing medications

\begin{tabular}{ll}
\hline Interventions & Thickened (with rice cereal) and unthickened feeds \\
\hline Outcomes & Cough frequency during feeds and post-prandial per hour \\
\hline Notes & $\begin{array}{l}\text { Results showed that cough frequency when on thickened feeds (3.9) was significantly higher than when } \\
\text { on unthickened feeds (2.2); } \mathrm{P}=0.006\end{array}$ \\
\hline
\end{tabular}

\section{Risk of bias}

\begin{tabular}{lll}
\hline Bias & Authors' judgement & Support for judgement \\
\hline $\begin{array}{l}\text { Adequate sequence gener- } \\
\text { ation? }\end{array}$ & Low risk & Randomisation by lottery in blocks of 10 \\
\hline Allocation concealment? & Unclear risk & Information not available \\
\hline $\begin{array}{l}\text { Blinding? } \\
\text { Clinical cure/failure }\end{array}$ & Unclear risk & Blinding not described \\
\hline $\begin{array}{l}\text { Blinding? } \\
\text { Cough frequency or score }\end{array}$ & Unclear risk & Blinding not described \\
\hline \begin{tabular}{l} 
Free of other bias? \\
\hline
\end{tabular} & Unclear risk & Non-pharmaceutical company study. Insufficient data available
\end{tabular}

\section{Orenstein 2009}

\section{Methods}

Multicentre, randomised, double-blind, placebo-controlled, parallel-group study in infants with symptomatic GORD who remained symptomatic with crying, fussing, or irritability (designated 'crying' hereinafter) during or within 1 hour after feeding despite at least 1 week of non-pharmacologic management (NPM). NPM consisted of: (1) reduction of tobacco smoke exposure, (2) 1 or more feeding strategy (frequent burping, frequent small feedings, use of hypoallergenic and thickened formula, or dairy avoidance by breast-feeding mother), and (3) 1 or more positioning strategy (minimising seated and awake supine positioning, avoiding vigorous handling, particularly post-feeding). Symptomatic GORD defined by score on validated Orenstein GORD questionnaire (I-GERD-MH) 
Study comprised of 3 periods: pretreatment (1 to 2 weeks before randomisation), treatment (maximum 4 weeks of study drug treatment), and post-treatment. Infants were further screened through parental completion of the Infant Gastroesophageal Reflux Questionnaire Medical History (I-GERQ-MH) and by 7 to 14 days of NPM before randomisation

In pretreatment phase, parents were required to institute and record in a daily diary NPM strategies and outcomes. Randomisation qualification was then assessed - eligible if NPM failed to reduce mealrelated crying to $<25 \%$ of all feedings during the final 4 pretreatment period days

Treatment phase: after 1 week of double-blind treatment, infants discontinuing the treatment due to inefficacy (as judged by the site investigator) were eligible for open-label lansoprazole at the investigator's discretion and with parent consent

Post-treatment phase: telephone calls and a safety follow-up visit with global symptom assessment (GA) of symptoms 30 days after the last dose of any study drug (double-blind or open-label). The subjects also completed daily diaries for 7 days before the safety follow-up visit

Treatment assigned through a central web-based system according to a schedule that was computer-generated

Compliance was assessed at study visits based on the number of returned kits, daily diaries and parental interview. Compliance ( $>=90 \%$ drug given) achieved in $93 \%$ of subjects in lansoprazole group and $95 \%$ in placebo group

Quality score: A, A, A, C

Participants

162 infants randomised ( 81 in each group)

Lansoprazole group: median (range) age $=16$ weeks ( 4 to 49 ), $47 \%$ male

Placebo group: median (range) age $=18$ weeks ( 4 to 51 ), $53 \%$ male

No significant difference in any baseline characteristic between groups. At baseline, coughing present in $75 \%$ infants in lansoprazole group and $72 \%$ in placebo group. Percentage days coughing per week was $55 \%$ in both groups

96 (49 in lansoprazole group and 47 in placebo group) completed double-blind study. Further 53 completed open-label study

Inclusion criteria: infants age 28 days to 12 months (for preterm infants, corrected age of 44 weeks but 12 months) with symptomatic GORD. Weight $>2.0 \mathrm{~kg}$ and daily diary documented crying during or within 1 hour after $25 \%$ of feeds during the 4 days before randomisation despite 7 days of specified NPM strategies

Exclusion criteria were: (1) several categories of unstable clinically significant disease, laboratory results or surgery; (2) coexisting oesophageal disease or upper gastrointestinal congenital anomaly; (3) participation in other drug research; (4) previous use of a PPI within 30 days or a H2RA within 7 days; (5) discontinuation of previous H2RA for study eligibility; (6) allergy to any component or excipient of any PPI; (7) requirement for continuous tube feedings; (8) history of acute life-threatening events attributed to GORD; (9) unstable doses or levels of various medications; and (10) anticipated non-compliance a 30 -minute fast, at 0.2 to $0.3 \mathrm{mg} / \mathrm{kg} /$ day for infants age 10 or less weeks and at 1.0 to $1.5 \mathrm{mg} / \mathrm{kg} / \mathrm{day}$ for those age $>10$ weeks. Dosing, based on age and weight on day 1 of the double-blind treatment, was unchanged during the treatment

Outcomes

Parent recorded daily diaries of feeding dates/times and symptoms (crying, regurgitation, stop feeding, refuse feed, arching back, wheezing, coughing, hoarseness), global assessment by parents and investigators. Adverse events (including respiratory infections) and laboratory data. Treatment-emergent adverse events (AEs) encompassed all AEs with onset or worsening on or after day 1 of drug exposure up to 30 days after last dose; treatment-related AEs were treatment emergent AEs considered by site investigators to have a definite or possible relationship to the study drug

Daily dairy recorded for $>=90 \%$ days available in $96 \%$ of subjects in lansoprazole group, $100 \%$ in placebo group. 
Orenstein 2009 (Continued)

Primary efficacy variables were daily diary-documented number and duration of crying episodes dur-

ing or $=<1$ hour after feeding.

Notes Wrote to authors 23 April 2010

\section{Risk of bias}

\begin{tabular}{|c|c|c|}
\hline Bias & Authors' judgement & Support for judgement \\
\hline $\begin{array}{l}\text { Adequate sequence gener- } \\
\text { ation? }\end{array}$ & Low risk & $\begin{array}{l}\text { Double-blind treatment assignments were made through a central web-based } \\
\text { system according to a schedule that was computer-generated by Takeda Glob- } \\
\text { al Research \& Development Center, Inc and concealed from study personnel }\end{array}$ \\
\hline Allocation concealment? & Low risk & $\begin{array}{l}\text { Double-blind treatment assignments were made through a central web-based } \\
\text { system according to a schedule that was computer-generated by Takeda Glob- } \\
\text { al Research \& Development Center, Inc and concealed from study personnel }\end{array}$ \\
\hline $\begin{array}{l}\text { Blinding? } \\
\text { Clinical cure/failure }\end{array}$ & Low risk & Placebo-controlled study, identical appearance \\
\hline $\begin{array}{l}\text { Blinding? } \\
\text { Cough frequency or score }\end{array}$ & Unclear risk & Not applicable here \\
\hline Free of other bias? & Low risk & $\begin{array}{l}\text { Multicentre study. Although supported by pharmaceutical industry, negative } \\
\text { study published }\end{array}$ \\
\hline
\end{tabular}

\section{Ours 1999}

$\begin{array}{ll}\text { Methods } & \text { Randomised, double-blind, parallel comparison of omeprazole versus placebo in adults with chronic } \\ \text { cough and GORD (defined on } \mathrm{pH}-\text {-metry). Potential participants screened for exclusion criteria. Patients } \\ \text { completed } 2 \text { weeks observation by diary cards. Those with score of at least } 3 \text { were treated with antihis- } \\ \text { tamine and nasal corticosteroids. If persistent cough remained (score }>=2 \text { ) oesophageal manometry } \\ \text { and pH-metry were undertaken. Those with GORD were randomised. No withdrawals. After end of trial } \\ \text { (12 weeks), open study performed using omeprazole (1 month) }\end{array}$

Randomisation by computer but allocation method not described. Compliance monitored by pill counts after treatment period

All completed trial. Analysis by intention-to-treat possible

Quality score: B, A, A, A

Participants

17 participants randomised from 71 patients screened. Patients with chronic cough enrolled from newspaper advertisements and outpatients (most were enrolled from community). Mean age and duration of cough in those randomised were not given. Median age of 36 patients in study prior to results of $\mathrm{pH}$-metry was 58 years with cough duration of 5 years (interquartile range 2 to 10 )

Inclusion: aged 18 to 80 years with chronic cough ( $>=6$ weeks) with score of $>=2$ and with excessive acid reflux distally or proximal (defined by $\mathrm{pH}$-metry)

Exclusion: abnormal chest radiology, positive methacholine test, smokers, ex-smokers $=<3$ months or $>=20$ pack-year history of smoking, upper respiratory infection within 8 weeks of entry, use of angiotensin converting enzyme inhibitor or beta blockers, unable to be weaned off some medications (corticosteroids, methylxanthines, cough suppressants, beta agonist, anti-cholinergics, or anti- inflammatory agents), history of pulmonary disease, malignancy or any co-morbid condition requiring treatment 
Ours 1999 (Continued)

Interventions Omeprazole $40 \mathrm{mg}$ bd or identical appearing placebo for 12 weeks

Outcomes Cough severity and cough frequency scale (0 to 8), day and night, measured daily by diary cards for 12 weeks

Response to treatment defined as weekly cough frequency combined with severity score for daytime or night-time cough of $=<1$ for $>=2$ weeks consecutively.

Notes

Paper provided failure and success rates but no details on cough scores that can be entered for other meta-analysis

Open trial results not used for analysis

\section{Risk of bias}

\begin{tabular}{lll}
\hline Bias & Authors' judgement & Support for judgement \\
\hline $\begin{array}{l}\text { Adequate sequence gener- } \\
\text { ation? }\end{array}$ & Low risk & Computer-generated program used \\
\hline Allocation concealment? & Unclear risk & Information not available \\
\hline $\begin{array}{l}\text { Blinding? } \\
\text { Clinical cure/failure }\end{array}$ & Low risk & Placebo-controlled study, identical appearance \\
\hline $\begin{array}{l}\text { Blinding? } \\
\text { Cough frequency or score }\end{array}$ & Low risk & Placebo-controlled study, identical appearance \\
\hline \begin{tabular}{l} 
Free of other bias? \\
\hline
\end{tabular} & Low risk & Good follow up and outcomes described \\
\hline
\end{tabular}

Pawar 2007

Methods Single centre, double-blinded, randomised, placebo-controlled trial that compared twice-daily rabeprazole with placebo for 90 days in adults with "post nasal drip (PND), throat clearing or excessive throat mucus"

Subjects were recruited from otolaryngology clinic at Medical College of Wisconsin or through newspaper advertisements. Rigid nasal endoscopy, 2-site 24-hour pharyngeal $\mathrm{pH}$ probe monitoring ( $\mathrm{pH}$ threshold =5) and video laryngoscopy performed before Rx. Video laryngoscopy and other 2 outcomes below repeated on day 90

Non-prescription antacids (including $\mathrm{H} 2$ antagonists and other PPIs), anti-histamines, decongestants disallowed to be used concomitantly

Randomisation method and allocation method not described

Quality score: B, A, B, B (no intention-to-treat analysis)

Study was financially supported in part by a pharmaceutical company

Participants

180 people screened. Of these 53 subjects enrolled, 47 (89\%) completed study

Rabeprazole group: $\mathrm{n}=21$ ( 11 males, 10 female), mean age $=55.6$ years (range 40 to 75 )

Placebo group: $\mathrm{n}=26$ (12 males, 14 female), mean age $=54.3$ years (range 24 to 76 )

Inclusion: aged 18 to 80 with main complain of PND, throat clearing or excessive throat mucous 
Pawar 2007 (Continued)

Exclusion: acute or chronic sinus disease (using nasal endoscopy and/or coronal sinus CT scan), acute rhinosinusitis, nasal polyps or neoplasms, subjects with vasomotor rhinitis or GOR treated in preceding 2 months, smoking, oesophageal or gastric surgery, cardiovascular diease, allergies or pregnancy

\begin{tabular}{ll}
\hline Interventions & Rabeprazole (20 mg, orally twice-daily) or placebo for 90 days \\
\hline Outcomes & $\begin{array}{l}\text { Visual analogue scales for PND symptoms, reflux symptom index (higher score = worse), and reflux find- } \\
\text { ing score (RFS) (higher score = worse) }\end{array}$ \\
\hline Notes & $\begin{array}{l}\text { Symptomatic score significantly improved in intervention arm but the objective score (RFS) was signifi- } \\
\text { cantly worse. Wrote to authors } 30 \text { May } 2008\end{array}$ \\
\hline
\end{tabular}

\section{Risk of bias}

\begin{tabular}{lll}
\hline Bias & Authors' judgement & Support for judgement \\
\hline $\begin{array}{l}\text { Adequate sequence gener- } \\
\text { ation? }\end{array}$ & Unclear risk & Not described \\
\hline Allocation concealment? & Unclear risk & Randomised by research pharmacist but insufficient data provided \\
\hline $\begin{array}{l}\text { Blinding? } \\
\text { Clinical cure/failure }\end{array}$ & Low risk & Placebo-controlled study, identical appearance \\
\hline $\begin{array}{l}\text { Blinding? } \\
\text { Cough frequency or score }\end{array}$ & Low risk & Placebo-controlled study, identical appearance \\
\hline \begin{tabular}{l} 
Free of other bias? \\
\hline
\end{tabular} & Unclear risk & Study supported by pharmaceutical company \\
\hline
\end{tabular}

\section{Steward 2004}

\section{Methods}

Single-centre, randomised, double-blind, parallel comparison of rabeprazole versus placebo in adults with chronic cough and GORD (defined on $\mathrm{pH}$-metry). Potential participants screened for exclusion criteria. Patients completed underwent video strobo-laryngoscopy and undertook questionnaire. 24-hour dual probe $\mathrm{pH}$-metry was initially part of protocol but was later optional (as patients poorly tolerated it)

Randomisation by computer-generated random number table and allocation concealed (using sealed envelopes). Compliance to PPI/placebo not described

Analysis available for 30 of the $42(71.4 \%)$ subjects randomised. Intention-to-treat data not available

High quality score: $A, A, B, C$

Participants 
or hypopharyngeal neoplasm; 9) previous radiation therapy to neck; 10) endotracheal tube intubation within past 2 months; 11) diagnosis of vocal cord paralysis; 12) diagnosis of active granulomatous disease (laryngeal or pulmonary, including sarcoid, Wegener's, tuberculosis, histoplasmosis, blastomycosis) requiring systemic therapy; and 13) suspicion of laryngeal neoplasm requiring biopsy for diagnosis

Interventions

Rabeprazole $20 \mathrm{mg}$ twice-daily or placebo (identical appearance) for 2 months. All also received lifestyle modification instructions minimise acid reflux (avoidance of fatty meals, caffeine, alcohol, smoking, and oral intake within 2 hours of lying down or bedtime, as well as the addition of extra pillows to raise the head or bedpost blocks to elevate the head of the bed 6 inches)

Outcomes

The primary outcome measures: change in total reflux symptom scores and proportion of subjects noting significant global improvement. The reflux symptom scores were modification of a previously validated GERD outcome questionnaire that included laryngo-pharyngeal symptoms. The questionnaire included 9 items (heartburn, acid regurgitation, dysphagia, globus, throat clearing, hoarseness, sinus drainage or phlegm, sore throat and dry cough). Patients responded to frequency of symptoms (never, monthly, weekly, several times per week or daily) and severity of symptoms (none, mild, moderate, severe, very severe), both scored 0 to 4 on a Likert scale. The total reflux symptom score included sum of frequency and severity scores for all items

The secondary outcome measures were change in SF36, change in laryngeal grading of videostrobolaryngoscopy, and changes in component reflux symptoms scores (frequency, severity, "typical," "laryngeal," "pharyngeal" and individual symptoms). The component reflux symptom scores were defined as follows: frequency = sum of all reflux symptom frequency scores; severity = sum of all reflux symptom severity scores; "typical" = sum of frequency and severity scores for symptoms of heartburn and acid regurgitation; "laryngeal" = sum of frequency and severity scores for symptoms of hoarseness, dry cough and throat clearing; and "pharyngeal" = sum of frequency and severity scores for symptoms of throat clearing, globus sensation and phlegm

The tertiary outcome measures were changes in frequency of lifestyle factors related to reflux derived from the lifestyle questionnaire. The lifestyle questionnaire included 9 items (smoking, alcohol use, caffeine use, head of bed elevation with blocks, use of 2 pillows to raise head, oral intake within 2 hours of bedtime, oral intake within 2 hours of lying down, antacid use and histamine-2 receptor blocker use). Response choices included: never, monthly, weekly, several times per week, and daily (0 to 4 Likert scale)

Notes Cough reported separately in paper. Authors contacted for further data

\section{Risk of bias}

\begin{tabular}{|c|c|c|}
\hline Bias & Authors' judgement & Support for judgement \\
\hline $\begin{array}{l}\text { Adequate sequence gener- } \\
\text { ation? }\end{array}$ & Low risk & Randomisation by computer generated random number table \\
\hline Allocation concealment? & Low risk & Sealed envelopes concealed randomisation process from study investigators. \\
\hline $\begin{array}{l}\text { Blinding? } \\
\text { Clinical cure/failure }\end{array}$ & Low risk & Placebo-controlled study, identical appearance \\
\hline $\begin{array}{l}\text { Blinding? } \\
\text { Cough frequency or score }\end{array}$ & Low risk & Placebo-controlled study, identical appearance \\
\hline Free of other bias? & Unclear risk & $\begin{array}{l}\text { Completion rate in } 71.4 \% \text {. Although supported by pharmaceutical industry, } \\
\text { negative study published }\end{array}$ \\
\hline
\end{tabular}



symptoms and signs from GOR (but those with significant GI manifestations of GOR were excluded - see exclusion criteria)

Screening laryngoscopy and screening period were performed. Eligible patients then underwent a 7- to 14-day screening period without treatment, during which they completed a daily diary card on which they assessed each of 5 symptoms (throat clearing, cough, globus, sore throat and hoarseness) over the past 24 hours on a 7-point Likert scale $(0=$ none to $6=$ very severe). At the end of this period, patients each identified their single most bothersome symptom as the primary symptom. Patients eligible for randomisation must have completed at least $80 \%$ of diary entries, had a cumulative primary symptom score of $>=9$, and had $>=3$ days with moderately severe symptoms ( $>=3$ points) over any 7 consecutive days of the 7 to 14 days

Participants randomised in a 2:1 ratio (esomeprazole:placebo) at each centre by blocks of 6 After randomisation and before receipt of study medication, patients had for ambulatory pharyngoesophageal $\mathrm{pH}$ monitoring (APEM). Patients who refused APEM were allowed to participate. APEM consisted of 2-catheter, 3-probe 24-hour study with probe placement in the hypopharynx, proximal oesophagus and distal oesophagus. APEM was assessed by a single, independent investigator at a central laboratory, blinded to patient-identifying data

Patients used daily diary card used to assess symptoms each day throughout the 16-week trial. At weeks $0,4,8,12$ and 16 , the investigator assessed the same symptoms that the patients assessed in their diary cards using a 4-point Likert scale $(0=$ none to $3=$ severe $)$. At the final visit, the investigator also provided an overall evaluation of improvement

Allocation method not described. Compliance monitored by pill counting. Analysis was by intention-totreat not relevant. Total of 17 (11.7\%) withdrawals

Quality score: B, A, A, B

Participants

146 participants randomised but 1 dropped out prior to any Rx (number screened not given). Patients enrolled from 7 US centres. Esomeprazole group $(n=95)$ : mean age (SD) $=51.5(15.2), 48$ males and 47 females. Placebo group $(n=50)$ : mean age $(S D)=50.5(14.5), 23$ males and 27 females

Inclusion criteria: aged $>18$ years and had one or more of the following symptoms for 3 or more consecutive months before screening: throat clearing, cough, globus, sore throat or hoarseness; and laryngoscopic signs consistent with reflux (assessed by a panel via consensus)

Exclusion: clinically significant conditions that might, in the judgment of the investigator, put the patient at risk, influence the results, affect the patient's ability to participate in the study, or necessitate surgery during the study. Patients who had experienced moderate-to-severe heartburn 3 or more days per week over a 3-month period before screening; history of respiratory or gastro-intestinal malignancy; radiation therapy to the head and neck, lung, or gastrointestinal tract; gastroesophageal surgery; chronic sinusitis or rhinitis in the last year; an allergic cause of laryngitis; an acute traumatic event near the larynx in the last year; tracheostomy or other significant laryngeal or tracheal surgery; and substance or alcohol abuse in the past year; other malignancy (except superficial basal cell carcinoma) within the previous 5 years; presence of an infectious cause of laryngitis in the past 3 months; need for continuous therapy within 1 week of randomisation with diazepam, phenytoin, mephenytoin, warfarin, anticholinergics, antineoplastics, prostaglandin analogues, $\mathrm{H} 2$-receptor antagonists, steroids (inhaled, oral, or intravenous), promotility drugs, and sucralfate; use of tobacco products in the past year, any $\mathrm{PPI}$ in the last 2 weeks, theophylline, or any other investigational compound or participation in another investigational drug study in the past 30 days; and any contraindication to esomeprazole, such as known or suspected allergy or sensitivity to any PPI; or pregnancy and lactating women 
Vaezi 2006 (Continued)

also provided an overall evaluation of improvement for each symptom as follows: $0=$ resolved, $1=\mathrm{im}$ proved, 2 = same, 3 = worse

Laryngoscopic scoring performed at week 8 and 16

The primary outcome was \% patients who had resolution of the primary symptom according to patient diary card assessment at the final visit. Symptom resolution was defined as a primary symptom severity score of 0 (none) during the last 7 days of the study, but allowing a score of 1 (minimal severity) for up to 3 days

Secondary efficacy variables included relief of the primary symptom (by patient ), $\%$ symptom-free days and \% of symptom-free patients, symptom severity change from baseline, and the investigator's assessment of symptom-free patients. Relief of the primary symptom was defined as a greater than $50 \%$ reduction from baseline in the primary symptom score during the final week

Notes Authors provided additional cough specific data

\section{Risk of bias}

\begin{tabular}{lll}
\hline Bias & Authors' judgement & Support for judgement \\
\hline $\begin{array}{l}\text { Adequate sequence gener- } \\
\text { ation? }\end{array}$ & Unclear risk & Not described \\
\hline Allocation concealment? & Unclear risk & Information not available \\
\hline $\begin{array}{lll}\text { Blinding? } \\
\text { Clinical cure/failure }\end{array}$ & Low risk & Placebo-controlled study, identical appearance \\
\hline $\begin{array}{l}\text { Blinding? } \\
\text { Cough frequency or score }\end{array}$ & Low risk & Placebo-controlled study, identical appearance \\
\hline $\begin{array}{l}\text { Free of other bias? } \\
\end{array}$ & Low risk & $\begin{array}{l}\text { Additional data provided by authors. Although supported by pharmaceutical } \\
\text { company, this negative study was published. Good follow-up rate }\end{array}$ \\
\hline
\end{tabular}

Vanderhoof 2003

Methods Multi-centre, randomised, double-blind, parallel study comparing a pre-thickened formula with placebo in infants with regurgitant reflux

Parents of infants kept diary cards for 2 days and if eligible randomised. After 1 week, infants were reviewed and commenced on pharmacological intervention (ranitidine after day $7 / 8$ and cisapride after day 14/15). Further follow up until day 35/36

Randomisation well described based on site but allocation method not described

Compliance monitoring done

Drop outs ( $n=12,10.9 \%$ of those randomised. Drop outs included in some analysis but not described as treatment failures. Analysis by intention-to-treat not possible

Quality score: B, A, A, B

Participants

110 infants randomised (number screened not given) from 6 North American paediatric centres. 7 drop outs and of remaining 103, mean age of 55 (27 males, 28 females) intervention group was 61 days (SD 4) and that of control group (26 males, 23 females) was 58 days (SD 4)

Inclusion: >= 5 regurgitations per day for 2 baseline days, age 14 to 120 days, gestational age $>37$ weeks, birth weight $>=2.5 \mathrm{~kg}$, maternal age $>=18$ years 
Vanderhoof 2003 (Continued)

Exclusion: congenital abnormalities interfering with normal feeding or causing repeated regurgitation.

Fever, infectious illness, clinical diagnosis of milk or soy protein allergy, complicated GORD (oesophagi-

tis, haematemesis, recurrent respiratory symptoms, failure to thrive), previous treatment with thick-

ened formula, or treatment with prokinetic medications 5 days before start of study

$\begin{array}{ll}\text { Interventions } & \begin{array}{l}\text { A pre-thickened formula (Enfamil AR) with placebo for 35/36 days, with equal access to additional phar- } \\ \text { macological intervention }\end{array}\end{array}$

1. Regurgitation frequency, regurgitation volume, as documented on daily diary sheets for the first
week and then 2 days/week subsequently
2. Percentage feeds followed by choke/gag/cough
3. Trouble sleeping
4. Adverse events
Measured at week 1 and end of participation.

Notes Authors replied but were unable to provide information on cough alone as an outcome measure

\section{Risk of bias}

\begin{tabular}{lll}
\hline Bias & Authors' judgement & Support for judgement \\
\hline $\begin{array}{l}\text { Adequate sequence gener- } \\
\text { ation? }\end{array}$ & Unclear risk & Randomisation done per site but method used not described \\
\hline Allocation concealment? & Unclear risk & Information not available \\
\hline $\begin{array}{l}\text { Blinding? } \\
\text { Clinical cure/failure }\end{array}$ & Low risk & Placebo-controlled study, identical appearance \\
\hline $\begin{array}{l}\text { Blinding? } \\
\text { Cough frequency or score }\end{array}$ & Unclear risk & Not applicable for this study \\
\hline \begin{tabular}{l} 
Free of other bias? \\
\hline
\end{tabular} & Unclear risk & Insufficient data \\
\hline
\end{tabular}

Wo 2006

Methods Single centre, double-blinded, randomised, placebo-controlled trial that compared once daily panto-
prazole with placebo for 12 weeks in adults

Protocol was 2-week run-in, 12-week randomised treatment, and 4-week off-treatment follow-up periods. During the run-in period, subjects filled out weekly diaries. Subjects were seen mid protocol. Naso-pharyngoscopy, oesophageal manometry and triple sensor $\mathrm{pH}$ monitoring performed before $\mathrm{Rx}$. Naso-pharyngoscopy, laryngoscopy and triple sensor pH monitoring performed repeated on end of week 12. Diaries collected till 4 weeks post-Rx

Randomisation method and allocation method clearly described

High quality score: $B, A, A, A$

Study was financially supported by a pharmaceutical research grant

Participants

42 of 51 who had $\mathrm{pH}$ monitoring qualified for study. Of these 42 adults, 39 were randomised and all completed study

Pantoprazole group: $\mathrm{n}=20$ (7 males, 13 female), mean age $=39$ years (range 23 to 59 )

Placebo group: $\mathrm{n}=19$ (6 males, 13 female), mean age $=37$ years (range 23 to 61 ) 
Wo 2006 (Continued)

Subjects were recruited from otolaryngology clinics at University of Louisville or through newspaper advertisements

Inclusion criteria: subjects with the main complaint of hoarseness, sore throat, throat burning/pain, throat clearing, voice loss, cough, excessive throat mucus, globus, or choking for $>3$ days per week in the past 2 months. The diagnosis of LPR was confirmed by laryngeal exam and a positive $\mathrm{pH}$ test of the hypopharynx or distal oesophagus (defined as total number of hypopharyngeal reflux episodes $>=3$ or distal oesophageal total time $\mathrm{pH}<4$ was $>=4.2 \%$ )

Exclusion criteria: previous treatment of LPR or GORD, known gastroparesis, connective tissue disorder, previous endoscopic or surgical antireflux procedure, or gastric surgery. Also those with vocal cord ulcer, vocal cord granuloma, or laryngeal malignancy seen on naso-pharyngoscopic examination were excluded.

\begin{tabular}{ll} 
Interventions & Pantoprazole ( $40 \mathrm{mg}$ once daily) or placebo for 12 weeks \\
\hline Outcomes & Symptom assessment: weekly diaries of visual analogue scales (0: none to 20: severe) for 6 laryngeal \\
& symptoms: globus, cough, sore throat, hoarseness, throat clearing and excessive throat mucus. A total \\
& laryngeal symptom score (0 to 120$)$ was defined as the sum of the laryngeal symptoms. A similar visual \\
& analogue scale (0 to 20$)$ was obtained for daytime and night-time heartburn
\end{tabular}

Nasopharyngoscopy: reflux finding score (RFS) (higher = worse)

\begin{tabular}{|c|c|c|}
\hline Notes & - & \\
\hline \multicolumn{3}{|l|}{ Risk of bias } \\
\hline Bias & Authors' judgement & Support for judgement \\
\hline $\begin{array}{l}\text { Adequate sequence gener- } \\
\text { ation? }\end{array}$ & Low risk & $\begin{array}{l}\text { Randomisation assignment generated by third party in blocks of } 4 \text { with se- } \\
\text { quential numbering }\end{array}$ \\
\hline Allocation concealment? & Unclear risk & Insufficient details to be certain if allocation concealment occurred \\
\hline $\begin{array}{l}\text { Blinding? } \\
\text { Clinical cure/failure }\end{array}$ & Low risk & Placebo-controlled study, identical appearance \\
\hline $\begin{array}{l}\text { Blinding? } \\
\text { Cough frequency or score }\end{array}$ & Low risk & Cough not measured but placebo-controlled study, identical appearance \\
\hline Free of other bias? & Unclear risk & Study was financially supported by a pharmaceutical research grant \\
\hline
\end{tabular}

Characteristics of excluded studies [ordered by study ID]

\begin{tabular}{ll}
\hline Study & Reason for exclusion \\
\hline Ahmad 2004 & Non-RCT. Prospective follow up study of 303 adults with otolaryngeal manifestations of GORD. \\
& $86 \%$ had cough and choking events presumed secondary to GORD (diagnosed on gastroscopy) \\
were treated with antireflux therapy (PPI's in $90 \%$, ranitidine in $3 \%$, Gaviscon in $11 \%)$. Complete re- \\
sponse to therapy occurred in $25.7 \%$, no response in $23.1 \%$ and the rest had variable response. Ad- \\
verse events not mentioned
\end{tabular}




\section{$\begin{array}{ll}\text { Study } & \text { Reason for exclusion }\end{array}$}

Allen 1998

Non-RCT. Prospective follow-up study of 195 adults with GORD (diagnosed objectively by combination of gastroscopy, $\mathrm{pH}$-metry, manometry) treated with Nissen fundoplication. Cough was primary reason for surgery in $42(21.5 \%)$ patients. Cough scores significant reduced post-surgery - 51\% were cough-free and $31 \%$ improved. Cough scores correlated to dysphagia score $(r=0.233, P=0.004)$ but did not relate to scores for heartburn, pain or regurgitation. Adverse events not mentioned

Non-RCT. Prospective study on predictors for response of cough to laparoscopic fundoplication in 354 adults (subgroup of total 603 fundoplication). Cough was eliminated in $54 \%$ of the $81 \%$ (287) followed up and improved in further $31 \%$. Strongest predictor for response of cough was preoperative cough score $(r=0.62)$. Change in cough score on and off PPI, i.e. positive response to PPI $(r=0.296)$ was a weak predictor. Timescale of response of PPI was not provided. Those with positive Bernstein test were more likely $(P=0.024)$ to respond but predictive value not given. Adverse events not reported

\begin{tabular}{ll}
\hline Allen 2004 & Non-RCT. Follow up of 209 with respiratory symptoms, mainly cough who underwent laparoscopic \\
Nissen fundoplication. $81 \%$ were followed at 6 months, $73 \%$ at 2 years, and $60 \%$ at 5 years. Cough \\
improved in $83 \%$ at 6 months, $74 \%$ at 2 years, and $71 \%$ at 5 years
\end{tabular}

Baldi 2006

Placebo not used. RCT comparing $30 \mathrm{mg}$ bd of lansoprazole to $30 \mathrm{mg}$ daily for 12 weeks. Authors suggest a positive response at 4 weeks of PPI is an effective criteria for assessing response to PPI treatment

\begin{tabular}{ll}
\hline Baldi 2006a & Non-RCT. Observational prospective study \\
\hline Belafsky 2008 & Retrospective study on LPR \\
\hline Birk 2009 & $\begin{array}{l}\text { Non-controlled study involving } 81 \text { adults. Registry study aimed to evaluate Plicator procedure safe- } \\
\text { ty and efficacy among GORD patients treated in routine clinical practice at multiple academic and } \\
\text { non-academic centres. 57\% of patients had chronic cough. No significant reduction in coughing (or } \\
\text { wheezing) post-surgery. Significant reduction in GOR symptoms (heartburn and regurgitation) plus } \\
\text { "extra-esophageal symptom of hoarseness" }\end{array}$ \\
\hline
\end{tabular}

Non-RCT. Prospective study of 29 adults with GORD (diagnosed on gastroscopy) and respiratory symptoms including cough $(n=19)$ following laparoscopic Nissen fundoplication. 14 months follow up; 3 required conversion to open procedure, 4 with major complications. Cough (assessed by subjective score) reported to resolve completely in $81 \%$ and improved in $13 \%$. pH-metry findings in those with respiratory symptoms similar to those with gastrointestinal symptoms

\begin{tabular}{ll}
\hline Chandra 2007 & Review paper. No additional references identified \\
\hline Chen 2000 & Non-RCT. Retrospective and prospective study of 90 adults undergoing laparoscopic Nissen fundo- \\
plication, $97 \%$ with typical GI symptoms, $56 \%$ with concurrent non-GI symptoms including cough \\
in $17 \%$. Post-surgery patients with non-GI symptoms improved in $54 \%$ but reflux symptoms in $95 \%$. \\
New symptoms of flatulence, belching, dysphagia, chest and abdominal pain were reported but \\
not measured. Surgical complications not mentioned
\end{tabular}

\begin{tabular}{ll}
\hline Coron 2007 & Review paper. One additional paper identified from references \\
\hline Dalby-Payne 2003 & $\begin{array}{l}\text { Meta-analysis of cisapride for treatment of GORD in children. Cough was not an outcome measure } \\
\text { in meta-analysis }\end{array}$ \\
\hline DeMeester 1990 & $\begin{array}{l}\text { Non-RCT. Prospective study evaluating the effect of fundoplication in } 17 \text { adults with chronic/per- } \\
\text { sistent respiratory symptoms (including cough) and GORD inpatients with or without chest radi- } \\
\text { ograph abnormality. Surgery was not beneficial only on those whose respiratory symptoms oc- } \\
\text { curred pre reflux event. Those whose respiratory symptoms occurred during or within } 3 \text { minutes } \\
\text { following or were unrelated to reflux episodes and had pre surgical normal motility were more like- } \\
\text { ly to benefit }\end{array}$
\end{tabular}




\begin{tabular}{ll}
\hline Study & Reason for exclusion \\
\hline Dore 2007 & $\begin{array}{l}\text { Non-placebo-controlled RCT. Study used different PPIs (rabeprazole, pantoprazole, esomeprazole } \\
\text { and lansoprazole) and placebo was not used }\end{array}$ \\
\hline Duffy 2003 & $\begin{array}{l}\text { Non-RCT. Prospective study of } 148 \text { adults with GORD (diagnosed on gastroscopy, pH-metry or } \\
\text { manometry) undergoing laparoscopic Nissen fundoplication. Of these } 31 \% \text { had cough pre-surgery. } \\
\text { Modified Gastrointestinal Quality of Life Index used and no cough-specific scores utilised. Improved } \\
\text { QOL post-surgery reported, surgical complications not reported }\end{array}$ \\
\hline
\end{tabular}

Ekstrom 2000

Non-RCT. Prospective study evaluating the effect of fundoplication on 24 patients with severe GORD) and concomitant asthma $(n=13)$ or chronic cough $(n=11)$. In non-asthmatic patients, daytime cough reduced by $47 \%$ and night cough by $80 \% 12$ months after surgery

\begin{tabular}{ll}
\hline El Hennawi 2004 & Non-RCT. 64 of 80 adults treated with 'anti-reflux Rx'. Before and after Rx effect described \\
\hline Eubanks 2001 & Non-RCT. Before and after PPI study for 3 months relating symptoms of cough, hoarseness and \\
& throat clearing with proximal pH-metry in 14 adults, 7 of whom had cough. 5 of the 7 who improved \\
with PPI had reduction of $>70 \%$ of pharyngeal acid reflux i.e. 2 of 7 improved without significant re- \\
duction. PPI well tolerated, no side effects reported
\end{tabular}

Farrell 2001

Prospective non-RCT. Symptoms measured pre and post-fundoplication (at 6 weeks) in 324 adults of which 67 had cough. Post-surgery, cough resolved in $67 \%$, those with atypical symptoms of GORD were more likely to have had less severe $\mathrm{pH}$-metry indices than those with classical GORD symptoms

\begin{tabular}{ll}
\hline Fock 2008 & Consensus guidelines. No additional references identified \\
\hline Fraser 2000 & $\begin{array}{l}\text { Prospective non-RCT. Symptoms measured pre and post-PPI treatment (20 mg daily and if no re- } \\
\text { sponse by } 3 \text { months increased to } 40 \mathrm{mg} \text { daily) in } 87 \text { adults ( } 25 \text { had cough as primary symptom). Af- } \\
\text { ter } 6 \text { weeks, } 52 \% \text { had good response (undefined) }\end{array}$
\end{tabular}

\begin{tabular}{|c|c|}
\hline Gatta 2007 & $\begin{array}{l}\text { Meta-analysis assessing the effectiveness of medical or surgical therapy for reflux disease in adult } \\
\text { patients with laryngeal or pharyngeal symptoms presumed to be due to gastro-oesophageal reflux } \\
\text { disease The authors concluded that "Therapy with a high-dose proton pump inhibitor is no more } \\
\text { effective than placebo in producing symptomatic improvement or resolution of laryngo-pharyn- } \\
\text { geal symptoms" }\end{array}$ \\
\hline
\end{tabular}

Gilger 2008 Study to evaluate safety, tolerability and symptom improvement with once-daily esomeprazole in children with endoscopically proven gastroesophageal reflux disease (GERD). "Extra-oesophageal symptom" including cough were reported in study but study excluded as placebo was not used

Greason 2002 Retrospective non-RCT in adults with primary respiratory symptoms. Most had abnormal pul-
monary function test

Grill $1985 \quad$ Non-RCT. Effect of domperidone ( 0.3 to $0.6 \mathrm{mg} / \mathrm{kg} /$ dose qid) on symptoms and oesophageal and gastric motility in 15 infants ( 6 boys, mean age 7.9 months), with moderate to severe GORD and upper gastrointestinal motility disturbances. Vomiting, "spitting" and coughing improved significantly after 6 weeks therapy

Habermann 1999 Non-RCT. 6-week PPI (pantoprazole) used in 29 adults with 'laryngeal' disorders presumed secondary to GORD with symptoms including cough. Follow up at 6 weeks at end of treatment and at 3 months while off therapy. Significant change in symptoms of heartburn, hoarseness, sore throat and dyspnoea but no significant reduction in cough reporting at 6 weeks

Habermann 2002

Non-RCT. Prospective study of 14 adults patients with pharyngoesophageal gastric acid reflux (symptoms include cough) receiving pantoprazole, $40 \mathrm{mg}$ daily for 6 weeks. Significant improvement was observed in all patients at 6 weeks, in $71 \%$ of the patients the 24 -hour pH-metry indicated reflux 


\begin{tabular}{ll}
\hline Study & Reason for exclusion \\
\hline Hui 2000 & $\begin{array}{l}\text { Retrospective non-RCT - } 30 \text { adults with cough and GORD. 60\% had symptoms resolve post-fundo- } \\
\text { plication assessed at } 6 \text { to } 36 \text { months. Those without pre-operative nausea were more likely to have } \\
\text { resolution of cough }\end{array}$
\end{tabular}

Hunter 1996

Non-RCT. Review of 300 adults post-laparoscopic fundoplication (252 Nissen and 48 Toupet) for gastroesophageal reflux refractory to medical therapy or requiring daily omeprazole or high-dose $\mathrm{H} 2$ antagonists. $64 \%$ had atypical gastroesophageal reflux symptoms (including cough, asthma, hoarseness, chest pain) pre surgery. Minor complications occurred in $6 \%$ and major complications in $2 \%$. Atypical reflux symptoms were eliminated or improved in $87 \%$ and no better in $13 \%$

Irwin 1993

Non-RCT. Determination of characteristics of 12 adults with cough and GORD (diagnosed on disappearance or marked improvement or treated with high protein, low fat, anti reflux diet). $75 \%$ of cohort had otherwise silent GORD and pH-metry sensitive in $92 \%$ but positive Bernstein and Baker tests unhelpful

Irwin 2002

Non-RCT. Report on 8 adults said to have medication resistant GORD (objective diagnosis) and cough, 4 of whom had previous fundoplication. All had surgery or repeat fundoplication and cough scores reduced postoperatively (median of 41 days). One year post fundoplication/repeat fundoplication, although median cough scores of group were still significantly lower than immediate postsurgery, cough scores increased in 5 patients. Surgical complications not mentioned clinics) treated with esomeprazole. After 8 weeks, 95\% were symptom-free

Non-RCT. Prospective study of 14 adults with persistent symptoms (typical GI and atypical-asthma, cough, hoarseness, throat burning or undetermined chest pain) despite standard PPI therapy (omeprazole $20 \mathrm{mg} \mathrm{bd}$ ). Of the 6 with atypical symptoms studied, increased dose of omeprazole (20 mg qid) controlled reflux but did not control atypical symptoms and $\mathrm{pH}$-metry showed poor correlation between symptoms and acid reflux (defined as $>50 \%$ association of symptoms with $\mathrm{pH}$ $<4$ within 5 minutes)

Leeder 2002

Non-RCT. Prospective study on effect of laparoscopic fundoplication in 14 adults objective evidence of GORD (without oesophagitis on endoscopy or pH-metry). Patients grouped into typical $\mathrm{GI}$ (heartburn, volume reflux, vomiting or regurgitation) or atypical (cough, chest pain, bloating, belching, or choking). 3 of the 7 (43\%) in atypical symptom group had poor outcome post-surgery. 2 of these patients had cough but the effect of these 2 patients were not explicitly reported

Monini 2006 Non-placebo-controlled trial. All with laryngeal symptoms clinically graded as having GORD were given PPI ment disorder treated with respiratory retraining therapy and management of laryngopharyngeal reflux

Novitsky 2002

Non-RCT. Prospective study on effect of fundoplication in 21 adults with chronic cough and GORD and were unresponsive to PPIs and other medical therapy. Fundoplication was laparoscopic in 18 and open in 3 . Cough improved in $86 \%$ of which $62 \%$ had complete resolution of cough. No major perioperative complications occurred

Omari 2006

RCT on effect of baclofen on physiological parameters of GOR with no clinical correlates measured as an outcome, as reported by correspondence to corresponding author

Oridate 2008

Non-RCT. Observational study on 45 patients with laryngopharyngeal and oesophageal symptoms receiving continuous proton-pump inhibitor for up to 6 months 


\begin{tabular}{ll}
\hline Study & Reason for exclusion \\
\hline Poe 2003 & $\begin{array}{l}\text { Non-RCT. Prospective study on } 56 \text { adults with chronic cough presumed related to GORD (clinical di- } \\
\text { agnosis). Patients treated with PPI and if no response, metoclopramide or cisapride added. In } 86 \% \\
\text { cough eliminated or markedly improved after } 4 \text { weeks }\end{array}$ \\
\hline
\end{tabular}

\begin{tabular}{ll} 
Songur 2008 & $\begin{array}{l}\text { Non-RCT examining effect of PPI in adults with symptomatic cough and GORD diagnosed using } \\
\text { scintigraphy }\end{array}$ \\
\hline Swoger 2006 & $\begin{array}{l}\text { Prospective, controlled, non-randomised trial of } 25 \text { adults with LPR (of which } 30 \% \text { to } 31 \% \text { had } \\
\text { chronic cough) to fundoplication versus no fundoplication. No difference found between groups at } \\
1 \text { year, despite technical success (increased lower oesophageal sphincter pressure and normalised } \\
\text { oesophageal acid) in the fundoplication group }\end{array}$
\end{tabular}

Thoman 2002

Non-RCT. Retrospective study on effect of laparoscopic fundoplication 37 adults with cough and GORD. Complete resolution of cough occurred in $64 \%$ with $10 \%$ reported improvement. Patients with cough and GORD were more likely to have dysphagia post-surgery

Tibbling 1993

Non-RCT. Comparison of adults (mixed respiratory and non-respiratory disease) with GORD treated with omeprazole $(n=89)$ and fundoplication $(n=199)$. Omeprazole (mean 50 days) did not significantly relieve cough ( $34 \%$ pre and $28 \%$ post), but patients who had fundoplication and crural repair showed a highly significant reduction of cough (34\% pre and $7 \%$ post)

\begin{tabular}{ll}
\hline Tibbling 1995 & Similar data set to 1993 paper \\
\hline van Zanten 2006 & $\begin{array}{l}\text { RCT on } 224 \text { adults with functional dyspepsia using esomeprazole versus placebo. Cough was not } \\
\text { listed amongst the symptoms examined }\end{array}$ \\
\hline
\end{tabular}

Waring 1995

Non-RCT. Prospective study evaluating the effect of anti-reflux therapy (omeprazole 20 to $40 \mathrm{mg}$ / day in 6 and fundoplication in 21) in 27 adults with GORD and chronic cough or hoarseness. $80 \%$ improved including $36 \%$ who became asymptomatic. Improvement of cough was more likely in those whose heartburn was eliminated. No features of dual $\mathrm{pH}$-metry could predict responders versus non- responders

Wo 1997

Non-RCT. Prospective study of 22 adults with posterior laryngitis (4 of whom the major symptom was cough) treated with $40 \mathrm{mg}$ qid of omeprazole for 8 weeks. Symptom score for cough significantly reduced by 8 weeks

Wright 2003

Non-RCT. Prospective study on effect of laparoscopic fundoplication in 145 adults with hiatus hernia and symptoms suggestive of GORD and laryngopharyngeal reflux. 55\% had abnormal pH-metry. $41 \%$ of cohort had cough pre-surgery of which $92 \%$ reported improvement. $5(1.4 \%)$ had significant complications (2nd surgery for bleeding, oesophageal perforation, severe odynophagia required in 3 and pulmonary embolus in 2)

Xinias 2003

Open placebo-controlled but non-randomised trial using modified milk for GORD in 56 infants. After 4 weeks of therapy, there was no change in cough scores although significant reduction in reflux index, vomiting and regurgitation episodes was found in treatment arm compared to placebo arm

Non-RCT. Patients with chronic cough treated with 8 weeks of PPI

bd: twice-daily; ENT: ear, nose and throat; GI: gastrointestinal; GORD: gastroesophageal reflux disease; LPR: laryngo-pharyngeal reflux; PPI: proton pump inhibitor; QID: four times a day; QOL: quality of life; RCT: randomised controlled trial; Rx: treatment

Characteristics of studies awaiting assessment [ordered by study ID]

Morice 2008

Methods RCT on proscriptive or standard anti-reflux advice with brief dietary weight loss intervention


Morice 2008 (Continued)

\begin{tabular}{ll} 
Participants & Obese adults with presumed cough associated with reflux \\
\hline Interventions & Dietary \\
\hline Outcomes & Cough QOL \\
\hline Notes & - \\
\hline
\end{tabular}

QOL: quality of life; RCT: randomised controlled trial

\section{DATA AND ANALYSES}

\section{Comparison 1. Thickened versus unthickened feeds (infants)}

\begin{tabular}{lllll}
\hline Outcome or subgroup title & $\begin{array}{l}\text { No. of } \\
\text { studies }\end{array}$ & $\begin{array}{l}\text { No. of } \\
\text { partici- } \\
\text { pants }\end{array}$ & Statistical method & Effect size \\
\hline $\begin{array}{l}1 \text { Subjects cured (of cough) at end of } \\
\text { study }\end{array}$ & 1 & & Odds Ratio (M-H, Fixed, 95\% Cl) & Totals not selected \\
\hline 2 Cough frequency & 1 & Coughs/hr (Fixed, 95\% Cl) & Totals not selected \\
\hline
\end{tabular}

Analysis 1.1. Comparison 1 Thickened versus unthickened feeds (infants), Outcome 1 Subjects cured (of cough) at end of study.

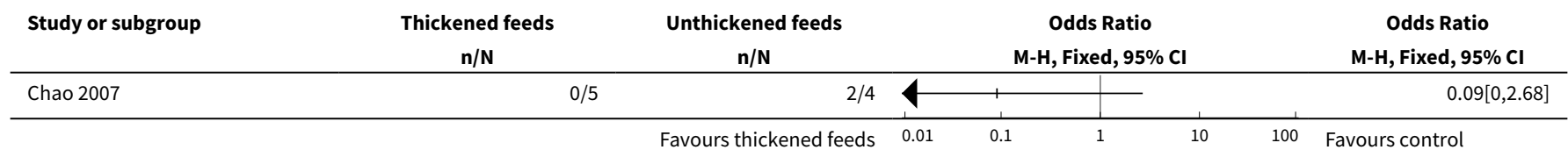

Analysis 1.2. Comparison 1 Thickened versus unthickened feeds (infants), Outcome 2 Cough frequency.

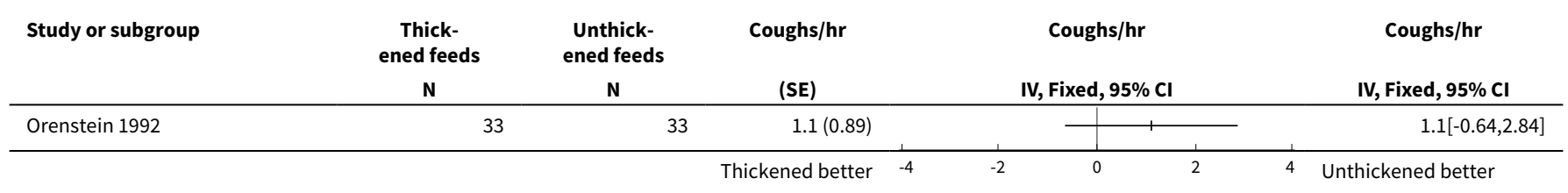

\section{Comparison 2. PPI versus placebo (children)}

\begin{tabular}{llll}
\hline Outcome or subgroup title & $\begin{array}{l}\text { No. of } \\
\text { studies }\end{array}$ & $\begin{array}{l}\text { No. of } \\
\text { partici- } \\
\text { pants }\end{array}$ & Statistical method \\
\hline 1 Coughing $(\%$ days/week) & 1 & 162 & Mean Difference (IV, Fixed, 95\% CI) \\
\hline \hline
\end{tabular}




\begin{tabular}{lllll}
\hline Outcome or subgroup title & $\begin{array}{l}\text { No. of } \\
\text { studies }\end{array}$ & $\begin{array}{l}\text { No. of } \\
\text { partici- } \\
\text { pants }\end{array}$ & Statistical method & Effect size \\
\hline $\begin{array}{l}2 \text { Clinical failures (still coughing at end of } \\
\text { trial or reporting period) }\end{array}$ & 1 & 119 & Odds Ratio (M-H, Fixed, 95\% Cl) & $1.61[0.57,4.55]$ \\
\hline $\begin{array}{l}3 \text { Treatment-emergent serious adverse } \\
\text { events }\end{array}$ & 1 & 162 & Odds Ratio (M-H, Fixed, 95\% Cl) & $5.56[1.18,26.25]$ \\
\hline
\end{tabular}

Analysis 2.1. Comparison 2 PPI versus placebo (children), Outcome 1 Coughing (\% days/week).

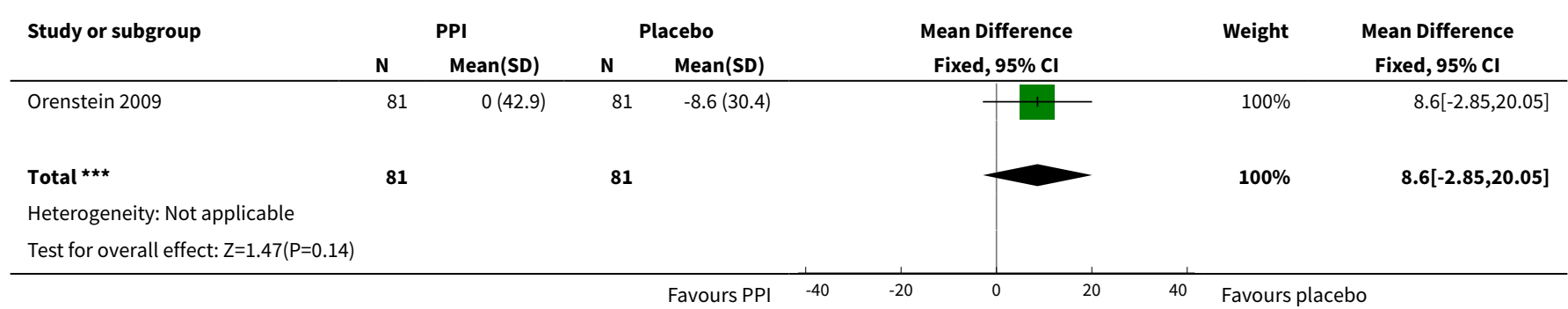

Analysis 2.2. Comparison 2 PPI versus placebo (children), Outcome 2 Clinical failures (still coughing at end of trial or reporting period).

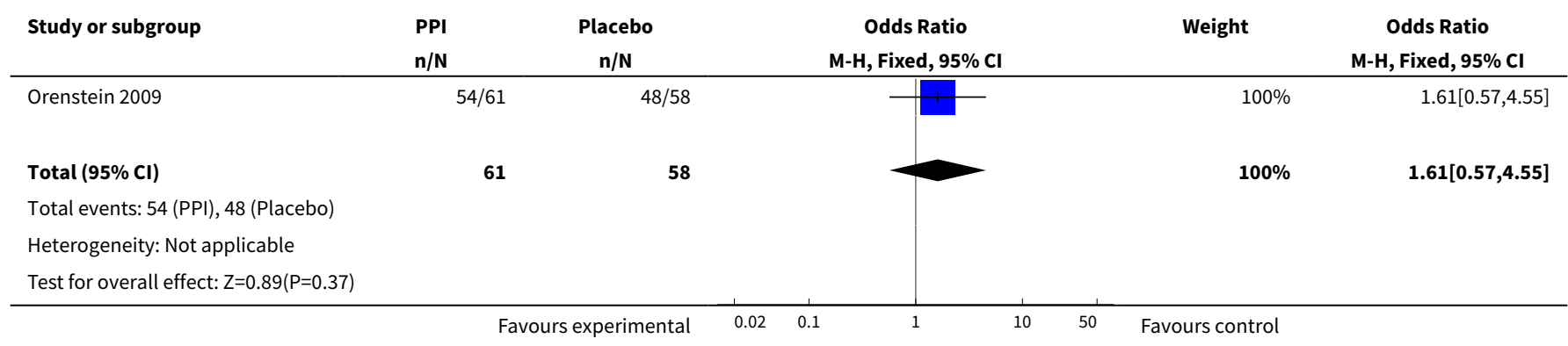

Analysis 2.3. Comparison 2 PPI versus placebo (children), Outcome 3 Treatment-emergent serious adverse events.

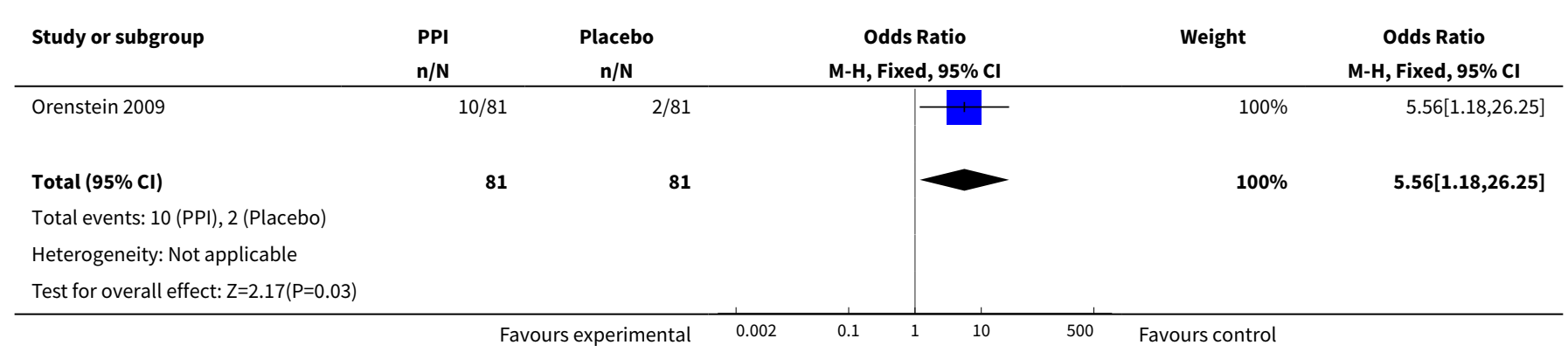


Comparison 3. PPI versus placebo ( $>18$ years)

\begin{tabular}{|c|c|c|c|c|}
\hline Outcome or subgroup title & $\begin{array}{l}\text { No. of } \\
\text { studies }\end{array}$ & $\begin{array}{l}\text { No. of } \\
\text { partici- } \\
\text { pants }\end{array}$ & Statistical method & Effect size \\
\hline $\begin{array}{l}1 \text { Clinical failures (still coughing at end of } \\
\text { trial or reporting period) }\end{array}$ & 4 & 191 & Odds Ratio (M-H, Random, 95\% Cl) & $0.46[0.19,1.15]$ \\
\hline 1.1 Medical clinics based enrolment & 2 & 38 & Odds Ratio (M-H, Random, 95\% Cl) & $0.17[0.02,1.73]$ \\
\hline 1.2 Otolaryngology based enrolment & 2 & 153 & Odds Ratio (M-H, Random, 95\% Cl) & $0.56[0.21,1.49]$ \\
\hline $\begin{array}{l}2 \text { Mean cough score at end of trial (1st arm } \\
\text { cross-over/parallel-group trials) }\end{array}$ & 4 & 109 & $\begin{array}{l}\text { Std. Mean Difference (IV, Fixed, 95\% } \\
\mathrm{CI} \text { ) }\end{array}$ & $-0.38[-0.77,0.00]$ \\
\hline 2.1 Medical clinic based enrolments & 1 & 21 & $\begin{array}{l}\text { Std. Mean Difference (IV, Fixed, 95\% } \\
\mathrm{Cl} \text { ) }\end{array}$ & $-0.86[-1.77,0.05]$ \\
\hline 2.2 Otolaryngology based enrolments & 3 & 88 & $\begin{array}{l}\text { Std. Mean Difference (IV, Fixed, 95\% } \\
\mathrm{CI})\end{array}$ & $-0.28[-0.70,0.14]$ \\
\hline $\begin{array}{l}3 \text { Change in cough scores (end-beginning } \\
\text { of intervention - 1st arm cross-over/paral- } \\
\text { lel-group trials) }\end{array}$ & 6 & 161 & $\begin{array}{l}\text { Std. Mean Difference (IV, Fixed, 95\% } \\
\mathrm{CI} \text { ) }\end{array}$ & $-0.39[-0.71,-0.08]$ \\
\hline 3.1 Studies using omeprazole & 2 & 51 & $\begin{array}{l}\text { Std. Mean Difference (IV, Fixed, 95\% } \\
\mathrm{CI} \text { ) }\end{array}$ & $-0.71[-1.29,-0.14]$ \\
\hline $\begin{array}{l}\text { 3.2 Studies using other PPI (lansoprazole, } \\
\text { pantoprazole, rabeprazole) }\end{array}$ & 4 & 110 & $\begin{array}{l}\text { Std. Mean Difference (IV, Fixed, 95\% } \\
\mathrm{Cl})\end{array}$ & $-0.26[-0.64,0.12]$ \\
\hline $\begin{array}{l}4 \text { Change in cough scores (cross-over stud- } \\
\text { ies; standardised scale) }\end{array}$ & 2 & & SD units (Fixed, 95\% Cl) & $-0.41[-0.75,-0.07]$ \\
\hline 4.1 Sub-category & 2 & & SD units (Fixed, 95\% Cl) & $-0.41[-0.75,-0.07]$ \\
\hline $\begin{array}{l}5 \text { Absolute cough scores (cross-over stud- } \\
\text { ies, standardised scale) }\end{array}$ & 2 & & SD units (Fixed, 95\% Cl) & $-0.29[-0.62,0.04]$ \\
\hline $\begin{array}{l}6 \text { Change in cough score after } 4 \text { weeks } \\
\text { treatment (1st arm cross-over/paral- } \\
\text { lel-group trials) }\end{array}$ & 2 & 51 & $\begin{array}{l}\text { Std. Mean Difference (IV, Fixed, 95\% } \\
\mathrm{Cl} \text { ) }\end{array}$ & $-0.51[-1.08,0.06]$ \\
\hline $\begin{array}{l}7 \text { Difference in cough scores at week } 8 \text { - } \\
\text { week } 4 \text { (1st arm cross-over/parallel-group } \\
\text { trials) }\end{array}$ & 2 & 51 & $\begin{array}{l}\text { Std. Mean Difference (IV, Fixed, 95\% } \\
\mathrm{Cl} \text { ) }\end{array}$ & $-0.44[-1.04,0.16]$ \\
\hline
\end{tabular}

Analysis 3.1. Comparison 3 PPI versus placebo (> 18 years), Outcome 1 Clinical failures (still coughing at end of trial or reporting period).

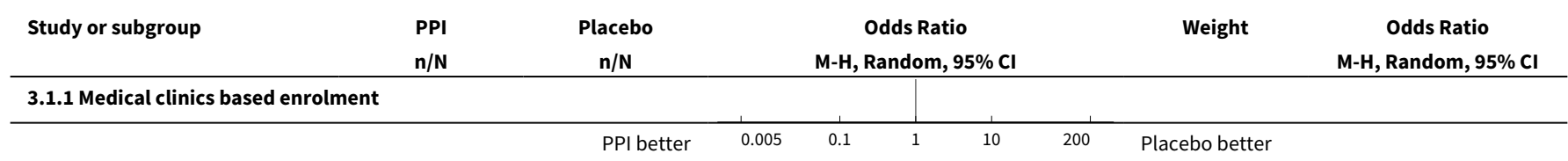




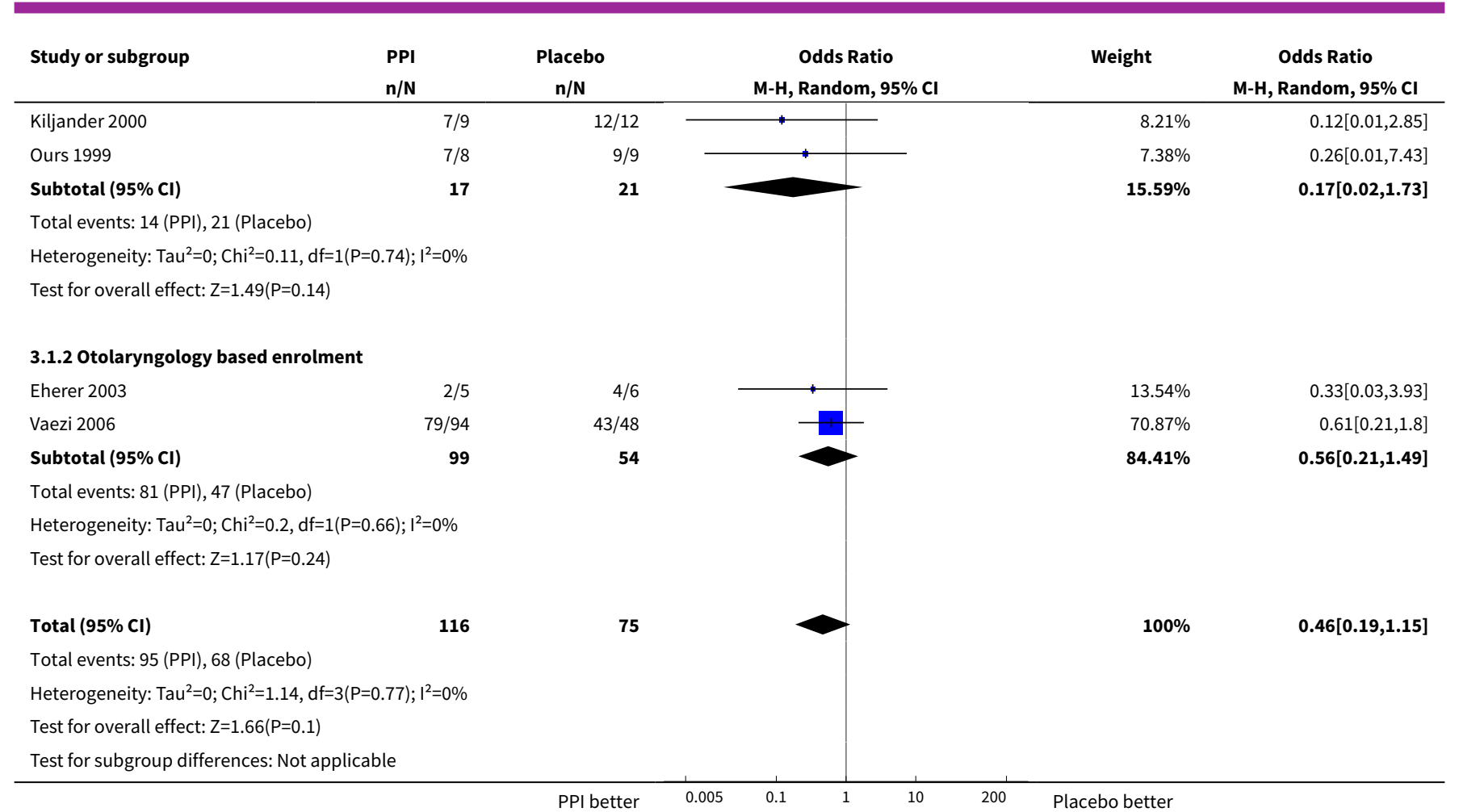

Analysis 3.2. Comparison 3 PPI versus placebo ( $>18$ years), Outcome 2 Mean cough score at end of trial (1st arm cross-over/parallel-group trials).

\begin{tabular}{|c|c|c|c|c|c|c|c|}
\hline \multirow[t]{2}{*}{ Study or subgroup } & \multicolumn{2}{|c|}{ PPI } & \multicolumn{2}{|c|}{ Placebo } & \multirow{2}{*}{$\begin{array}{c}\text { Std. Mean Difference } \\
\text { Fixed, } 95 \% \mathrm{Cl} \\
\end{array}$} & \multirow[t]{2}{*}{ Weight } & \multirow{2}{*}{$\begin{array}{c}\text { Std. Mean Difference } \\
\text { Fixed, } 95 \% \mathrm{Cl}\end{array}$} \\
\hline & $\mathbf{N}$ & Mean(SD) & $\mathbf{N}$ & Mean(SD) & & & \\
\hline \multicolumn{8}{|c|}{ 3.2.1 Medical clinic based enrolments } \\
\hline Kiljander 2000 & 9 & $5.9(5)$ & 12 & $9.9(4.1)$ & $\longrightarrow$ & $17.77 \%$ & $-0.86[-1.77,0.05]$ \\
\hline Subtotal $\star \star \star$ & 9 & & 12 & & & $17.77 \%$ & $-0.86[-1.77,0.05]$ \\
\hline \multicolumn{8}{|c|}{ Heterogeneity: Not applicable } \\
\hline \multicolumn{8}{|c|}{ Test for overall effect: $Z=1.84(P=0.07)$} \\
\hline \multicolumn{8}{|c|}{ 3.2.2 Otolaryngology based enrolments } \\
\hline Eherer 2003 & 5 & $0.4(0.6)$ & 6 & $1.5(1.6)$ & - & $9.34 \%$ & $-0.79[-2.04,0.47]$ \\
\hline Noordzij 2001 & 15 & $\begin{array}{r}243.3 \\
(346.6)\end{array}$ & 15 & $\begin{array}{r}328.2 \\
(473.7)\end{array}$ & $\boxplus$ & $28.61 \%$ & $-0.2[-0.92,0.52]$ \\
\hline Pawar 2007 & 21 & $0.3(0.6)$ & 26 & $0.5(1.1)$ & -1 & $44.28 \%$ & $-0.22[-0.8,0.35]$ \\
\hline Subtotal *** & 41 & & 47 & & & $82.23 \%$ & $-0.28[-0.7,0.14]$ \\
\hline \multicolumn{8}{|c|}{ Heterogeneity: $\operatorname{Tau}^{2}=0 ; \mathrm{Chi}^{2}=0.71, \mathrm{df}=2(\mathrm{P}=0.7) ;\left.\right|^{2}=0 \%$} \\
\hline \multicolumn{8}{|c|}{ Test for overall effect: $Z=1.29(P=0.2)$} \\
\hline 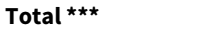 & 50 & & 59 & & & $100 \%$ & $-0.38[-0.77,0]$ \\
\hline \multicolumn{8}{|c|}{ Heterogeneity: $\mathrm{Tau}^{2}=0 ; \mathrm{Chi}^{2}=1.98, \mathrm{df}=3(\mathrm{P}=0.58) ; \mathrm{I}^{2}=0 \%$} \\
\hline \multicolumn{8}{|c|}{ Test for overall effect: $Z=1.95(P=0.05)$} \\
\hline \multicolumn{8}{|c|}{ Test for subgroup differences: $\mathrm{Chi}^{2}=1.27, \mathrm{df}=1(\mathrm{P}=0.26), \mathrm{I}^{2}=21.25 \%$} \\
\hline & & & & Favours PPI & -2 & Favours & \\
\hline
\end{tabular}


Analysis 3.3. Comparison 3 PPI versus placebo (> 18 years), Outcome 3 Change in cough scores (end-beginning of intervention - 1st arm cross-over/parallel-group trials).

\begin{tabular}{|c|c|c|c|c|c|c|c|}
\hline \multirow[t]{2}{*}{ Study or subgroup } & \multicolumn{2}{|c|}{ PPI } & \multicolumn{2}{|c|}{ Placebo } & \multirow{2}{*}{$\begin{array}{c}\text { Std. Mean Difference } \\
\text { Fixed, } 95 \% \mathrm{Cl}\end{array}$} & \multirow[t]{2}{*}{ Weight } & \multirow{2}{*}{$\begin{array}{c}\text { Std. Mean Difference } \\
\text { Fixed, } 95 \% \mathrm{Cl}\end{array}$} \\
\hline & $\mathbf{N}$ & Mean(SD) & $\mathbf{N}$ & Mean(SD) & & & \\
\hline \multicolumn{8}{|c|}{ 3.3.1 Studies using omeprazole } \\
\hline Kiljander 2000 & 9 & $-4.5(5.2)$ & 12 & $1.3(5.2)$ & & $11.4 \%$ & $-1.09[-2.03,-0.15]$ \\
\hline Noordzij 2001 & 15 & $\begin{array}{r}-112.9 \\
(165.7)\end{array}$ & 15 & $-20(207.2)$ & † & $18.96 \%$ & $-0.48[-1.21,0.25]$ \\
\hline Subtotal $* \star \star$ & 24 & & 27 & & & $30.36 \%$ & $-0.71[-1.29,-0.14]$ \\
\hline \multicolumn{8}{|c|}{ Heterogeneity: $\operatorname{Tau}^{2}=0 ; \mathrm{Chi}^{2}=1.01, \mathrm{df}=1(\mathrm{P}=0.32) ; \mathrm{I}^{2}=0.66 \%$} \\
\hline \multicolumn{8}{|c|}{ Test for overall effect: $\mathrm{Z}=2.42(\mathrm{P}=0.02)$} \\
\hline \multicolumn{8}{|c|}{ 3.3.2 Studies using other PPI (lansoprazole, pantoprazole, rabeprazole) } \\
\hline Eherer 2003 & 5 & $-1.4(2.7)$ & 6 & $-2.7(3.1)$ & + & $6.92 \%$ & $0.39[-0.81,1.59]$ \\
\hline Havas 1999 & 8 & $-0.9(3.4)$ & 7 & $-0.9(3.3)$ & & $9.75 \%$ & $-0.01[-1.03,1]$ \\
\hline Pawar 2007 & 21 & $-0.5(1.1)$ & 26 & $0.1(0.8)$ & \pm & $28.85 \%$ & $-0.62[-1.21,-0.03]$ \\
\hline 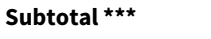 & 52 & & 58 & & & $69.64 \%$ & $-0.26[-0.64,0.12]$ \\
\hline \multicolumn{8}{|c|}{ Heterogeneity: $\operatorname{Tau}^{2}=0 ; \mathrm{Chi}^{2}=3.01, \mathrm{df}=3(\mathrm{P}=0.39) ; \mathrm{I}^{2}=0.23 \%$} \\
\hline \multicolumn{8}{|c|}{ Test for overall effect: $Z=1.33(P=0.19)$} \\
\hline 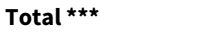 & 76 & & 85 & & & $100 \%$ & $-0.39[-0.71,-0.08]$ \\
\hline \multicolumn{8}{|c|}{ Heterogeneity: $\operatorname{Tau}^{2}=0 ; \mathrm{Chi}^{2}=5.68, \mathrm{df}=5(\mathrm{P}=0.34) ; \mathrm{I}^{2}=11.93 \%$} \\
\hline \multicolumn{8}{|c|}{ Test for overall effect: $Z=2.44(P=0.01)$} \\
\hline \multicolumn{8}{|c|}{ Test for subgroup differences: $\mathrm{Chi}^{2}=1.66, \mathrm{df}=1(\mathrm{P}=0.2), \mathrm{I}^{2}=39.89 \%$} \\
\hline & & & & Favours PPI & -1 & Favour & \\
\hline
\end{tabular}

Analysis 3.4. Comparison 3 PPI versus placebo ( $>18$ years), Outcome

4 Change in cough scores (cross-over studies; standardised scale).

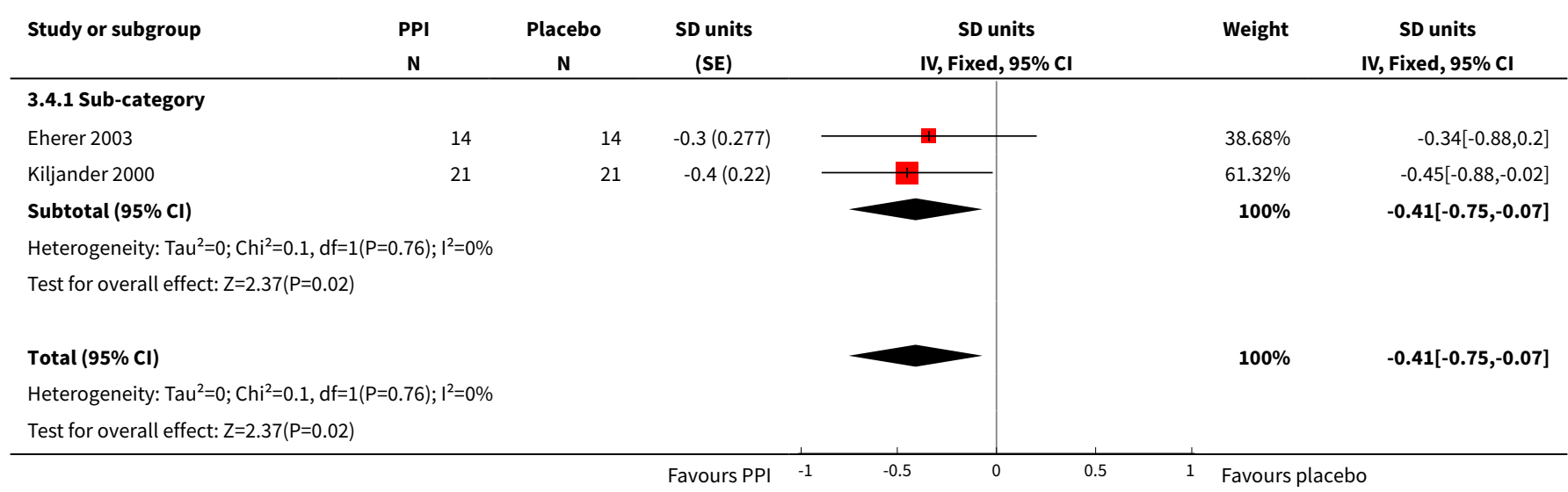


Analysis 3.5. Comparison 3 PPI versus placebo (> 18 years), Outcome

5 Absolute cough scores (cross-over studies, standardised scale).

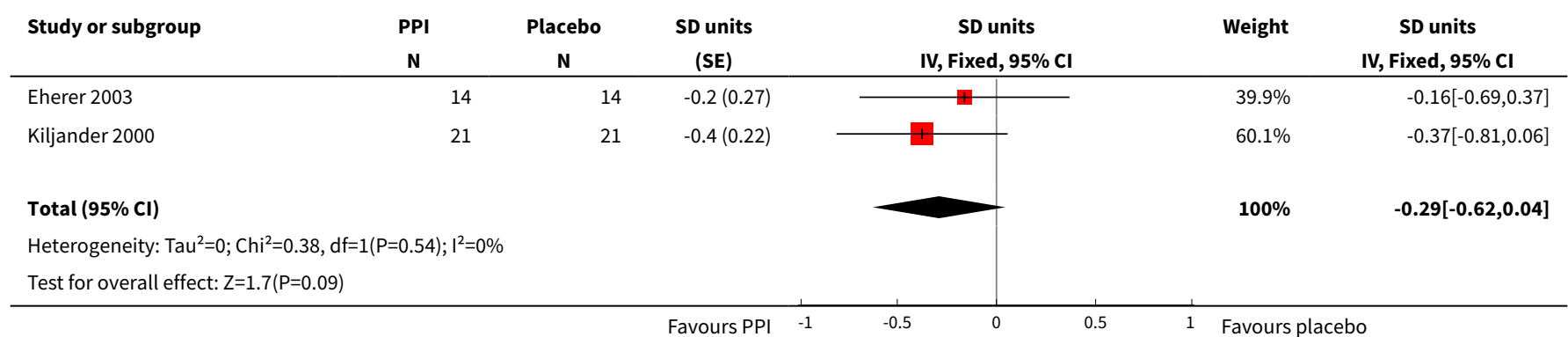

Analysis 3.6. Comparison 3 PPI versus placebo ( $>18$ years), Outcome 6 Change in cough score after 4 weeks treatment (1st arm cross-over/parallel-group trials).

\begin{tabular}{|c|c|c|c|c|c|c|c|}
\hline \multirow[t]{2}{*}{ Study or subgroup } & \multicolumn{2}{|c|}{ PPI } & \multicolumn{2}{|c|}{ Placebo } & \multirow{2}{*}{$\begin{array}{c}\text { Std. Mean Difference } \\
\text { Fixed, } 95 \% \mathrm{Cl}\end{array}$} & \multirow[t]{2}{*}{ Weight } & \multirow{2}{*}{$\begin{array}{l}\text { Std. Mean Difference } \\
\text { Fixed, } 95 \% \mathrm{Cl}\end{array}$} \\
\hline & $\mathbf{N}$ & Mean(SD) & $\mathbf{N}$ & Mean(SD) & & & \\
\hline Kiljander 2000 & 9 & $-1.8(4.5)$ & 12 & $-1.6(3.8)$ & -1 & $43.15 \%$ & $-0.05[-0.91,0.82]$ \\
\hline Noordzij 2001 & 15 & $\begin{array}{r}-166.8 \\
(197.2)\end{array}$ & 15 & $9.4(200)$ & $\longrightarrow$ & $56.85 \%$ & $-0.86[-1.62,-0.11]$ \\
\hline Total *** & 24 & & 27 & & & $100 \%$ & $-0.51[-1.08,0.06]$ \\
\hline \multicolumn{8}{|c|}{ Heterogeneity: $\mathrm{Tau}^{2}=0 ; \mathrm{Chi}^{2}=1.95, \mathrm{df}=1(\mathrm{P}=0.16) ; \mathrm{I}^{2}=48.66 \%$} \\
\hline \multicolumn{3}{|c|}{ Test for overall effect: $\mathrm{Z}=1.76(\mathrm{P}=0.08)$} & & & & & \\
\hline
\end{tabular}

Analysis 3.7. Comparison 3 PPI versus placebo ( $>18$ years), Outcome 7 Difference in cough scores at week 8 - week 4 (1st arm cross-over/parallel-group trials).

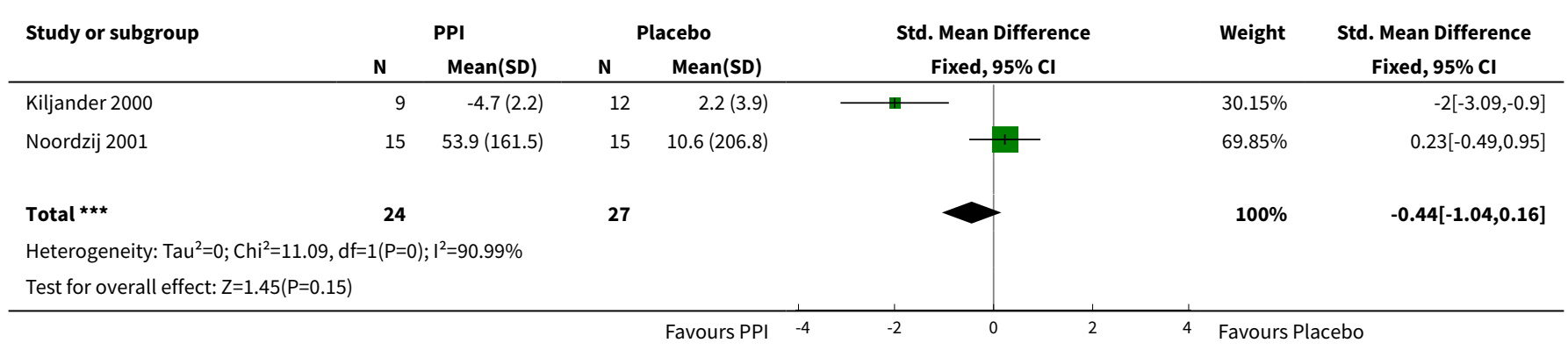

\section{AP PEN DICES}

\section{Appendix 1. Archive of search results (all years to April 2007)}

The Airways Group specialised register/search identified 763 potentially relevant titles in the original search in 2004. After assessing the abstracts, 84 papers were obtained for considered for inclusion into review. The main reason for non-eligibility of studies for review criteria was the non-controlled, non-randomised nature of the respective studies (see table 'Characteristics of excluded studies'). One controlled but non-randomised study was also excluded (Xinias 2003). Eleven studies were included in the original version of the review (see 'Characteristics of included studies'), and all but one (Vanderhoof 2003) were single centre studies. The multicentre study (Vanderhoof 2003) was 
also the only study supported by commercial interest then. In the 2005 update a further 11 articles were retrieved; one study was included (El Serag 2001) and the rest were excluded, with two described in the excluded table (El Hennawi 2004; Issing 2004). Following the 2006 search update, eight papers were retrieved. One RCT in adults (Vaezi 2006) was included and another RCT was excluded (Baldi 2006) as a placebo was not used. The excluded study compared two doses of lansoprazole for adults with chronic cough (Baldi 2006). Following the 2007 search update, 407 abstracts were reviewed, 12 papers were retrieved; none fulfilled eligibility criteria. One study that was excluded but should be highlighted was that of a controlled (but non-randomised) trial on fundoplication for laryngopharyngeal reflux (LPR) of which $30 \%$ to $31 \%$ of the subjects had chronic cough, the 2 nd or 3 rd most common symptom (Swoger 2006). Swoger 2006 described no difference between groups at one year, despite technical success of the fundoplication. A systematic review on the efficacy of PPIs for LPR was also excluded (Gatta 2007). The paper (Gatta 2007) however revealed a relevant study that was not found in previous searches; this study (Steward 2004) is now included in this update.

\section{Appendix 2. CENTRAL search strategy}

\#1 MeSH descriptor Gastroesophageal Reflux explode all trees in MeSH products

\#2 ((gastro-oesophageal next reflux) or (gastroesophageal next reflux) or (gastro-esophageal next reflux) or reflux or ger or gerd or acid or esophagus or oesophagus)

\#3 MeSH descriptor Esophagus explode all trees in MeSH products

\#4 (\#1 OR \#2 OR \#3)

\#5 MeSH descriptor Cough explode all trees in MeSH products

\#6 MeSH descriptor Bronchitis explode all trees in MeSH products

\#7 cough*

\#8 bronchiti*

\#9 (\#5 OR \#6 OR \#7 OR \#8)

\#10 (\#4 AND \#9)

\section{Appendix 3. MEDLINE search strategy}

1. $\exp \mathrm{COUGH} /$

2. exp Bronchitis/

3. (cough\$ or bronchit\$).mp.

4. 1 or 2 or 3

5. exp GASTROESOPHAGEAL REFLUX/

6. exp Esophagus/

7. (gastro-oesophageal reflux or gastroesophageal reflux or gastro-esophageal reflux or reflux or ger or gerd or acid or esophagus or oesophagus).mp.

8.5 or 6 or 7

9.4 and 8

(Combined with the RCT filter as described in 'About the Airways Group' on The Cochrane Library)

\section{Appendix 4. EMBASE search strategy}

1. exp Coughing/

2. exp Bronchitis/

3. (cough\$ or bronchit\$).mp.

4. 1 or 2 or 3

5. exp Gastroesophageal Reflux/

6. exp esophagus/

7. (gastro-oesophageal reflux or gastroesophageal reflux or gastro-esophageal reflux or reflux or ger or gerd or acid or esophagus or oesophagus).mp.

8.5 or 6 or 7

9.4 and 8

(Combined with the RCT filter as described in 'About the Airways Group' in The Cochrane Library).

WHAT'S NEW

Date Event Description

15 July $2010 \quad$ New search has been performed New literature search run.




\begin{tabular}{lll}
\hline Date & Event & Description \\
\hline 15 July 2010 & $\begin{array}{l}\text { New citation required and conclusions } \\
\text { have changed }\end{array}$ & $\begin{array}{l}\text { We updated the risk of bias using the Cochrane 'Risk of bias' } \\
\text { tool rather than the Jadad scoring system. We added one new } \\
\text { relatively large study. The conclusions changed for children as } \\
\text { proton pump inhibitors (PPI) were shown not to be efficacious } \\
\text { against cough in children with gastroesophageal reflux disease } \\
\text { (GORD) symptoms, and there were increased serious adverse } \\
\text { events. }\end{array}$ \\
& \\
&
\end{tabular}

\section{HISTORY}

Protocol first published: Issue 3, 2004

Review first published: Issue 2, 2005

\begin{tabular}{|c|c|c|}
\hline Date & Event & Description \\
\hline 23 April 2010 & Amended & New search performed. Studies added. \\
\hline 24 April 2009 & New search has been performed & Literature search re-run; no new studies were identified. \\
\hline 11 April 2008 & New search has been performed & $\begin{array}{l}\text { Literature search re-run; four new studies were identified which } \\
\text { met the eligibility criteria of the review. The conclusions were } \\
\text { not altered on the basis of the new trial evidence. }\end{array}$ \\
\hline 5 April 2008 & Amended & Converted to new review format. \\
\hline 1 August 2007 & $\begin{array}{l}\text { New citation required but conclusions } \\
\text { have not changed }\end{array}$ & $\begin{array}{l}\text { One new study met the entry criteria of the review (Steward } \\
\text { 2004). This study was identified from a systematic review on } \\
\text { laryngopharyngeal reflux and cough (Gatta 2007). It contributed } \\
\text { data to a secondary outcome (change in cough scores at end of } \\
\text { intervention), but did not alter the conclusions of the review. }\end{array}$ \\
\hline 6 September 2006 & $\begin{array}{l}\text { New citation required but conclusions } \\
\text { have not changed }\end{array}$ & $\begin{array}{l}\text { One new study met the entry criteria of the review (Vaezi 2006). } \\
\text { This study contributed data to the primary outcome (still cough- } \\
\text { ing at end of trial), but did not alter the conclusions of the re- } \\
\text { view. }\end{array}$ \\
\hline
\end{tabular}

\section{CONTRIBUTIONSOF AUTHORS}

A Chang: initiation, design and direction of review, writing of protocol and review, selection of studies, data extraction, performed analysis and interpretation of results. LG: selection of studies and data extraction, writing of primary protocol and review. JG: data extraction; FC: review of manuscript. TJL: data extraction and analysis, interpretation of results and writing of review. The online editor for this review was Dr. M McKean.

\section{DECLARATIONS OF INTEREST}

Nil.

\section{SOURCES OF SUPPORT}

\section{Internal sources}

- Royal Children's Hospital Foundation, Brisbane, Australia. 


\section{External sources}

- National Health and Medical Research Council, Australia.

Supports AC through a practitioner fellowship (grant 545216)

- Cochrane Child Health Field Bursary Scheme, Canada.

- Queensland Government Smart State Funds, Australia.

Salary Support for AC

\section{DIFFERENCES BETWEEN PROTOCOLAND REVIEW}

We have used the Cochrane risk of bias tool in this update. We included a new sensitivity analysis for cross-over and parallel studies.

\section{INDEX TERMS}

\section{Medical Subject Headings (MeSH)}

Age Factors; Chronic Disease; Cough [etiology] [*therapy]; Gastroesophageal Reflux [complications] [ ${ }^{\star}$ therapy]; Histamine H2 Antagonists [therapeutic use]; Proton Pump Inhibitors [therapeutic use]; Randomized Controlled Trials as Topic

\section{MeSH check words}

Adult; Child; Humans 